Research and Implementation Study

\title{
Evaluation of Zero Velocity Deicer Spreader and Salt Spreader Protocol
}

FHWA/IN/JTRP-2000/24

By

Tommy E. Nantung INDOT Research Division

Phone: (765) 463-1521 ext. 248

Fax: (765) 497-1665

e-mail: tnantung@indot.state.in.us

This study was conducted by the INDOT Research Division and

INDOT Zero Velocity Committee

In Cooperation with the U.S. Department of Transportation Federal Highway Administration

Indiana Department of Transportation

Research Division

1205 Montgomery Street

West Lafayette, IN 47906 
TECHNICAL REPORT STANDARD TITLE PAGE

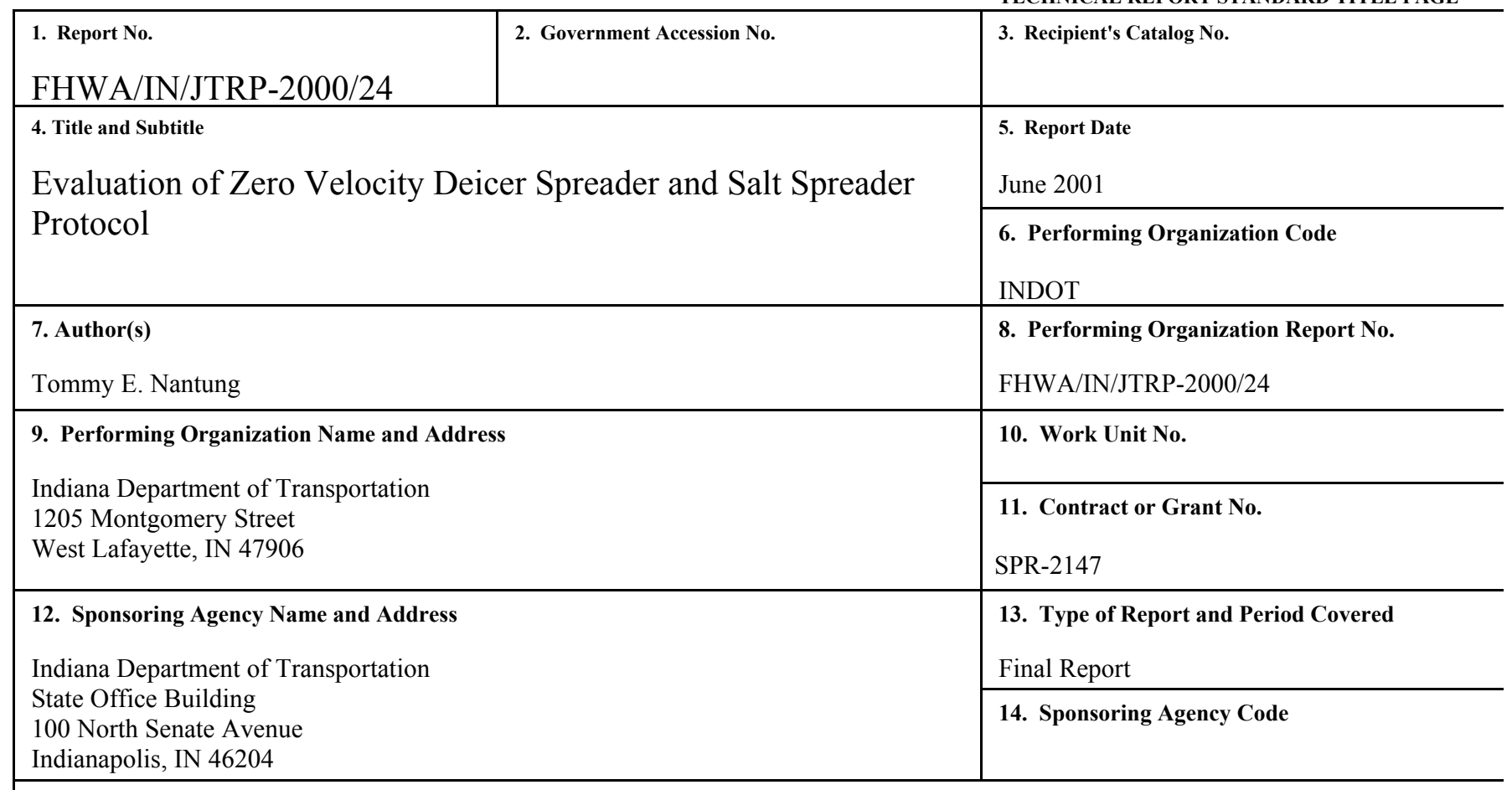

\section{Supplementary Notes}

Prepared in cooperation with the Federal Highway Administration.

\section{Abstract}

Increasing traffic volumes and declining resources have led to a need for innovative winter maintenance strategies, techniques, equipment and materials while not sacrificing the safety of the traveling public. Any reduction of salt usage will ease fund for other maintenance operations while minimizing salt runoff on surface and ground waters and effect of road salt on roadside vegetation.

In the past, conventional spreaders have been designed for sand and are generally incapable of metering the lower, more precise amount of salt desired. The use of materials in solid form demands critical timing of the application to minimize loss of the material by being blown off the road by traffic, especially by high speed and commercial vehicles. Further loss of a straight solid salt can occur during application with conventional spreaders because of the particles bouncing off the pavement. Advancements in the design of zero velocity spreaders have enabled the placement of solid chemicals on the pavement with minimum bounce.

The basic principle of the zero velocity spreader is rather simple. The zero velocity spreader ejects salt particles at zero velocity relative to the roadway. With this principle, salt particles are "placed" to the intended area on the roadway and a lot less to the area outside the roadway.

Based on the tests, the Zero Velocity Systems will give excellent performance with a large number of cost savings due to the accurate placement of salt particles on the roadway. However, on the slower truck speed, a modified system such as the Y system or Muncie system, can give a satisfactory result as well.

\section{Key Words}

zero velocity, salt spreader

\section{Distribution Statement}

No restrictions. This document is available to the public.
19. Security Classif. (of this report)

Unclassified
20. Security Classif. (of this page)

Unclassified

\section{No. of Pages}

42

\section{Price}




\section{Table of Contents}

List of Tables $\frac{\text { Page }}{\text { ii }}$

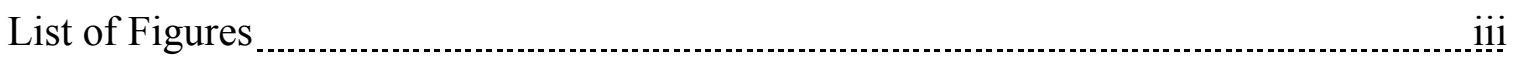

1. Introduction

2. Background $\ldots$

3. Objectives

4. Evaluation Procedures

5. Data Analysis

5A. Industrial Hydraulic System

5B. Muncie System

5C. Pengwyn Zero Velocity System $\ldots \ldots \ldots$

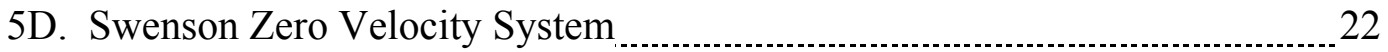

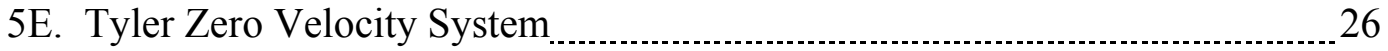

5F. Y Chute with the Industrial Hydraulic System

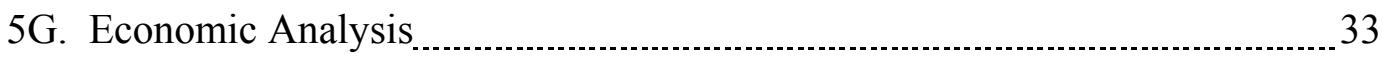

6. Conclusions 39

7. References

Appendix A - Spread Pattern Performance Test and Discharge Performance Test (SHRP Test Protocols)

Appendix B - Field Evaluation Form for Zero Velocity Spreader Evaluation

Appendix C - Zero Velocity Spreader Evaluation Field Data 


\section{List of Tables}

Table 1 - Zero Velocity Evaluation Equipment $\ldots \ldots$

Table 2 - Salt Costs for INDOT in the Last Four Years by Locations............................. 35

Table 3 - Predicted Savings on Amount of Salt and Salt Cost Per Year based on the Spreader Recovery Rate of the Industrial Hydraulic System 35

Table 4 - Predicted Savings on Amount of Salt and Salt Cost Per Year based on the Mean Spread Density of the Industrial Hydraulic System to Maintain Level of Service 36 


\section{List of Figures}

Figure 1 - Industrial Hydraulic System

Figure 2 - IHS (Industrial Hydraulic System) Salt Spread Pattern .................................. 12

Figure 3 - Percentage of total salt recovered at 32 kilometers/hour (20 MPH) for Industrial Hydraulic System

Figure 4 - Percentage of \#4 sieve salt recovered at 32 kilometers/hour (20 MPH) for

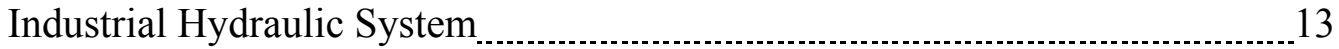

Figure 5 - Percentage of total salt recovered at 64 kilometers/hour (40 MPH) for Industrial Hydraulic System $\ldots$

Figure 6 - Percentage of \#4 sieve salt recovered at 64 kilometers/hour (40 MPH) Industrial Hydraulic System $\ldots$

Figure 7 - Muncie Spreader Controller

Figure 8 - Percentage of total salt recovered at 32 kilometers/hour (20 MPH) for Muncie System

Figure 9 - Percentage of \#4 sieve salt recovered at 32 kilometers/hour (20 MPH) for Muncie System

Figure 10 - Percentage of total salt recovered at 64 kilometers/hour (40 MPH) for Muncie System

Figure 11 - Percentage of \#4 sieve salt recovered at 64 kilometers/hour (40 MPH) Muncie System

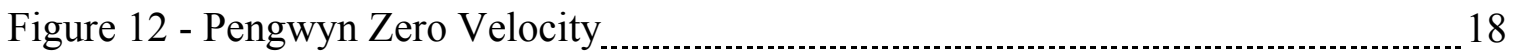

Figure 13 - Pengwyn Dispensing Unit

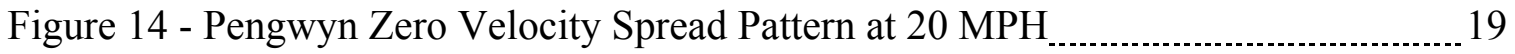

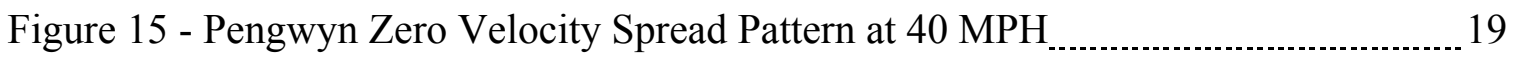

Figure 16 - Percentage of total salt recovered at 32 kilometers/hour (20 MPH) for Pengwyn System $\quad 20$

Figure 17 - Percentage of \#4 sieve salt recovered at 32 kilometers/hour (20 MPH) for Pengwyn System

Figure 18 - Percentage of total salt recovered at 64 kilometers/hour (40 MPH) for Pengwyn System

Figure 19 - Percentage of \#4 sieve salt recovered at 64 kilometers/hour (40 MPH) Pengwyn System

Figure 20 - Swenson Zero Velocity System ………............................................. 23

Figure 21 - Swenson Dispensing Unit (Shroud) _............................................ 23

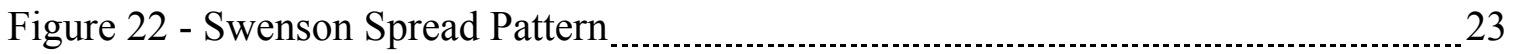




\section{List of Figures (continued...)}

Figure 23 - Percentage of total salt recovered at 32 kilometers/hour (20 MPH) for

Swenson System

$\underline{\text { Page }}$

Figure 24 - Percentage of \#4 sieve salt recovered at 32 kilometers/hour (20 MPH) for

Swenson System

Figure 25 - Percentage of total salt recovered at 64 kilometers/hour (40 MPH) for Swenson System

Figure 26 - Percentage of \#4 sieve salt recovered at 64 kilometers/hour (40 MPH) Swenson System 26

Figure 27 - Tyler Zero Velocity System

Figure 28 - Percentage of total salt recovered at 32 kilometers/hour (20 MPH) for Tyler System

Figure 29 - Percentage of \#4 sieve salt recovered at 32 kilometers/hour (20 MPH) for Tyler System 28

Figure 30 - Percentage of total salt recovered at 64 kilometers/hour (40 MPH) for Tyler System

Figure 31 - Percentage of \#4 sieve salt recovered at 64 kilometers/hour (40 MPH) Tyler System. 29

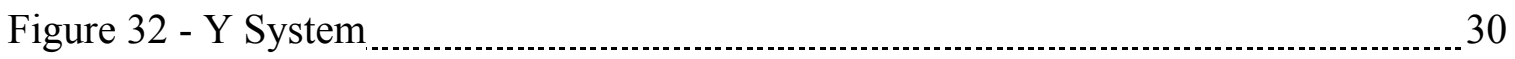

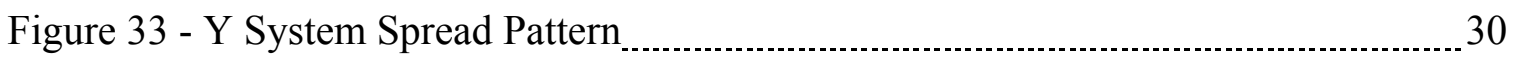

Figure 34 - Percentage of total salt recovered at 32 kilometers/hour (20 MPH) for Y System

Figure 35 - Percentage of \#4 sieve salt recovered at 32 kilometers/hour (20 MPH) for Y System

Figure 36 - Percentage of total salt recovered at 64 kilometers/hour (40 MPH) for Y System

Figure 37 - Percentage of \#4 sieve salt recovered at 64 kilometers/hour (40 MPH) Y System 33

Figure 38 - Percentage Recovery Rate of the Evaluated Salt Spreader Systems 37

Figure 39 - Mean Spread Density of the Evaluated Salt Spreader Systems 38 


\section{Evaluation of Zero Velocity Deicer Spreader and Salt Spreader Protocol}

\section{Introduction}

Deicing chemicals, principally salt or sodium chloride, have been used in the United States for snow and ice control on roadway since early this century. Snow and ice influence highway transportation activities in two major ways:

(1) in the increased hazard to safe travel with the consequent cost of death, injury, and property damage; and

(2) in the additional economic penalty on traveling public caused by the delay of traffic and the increased costs of operation.

The most widely used low price deicing chemical is road salt. Because of the reliable performance, easy application, and low price, it has been a primary material of snow and ice control programs. Salt can facilitate plowing, reduce the need for sanding and subsequent cleanup, and prevent the bonding of packed snow and ice to the pavement surface. However, evidence has grown that the use of salt in snow and ice control has many negative side effects. Damages attributable to the use of salt in snow and ice control includes corrosion of bridge reinforcing bars, increased sodium in drinking water, and adverse effect to the roadside vegetation.

Sodium chloride or road salt will continue to be used by highway agencies for snow and ice control for many years. Highway agencies and the industry continue to refine and research new technology to prevent and treat the use of salt in maintaining the roadway in the winter months. Research continues to aim at reducing salt use by developing anti-icing materials, improving salt application techniques, and exploring salt alternatives.

A few reports have been addressed to the problem faced by the highway maintenance engineer toward reducing the amount of salt applied to the pavement while 
keeping the pavement surface in a safe condition. Chemicals are applied to highway pavements to accomplish three things:

(1) To prevent formation of ice,

(2) To melt ice that has formed, and

(3) To prevent buildup of snow-pack.

Though friction improving-materials such as sand, slag, or cinders can be and are spread on a slippery surface, certain reasons have discourage the extensive use of abrasives in many places.

The great reliance has been on the use of sodium salt because of its low cost, ready availability, ease of application, solubility in water, and effectiveness as a melting agent. Its melting effectiveness diminishes below $20^{\circ} \mathrm{F}\left(-6.7^{\circ} \mathrm{C}\right)$, and it ceases all melting at $-6^{\circ} \mathrm{F}\left(-21^{\circ} \mathrm{C}\right)$. However, these advantages have in turn contributed to the increased use of salt, and part of the problem lies in not knowing how much salt to apply for a known climatic condition nor being able to apply a known, controlled amount.

Salt is distributed on the pavement either by:

(1) spreading over a wide path (covering parts of two lanes) by means of a spinning disk or a roller extending the width of the truck tailgate, or

(2) by windrowing in a narrow path of 1 to 3 feet $(0.3$ to $0.9 \mathrm{~m})$ through a tube or off a dead spinner.

Concentrated spreading of salt, either in a narrow band on two-lane roads or in a 4-feet $(1.2 \mathrm{~m})$ wide band spread near the center-line crown or on the high side of superelevations, is favored by many highway maintenance engineers as the most efficient use of salt. The purpose is to obtain a concentrated brine solution that will flow under the snow to break the bond, thus enabling traffic and plowing to remove the accumulation ${ }^{(1)}$.

Optimum salt application rate depends on the:

- Level of service required

- Weather conditions and their change with time 
- State and characteristics of the chemical used

- Time of application

- Traffic density at time of, and subsequent to, salt application

- Topography and the type of road surface

However, determination of the proper application rate is a matter of judgment and a guess as to weather conditions immediately following the application. In the winter season, tons of salt were spread on the roadway surface. While application of salt and sand is critical in providing a safe driving roadway, the amount used is often significantly more than is required.

Over salting the roadway can be seen on the roadways throughout the state. Salt dust and residue remain on the shoulders, ramps, and intersections for days after a snow fall event.

Several publications have appeared during the last several years describing the effects of deicing salt on soils, vegetation, and structural materials. Thus it appears that the cumulative effects of deicing chemicals and the awareness of an environmental problem have followed the salt use. A general awareness exists on the part of maintenance engineers that the use of salt should be minimized consistent with keeping the pavement surface in a safe condition. What constitutes a safe pavement surface, and how to achieve it with a minimum cost to the public and to the environment, are two questions that demand better answers.

It is accepted as a premise that it is desirable to reduce the quantity of deicing salt used and, therefore, there will be no evaluation of the economic consequences of their corrosion of automobiles, scaling of non-air-entrained concrete pavement, damage to vegetation, and intrusion into water supplies, nor of the extent to which these effects can properly be attributed to deicing salt.

\section{Background}

Increasing traffic volumes and declining resources have led to a need for innovative winter maintenance strategies, techniques, equipment and materials while not 
sacrificing the safety of the travelling public. Any reduction of salt usage will ease fund for other maintenance operations while minimizing salt runoff on surface and ground waters and effect of road salt on roadside vegetation ${ }^{(2)}$. Approaches to minimize deicing chemical use include ${ }^{(1)}$ :

- Pre-wetting salt with liquid chemicals. The pre-wetting of salts results in quicker melting, less salt waste because pre-wetted salt does not bounce and scatter, and a greater temperature range in which salt can be used. A Calcium Chloride solution is the pre-wetting liquid most often used.

- Direct application of liquid chemicals. Salt brine or calcium chloride solution applied directly result in quicker melting and less use of chemicals.

- Spreaders. Calibration is essential for controlling application rates. Various methods can be used, but it is important to calibrate each piece of equipment as not two pieces are likely to be the same. Devices to relate spreading directly to ground speed have been credited with reducing chemical use. These devices deliver a preset amount of chemical per unit area regardless of truck speed.

- Better management control. Establishment of levels of service, standards for chemical application, and reporting procedures give management better control over use of chemicals.

- Training. Many maintenance engineers believe that training of personnel involved with ice and snow control is one of the most important factors in controlling chemical use. Comprehensive training programs have been organized by several agencies.

- Adequate weather forecasts. The most significant factor in starting snow and ice control operations is adequate warning of an approaching storm. Several agencies have contracts with private weather forecasters and some have experimented with elaborate ice detection systems that use sensors in the pavement. 
- Use of abrasives. Although abrasives neither prevent nor remove buildup of snow-pack they can be used instead of chemicals in locations where traffic is not heavy enough to remove them rapidly from the road, or where aerodynamic forces will not remove them.

- Snowplowing. Early plowing during moderate to heavy snowfall reduces chemical use.

While INDOT is moving toward more efficient and effective means of snow and ice control activities by improving or applying the above approaches, improving the spreaders and pre-wetting of salt are the two approaches that can cut more of the salt usage. Both methods will save a large amount of salt cost but not all agencies agree that one method is superior to the other, rather, the two methods are complimentary to each other. While improving the spread pattern of the spreader will reduce the use of salt, prewetting the salt will melt the snow quicker, therefore, the 30 to 45 minutes requirement for brine to form will be nearly eliminated.

In the past, conventional spreaders have been designed for sand and are generally incapable of metering the lower, more precise amount of salt desired. The use of materials in solid form demands critical timing of the application to minimize loss of the material by being blown off the road by traffic, especially by high speed and commercial vehicles. Further loss of a straight solid salt can occur during application with conventional spreaders because of the particles bouncing off the pavement. Advancements in the design of zero velocity spreaders have enabled the placement of solid chemicals on the pavement with minimum bounce.

A study by the Michigan Department of Transportation indicated that an ordinary spreaders spread salt $30 \%$ off the pavement and $24 \%$ in the pavement but out of target area, that left only $46 \%$ on the target area. Pre-wetting the salt will reduce the out of target area by $22 \%{ }^{(1)}$.

Studies by the Strategic Highway Research Program (SHRP) indicated that the salt spreader industry does not test its equipment's operating characteristics under actual field conditions ${ }^{(3)}$. In addition, the only standard test method found in the literature of American made spreader equipment was the one developed by the American Society of 
Agriculture Engineers. However, this test procedure is used for fertilizers, which have a narrow gradation band in comparison to salt. Furthermore, this standard test does not pertain to application on a hard surface, such as pavement.

According to SHRP, the proposed "American Testing Protocol for Winter Spreaders" measures the ability of the spreader to control the distribution pattern and the application rate of spread material. The distribution pattern should be evaluated at speeds of $20 \mathrm{~km} / \mathrm{hr}(12.4 \mathrm{mph})$ and $40 \mathrm{~km} / \mathrm{hr}(24.8 \mathrm{mph})$, with controls set to deliver $20 \mathrm{~g} / \mathrm{m}^{2}$ (260 lbs./lane-mile) of spread material over a 6-meter (19.7-ft) width. This application rate is equivalent to applying $194 \mathrm{~kg}(427.7 \mathrm{lbs}$.) of material over a 6 meters (19.7-ft) wide roadway surface 1.6 kilometers $(1$ mile) in length. The spreader should be driven over a marked grid system spreading dry salt ${ }^{(3)}$.

The proposed protocol by SHRP with a $24.8 \mathrm{mph}$ truck speed does not address the new generation of zero velocity spreader, since this type of spreader can spread salt effectively at $50 \mathrm{mph}$. Therefore, there are needs to evaluate the zero velocity spreaders and the spreader protocols developed by SHRP.

\section{Objectives}

INDOT winter maintenance equipment spread salt or salt/sand mixes dry or prewetted with salt brine using rear mounted sander boxes. For a dry operation, the salt or salt/sand mix is dumped to the sander box by raising the truck box and then deposited on the spinner blade through an auger in the sander box. The salt or salt/sand mix is spread on the roadway surface in an approximate spiral pattern. Research by the Minnesota Department of Transportation during the 1992-1993 winter season showed that up to a third of the dry salt is lost to the road shoulder as a direct result of both the initial application or subsequent gravitation of salt particles down the road cross slope due to the passage of auto and truck traffic. In other words, one third of the dry salt is lost before it has a chance to work. Pre-wetting of the salt or salt/sand mix will reduce this salt loss by about $20 \%{ }^{(2)}$.

A modification of the spinner blade unit is the use of a "V"-box with an auger to bring the material to a drop chute. Another variation is the "Y" spreader that includes 
one or two rear discharge drop chutes placed at a certain discharge angle. However, while these drop chutes can direct the spread and alter the spread pattern and width, the salt particles still bounce on impact with the roadway surface. Moving the drop chutes closer to the roadway surface does not eliminate the salt particles bouncing out of the roadway due to the speed differential between the moving truck and the roadway surface.

INDOT Zero Velocity Committee was formed to explore some new techniques available in the market to improve the maintenance operation more efficiently and effectively. One of the new techniques is the zero velocity deicer/spreader. The concept of zero-velocity is to project the material out of the rear of the truck at precisely the same speed the truck is traveling forward. The resulting velocity of the deicing material is zero, relative to the roadway. This allows the material to stay where it is effective in the traffic lanes. A typical spinner spreader will cast up to $40 \%$ of the deicing material into an area outside the traffic lanes where it will do nothing to help clear the roadway.

As important as cost savings are, the most important thing is to serve the traveling public in the best possible manner. In this case, that means to make the roadway safe as quickly as possible. As the spreader operator travels along at $20 \mathrm{mph}$, the traffic will continue to travel at speeds of 55 to $65 \mathrm{mph}$. This difference in speed creates a potentially dangerous situation. The zero velocity system has an ability to spread at speeds up to $45 \mathrm{mph}$ effectively, thus reducing the speed differential.

The purpose of this research project is to determine the effectiveness of the zero velocity deicer spreader through a "real performance" in the field, based on an unbiased evaluation. So far, there is no guidelines or standard procedures to evaluate the performance of this equipment based on safety, time, cost, and environment. In the SHRP H-385 publication, it includes a proposal of American Testing Protocol for winter maintenance spreaders. This protocol is to identify the capabilities of winter maintenance spreader equipment for achieving low application rates and controlling the spreading pattern over a wide range of rates. It includes spread pattern performance test and discharge performance test. However, except for the discharge performance test, this test protocol is most suitable for a conventional spreader and should be done by the manufacturers rather than the users. The "real" performance of the equipment during the 
winter season is hardly tested. With the emerging technology of new spreaders, an evaluation procedure should be proposed based on effectiveness and efficiency of controlling snow and ice.

The INDOT Zero Velocity Committee recommends that seven systems should be evaluated in the same location. The original study plan called for dry and pre-wetting application. The following systems were recommended:

- Standard system without pre-wetting

- Standard system with pre-wetting

- Standard system with pre-wetting and the spinner slowed

- Standard system without pre-wetting and a "Y" splitter instead of the spinner

- Standard system with pre-wetting and a "Y" splitter instead of spinner

- Tyler Zero Velocity system

- Pengwyn Zero Velocity System

During the course of the research, modifications and events from the field changed the evaluation plan for the equipment. The testing protocol from SHRP was set up to "dry run" only. Therefore, the pre-wetting option was eliminated not only for the procedures in the protocol but also because some equipment cannot operate well with the pre-wet salt. Caking occurred during actual operation of some of the spreaders. Also, the auger system used to bring the pre-wet salt to the blower or belt was jammed.

A few months before the dry-run test, the Y splitter with an industrial hydraulic system was retired due to fire. Therefore, this equipment was tested in the following fall season. The equipment testing arrangements are: 
Table 1 - Zero Velocity Evaluation Equipment

\begin{tabular}{|c|l|c|}
\hline Unit Number & Unit Description & $\begin{array}{l}\text { Spread Quantity } \\
\text { (lbs./mile) }\end{array}$ \\
\hline 62589 & $\begin{array}{l}\text { 1994 International } \\
\text { Tyler Zero Velocity }\end{array}$ & 200 \\
\hline 62313 & $\begin{array}{l}\text { 1991 International } \\
\text { Industrial Hydraulic System }\end{array}$ & 250 \\
\hline 62741 & $\begin{array}{l}\text { 1997 Ford } \\
\text { Swenson Zero Velocity }\end{array}$ & 250 \\
\hline 62740 & $\begin{array}{l}\text { 1997 Ford } \\
\text { Muncie Hydraulic System }\end{array}$ & 205 \\
\hline 62276 & $\begin{array}{l}\text { 1990 Ford } \\
\text { Pengwyn Zero Velocity }\end{array}$ & 200 \\
\hline 1990 International \\
Y Chute with Industrial Hydraulic System
\end{tabular}

As for the testing protocol, Appendix A shows the proposed protocol from SHRP. Based on information from the operators of the spreaders to accommodate the speed for the zero velocity systems, the truck speeds were increased to 32 kilometers/hour (20 $\mathrm{mph})$ and 64 kilometers/hour (40 $\mathrm{mph})$. This arrangement was set to determine the advantage of the zero velocity spreader to clear up the road as quickly as possible while maintaining the salt particles on the target area.

\section{Evaluation Procedures}

The evaluation procedure included a spread pattern performance test (adopted with modification from SHRP protocol) and a winter-season performance test based on visual inspection with a proposed winter activity log form.

Task 1: The spread pattern test was conducted at a speed of 32 kilometers/hour (20 mph) and 64 kilometers/hour (40 $\mathrm{mph}$ ) with control set to deliver based on the spreader set to disperse the spread material over 6 meter (20 feet) spread width. With the hopper loaded to approximately half capacity, the salt spreader was driven over a marked grid system spreading dry salt (see Appendix A for the grid system). The salt sample was vacuumed into paper filters from the surface of the grid system, and the mass of the salt vacuumed from each sampling rectangle area was weighed to an accuracy of 0.1 gram and recorded. 
The data were analyzed to determine the characteristic of the longitudinal and transverse distribution pattern.

Task 2: For the discharge performance test, the amount of spread material released from the spreader vehicle in a unit of time depended on the setting that controls the auger or belt speed and the speed of the vehicle that was measured. The discharge test measured the accuracy of releasing material in accordance with the normal operational range of the spreader. This test attempted to reflect the amount of material applied to the roadway.

Task 3: The actual performance of the spreader in the field was measured during the Winter of 1996-1999 included evaluation by truck drivers and foremen. The modified winter activity log form included the weather and pavement condition log, rate of application, distance spread, treatment stages, type of pavement, etc. These collected data were analyzed to evaluate the effectiveness and efficiency of the spreader.

Task 4: Data analysis and final report.

\section{Data Analysis}

The spread pattern test was conducted at truck speeds of 32 kilometers/hour (20 $\mathrm{mph}$ ) and 64 kilometers/hour (40 mph). The truck operators were asked to begin spreading the salt particles 100 feet before entering the grid area. The salt sample was vacuumed into filter paper from the surface of the grid system, and the mass of the salt vacuumed from each rectangle area was separated into two different size groups based on the ASTM C-136 sieve analysis. One group passing the \#4 sieve with 4.75 millimeter square openings, and one group retained on the \#4 sieve (coarser salt particles).

It has been known that coarse salt particles mostly bounced to outside the roadway area when dropped from the back of the spreader truck due to the mass and the speed differential between the truck and the roadway. An average of three samples taken from the salt stockpile, indicated that $64 \%$ by weight of the salt particles are coarse particles retained on the \#4 sieve. With $36 \%$ by weight of the salt particles passing the \#4 sieve, the cost savings claimed by the zero velocity system manufacturers, therefore, may come from the fact that the zero velocity system can keep the coarser salt particles on the roadway. 
Based on the particle distribution, the finer particles (36\%) will generate brine solution faster than the larger particles because of the specific surface area. Finer particles, with their higher specific surface area, dilute in water quicker than the larger particles. However, larger particles with lower specific surface areas dilute slower and can keep producing brine solution longer to keep the roadway clear for a longer period of time.

The data were analyzed using the SHRP protocol in Appendix A to determine the characteristic of the longitudinal and transverse distribution pattern. The results of the analysis are included in the Appendix C. Below are the results of the spread pattern tests.

\section{$\underline{5 \mathrm{~A} . \text { Industrial Hydraulic System (IHS) }}$}

This "de facto" standard salt spreader has been used by the highway agencies for many years. Figure 1 shows the Industrial Hydraulic system at INDOT Angola Subdistrict. The working principle of this salt spreader involves chanelling the salt to the conveyor or auger, to the hopper chute, and finally to the rotating disc in the spreader unit. This unit modulates the spreading mechanism to deliver a preset amount per unit area regardless of truck speed. Many states have been installing gear reduction drives to reduce the speed of the hydraulic motor driving the conveyor or auger on its hopper body. However, because a majority of the coarser salt particles released from the back of the truck at the truck speed, most of these salt particles still landed in out-of-target areas.

For this evaluation program, the Industrial Hydraulic system feed rate was set to $70.46 \mathrm{~kg} / \mathrm{km}$ (250 lbs/mile). Figure 2 shows the Industrial Hydraulic System spread pattern running at 32 kilometers/hour $(20 \mathrm{mph})$. The spreader unit was aimed at the center line of the roadway. The spread pattern shows that this system spread the salt particles "in a large area" rather than a narrow strip pattern. Traces of salt particles on the roadway were very scarce.

Figure 3 shows the result of the spread pattern analysis with only $28.46 \%$ recovery rate for the total salt particles. Figure 4 shows the spread pattern for salt particles retained on \#4 sieve (coarse salt particles). While $64 \%$ of the salt particles belong to the coarse particle size, the recovery rate for this size is only $10.78 \%$. It shows that $89.22 \%$ of the coarse salt particles fell into the "out-of-target" area that did not 
contribute to melting the snow for the travelling public. Therefore, the contribution of the coarser salt particles to prolong the supply of brine solution to melt the snow to maintain clear roadways is proven ineffective with this system.

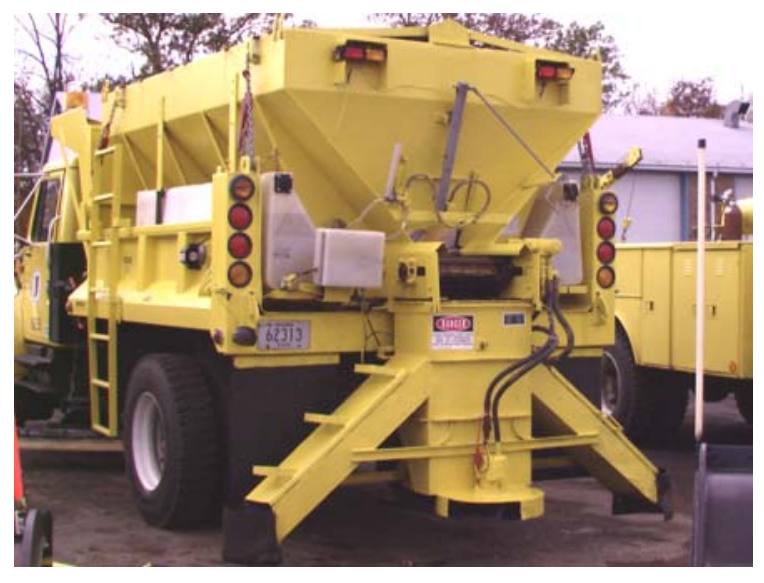

Figure 1 - Industrial Hydraulic System

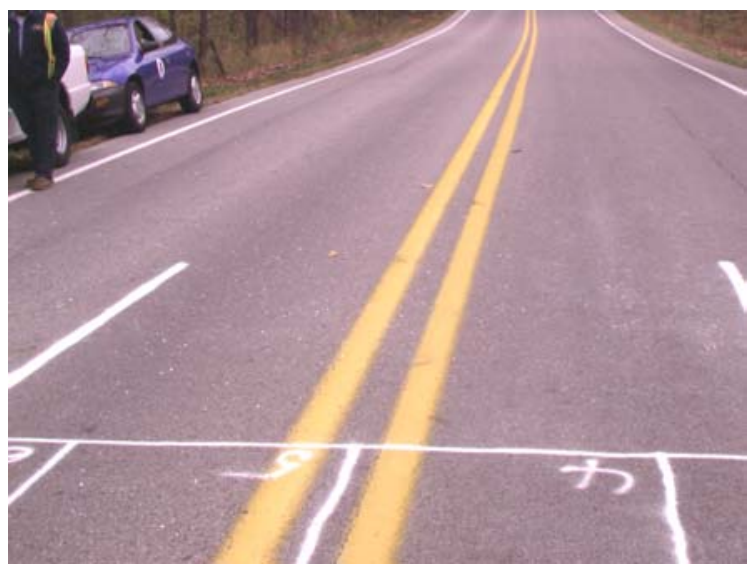

Figure 2 - IHS Salt Spread Pattern

Figure 5 shows the spread pattern of the total salt particles at a truck speed of 64 kilometers/hour (40 mph). It shows that the spread is concentrated in a smaller area but the recovery rate of only $23.62 \%$, which is less than $28.46 \%$ when the truck run at 32 kilometers/hour (20 mph).

For coarser salt particles, the spread pattern is indicated in Figure 6 with a recovery rate of only $2.37 \%$. Therefore, at a higher speed, the coarser salt particles mostly fall outside of the intended area by $97.63 \%$. With $64 \%$ of the salt particles are coarser in size, therefore, $62.48 \%$ (64\% of $97.63 \%)$ of the total amount of salt was ineffective during a snow control operation.

From Figures 3 and 5, the Industrial Hydraulic system gives a different pattern based on the speed. This indicates inconsistency of spread pattern relative to the speed of the truck. The causes of the inconsistency and the low recovery rate in a higher speed are the vortices on the tail of the truck and the method of spreading using a rotating disc on the spreader unit. 


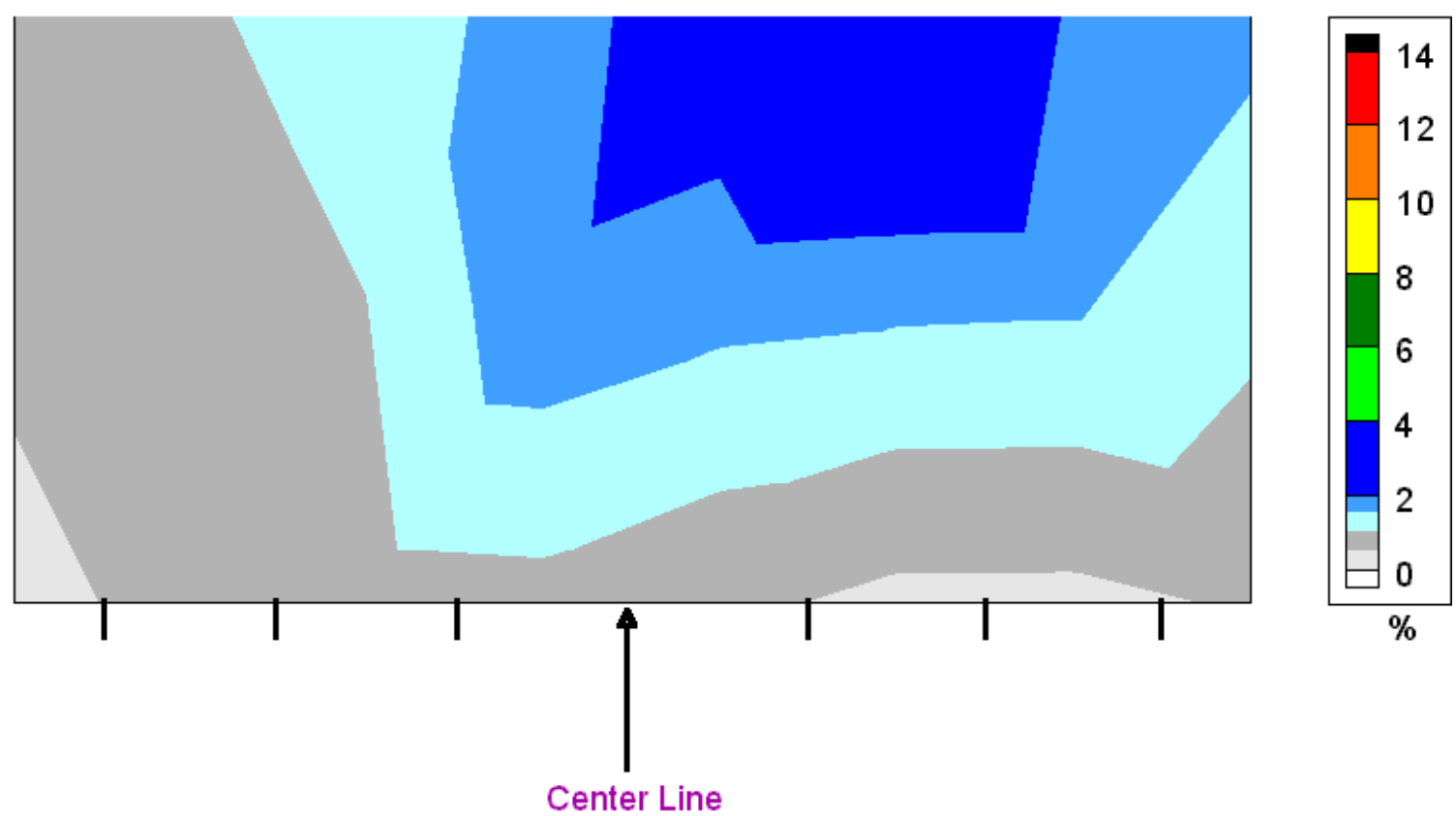

Figure 3 - Percentage of total salt recovered at 32 kilometers/hour (20 MPH) for Industrial Hydraulic System
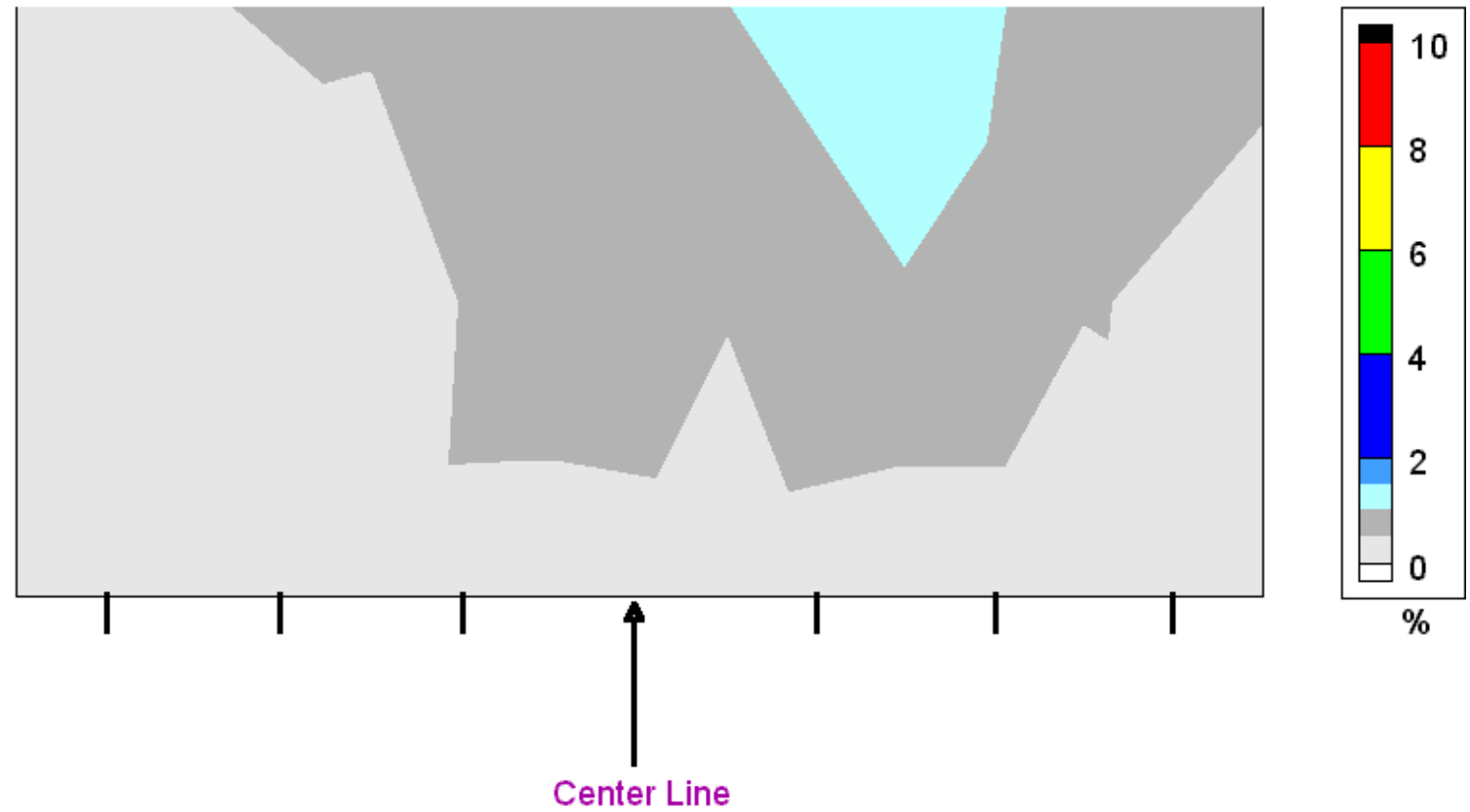

Figure 4 - Percentage of \#4 sieve salt recovered at 32 kilometers/hour (20 MPH) for Industrial Hydraulic System 


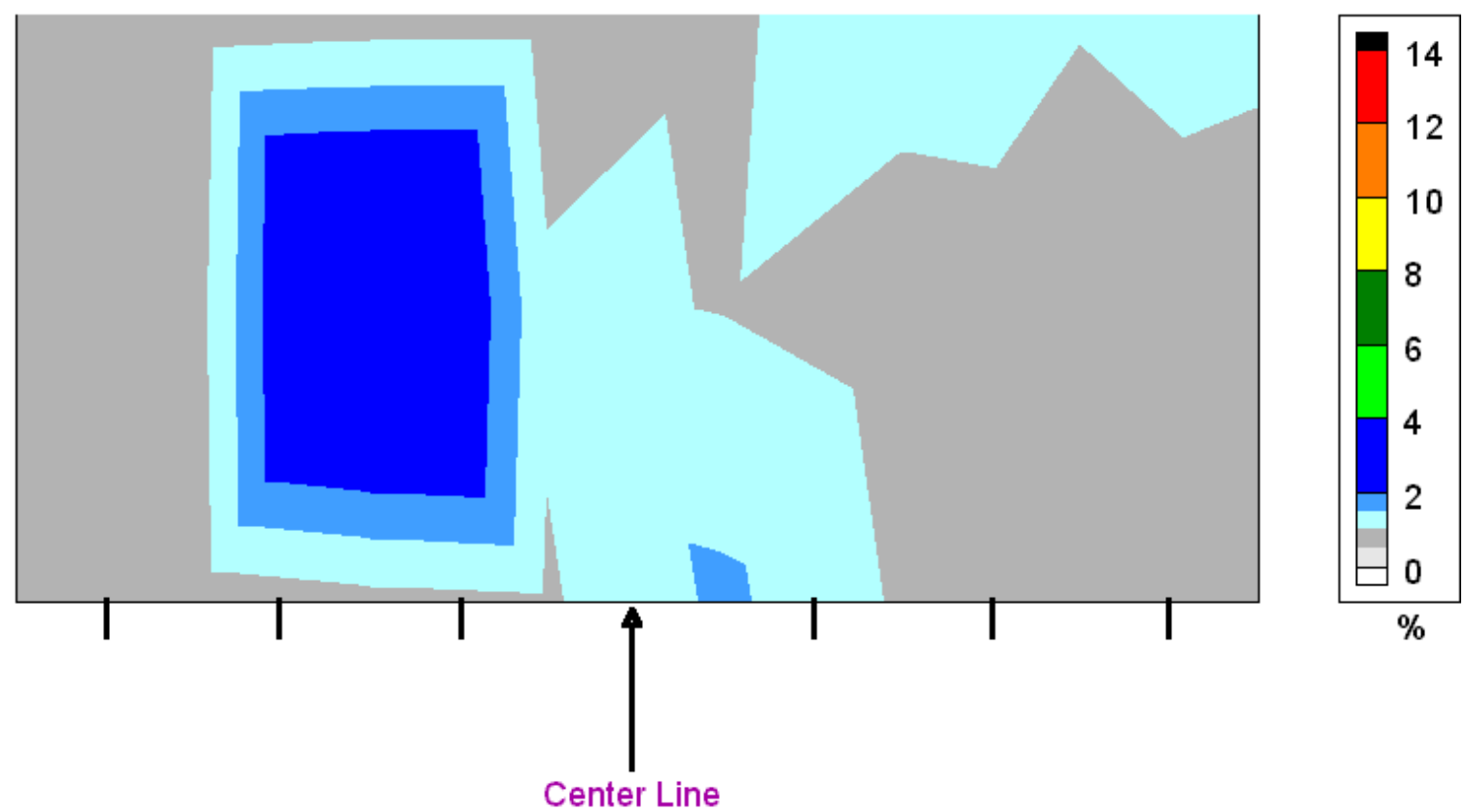

Figure 5 - Percentage of total salt recovered at 64 kilometers/hour (40 MPH) for Industrial Hydraulic System

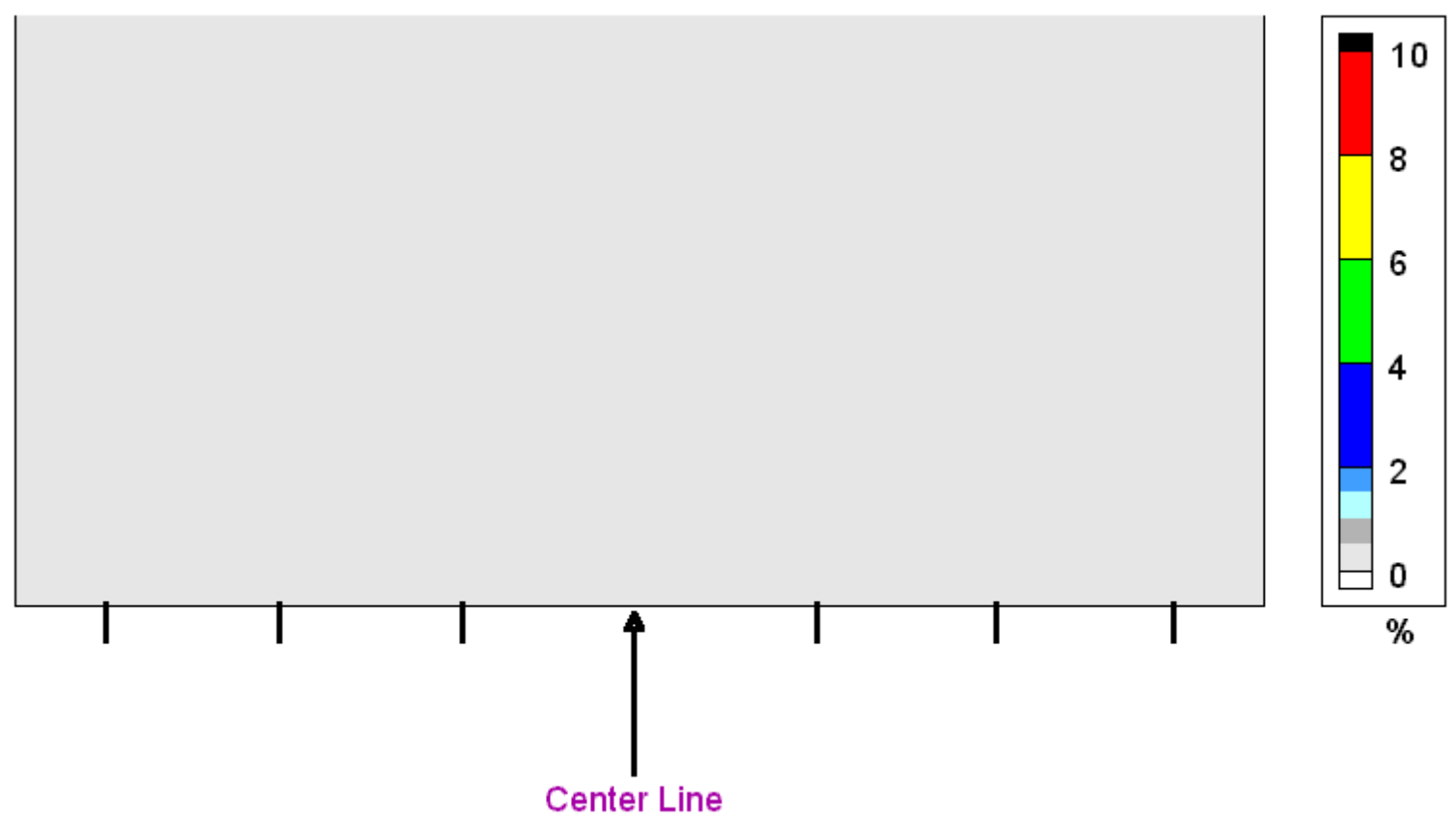

Figure 6 - Percentage of \#4 sieve salt recovered at 64 kilometers/hour (40 MPH) for Industrial Hydraulic System 


\section{B. Muncie System}

The Muncie Electronic Spreader Package (MESP) is a microprocessor based electronic package for heavy-duty snow and ice control. Unlike the conventional systems, the MESP utilizes groundspeed orientation to control the feed rate. This simply means that the same amount of salt or sand mix will be spread per mile regardless of how fast or slow the truck is moving.

This spreader unit is equiped with a lane width selector that controls the width of the spread pattern and a controller that regulates the feed rate as shown in Figure 7. Since the spinner speed does not adjust to changes in road speed, the spread amount depends on the feed rate. During the evaluation process, this Muncie MESP 3200 Series System feed rate was set to $57.78 \mathrm{~kg} / \mathrm{km}$ (205 lbs/mile), based on the level of service required from INDOT Angola Sub-district. The truck operator was asked to run on the center line of the grid system width a spread width of 4 meters (13.12 feet). The spreader unit was aimed at the center line of the roadway.

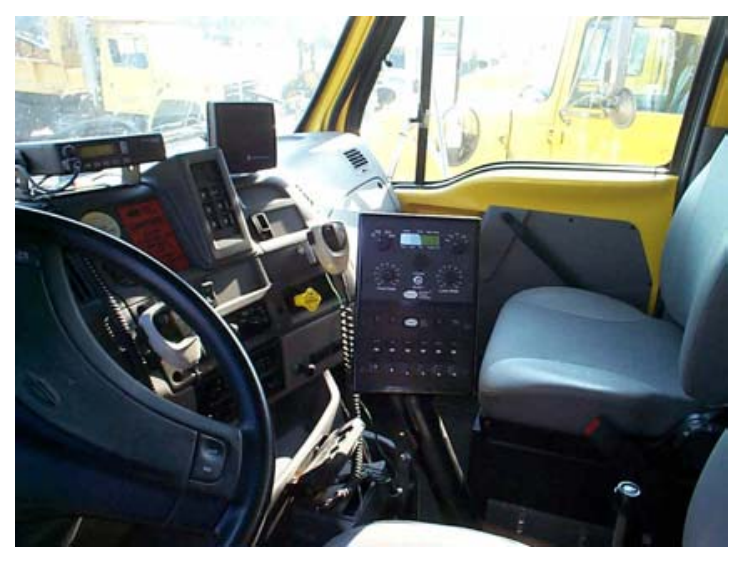

Figure 7 - Muncie Spreader Controller

Figure 8 shows the spread pattern of the Muncie System running at 32 kilometers/hour (20 MPH). The pattern shows that the Muncie System distributed the salt in the targeted 4 meter width with a satisfactory recovery rate at $51.04 \%$.

Figure 9 shows the spread pattern of the coarser salt particles at the truck speed to that of Figure 8 . While the spread pattern of the total salt particles in Figure 8 shows a 
good spread pattern, the nature of the spreader in this Muncie System gives a spread pattern of coarser particles as shown in Figure 9 with spread density of the coarser salt particles apparently heavier on the right side of the roadway. This phenomenon occurred probably due to the direction of the spinner (clockwise direction with a reflector). However, this Muncie System gives a satisfactory rate-of-recovery of the coarser salt particles at $22.61 \%$.

Figures 10 and 11 show the spread patterns of the total salt and the coarser salt particles at a truck speed of 64 kilometers/hour $(40 \mathrm{MPH})$. The recovery rate of the total salt particles is $17.79 \%$ and the $\# 4$ sieve salt particles is $2.53 \%$. These results indicate that the advantages of the Muncie System are diminishing at a higher truck speed. Speed of the truck, vortices on the tail of the truck, and the mechanics of the spreader unit are the main reasons for the change in the spread pattern.

Comparing the results of the non-zero velocity spreaders, in this case between the Industrial Hydraulic System and the Muncie System, this Muncie System gives 22.58\% advantage of recovery rate at 32 kilometers/hour (20 MPH). However, at 64 kilometers/hour (40 MPH), there is no difference between the two systems.

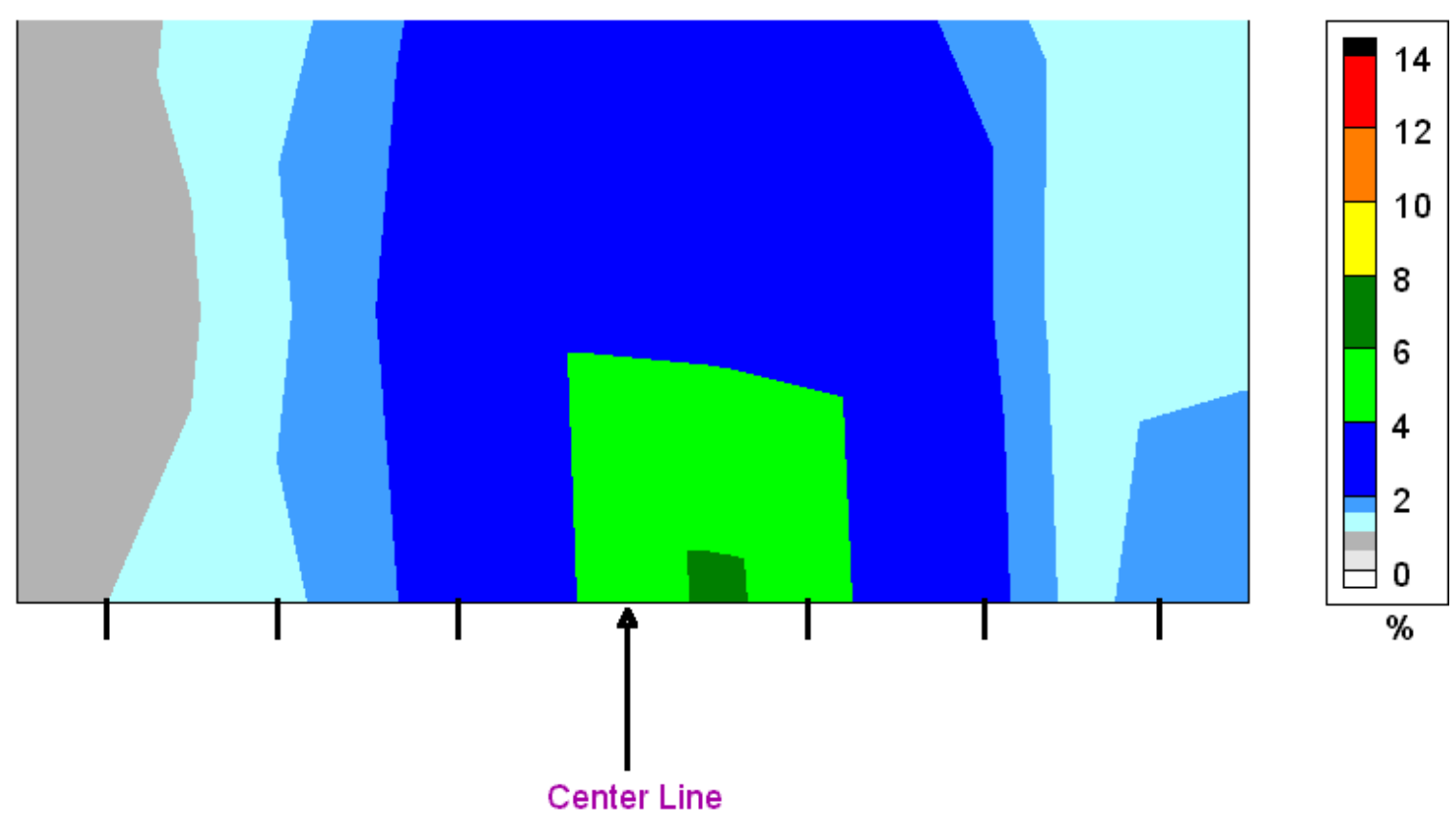

Figure 8 - Percentage of total salt recovered at 32 kilometers/hour (20 MPH) for Muncie System 


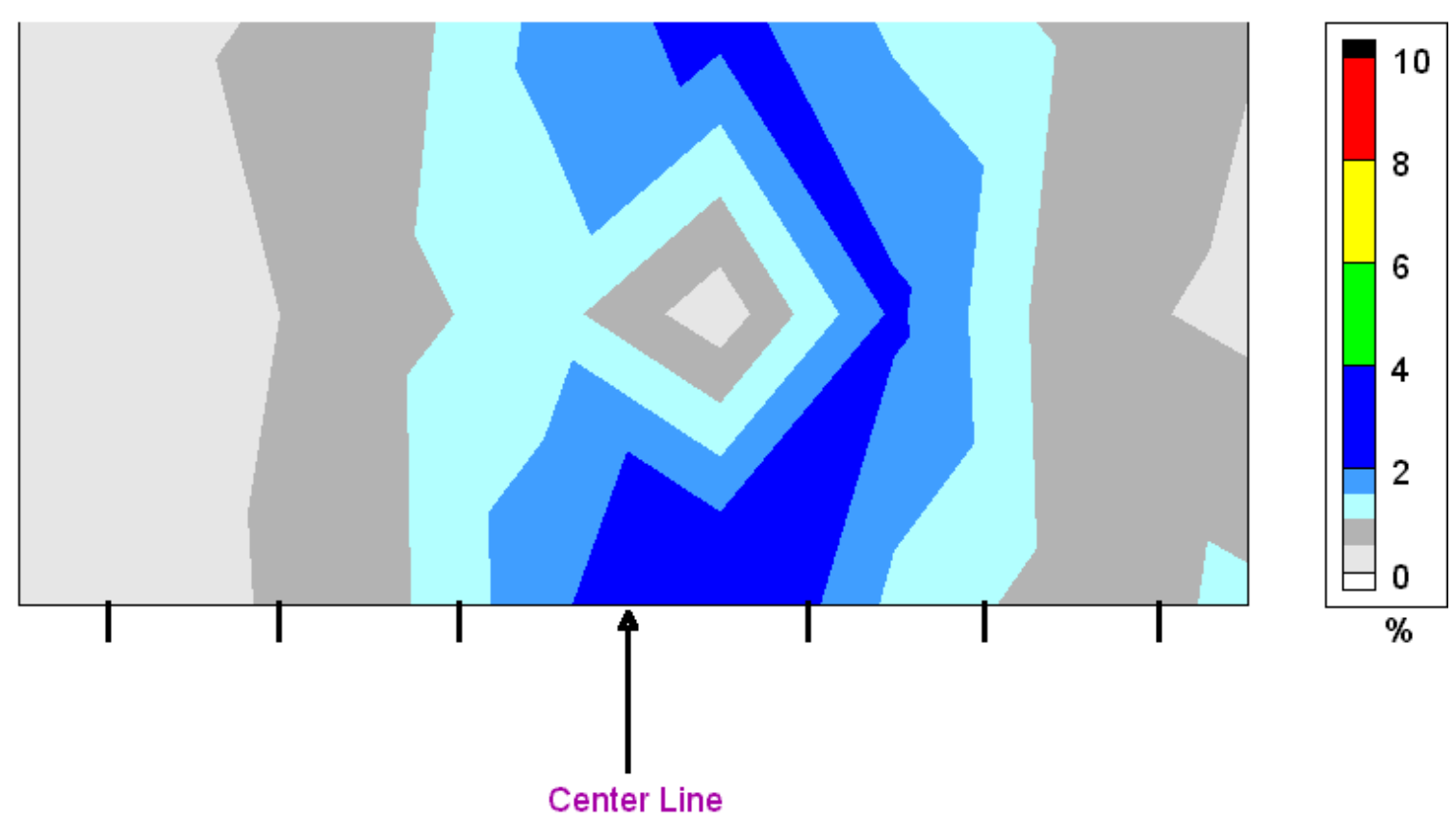

Figure 9 - Percentage of \#4 sieve salt recovered at 64 kilometers/hour (40 MPH) for Muncie System
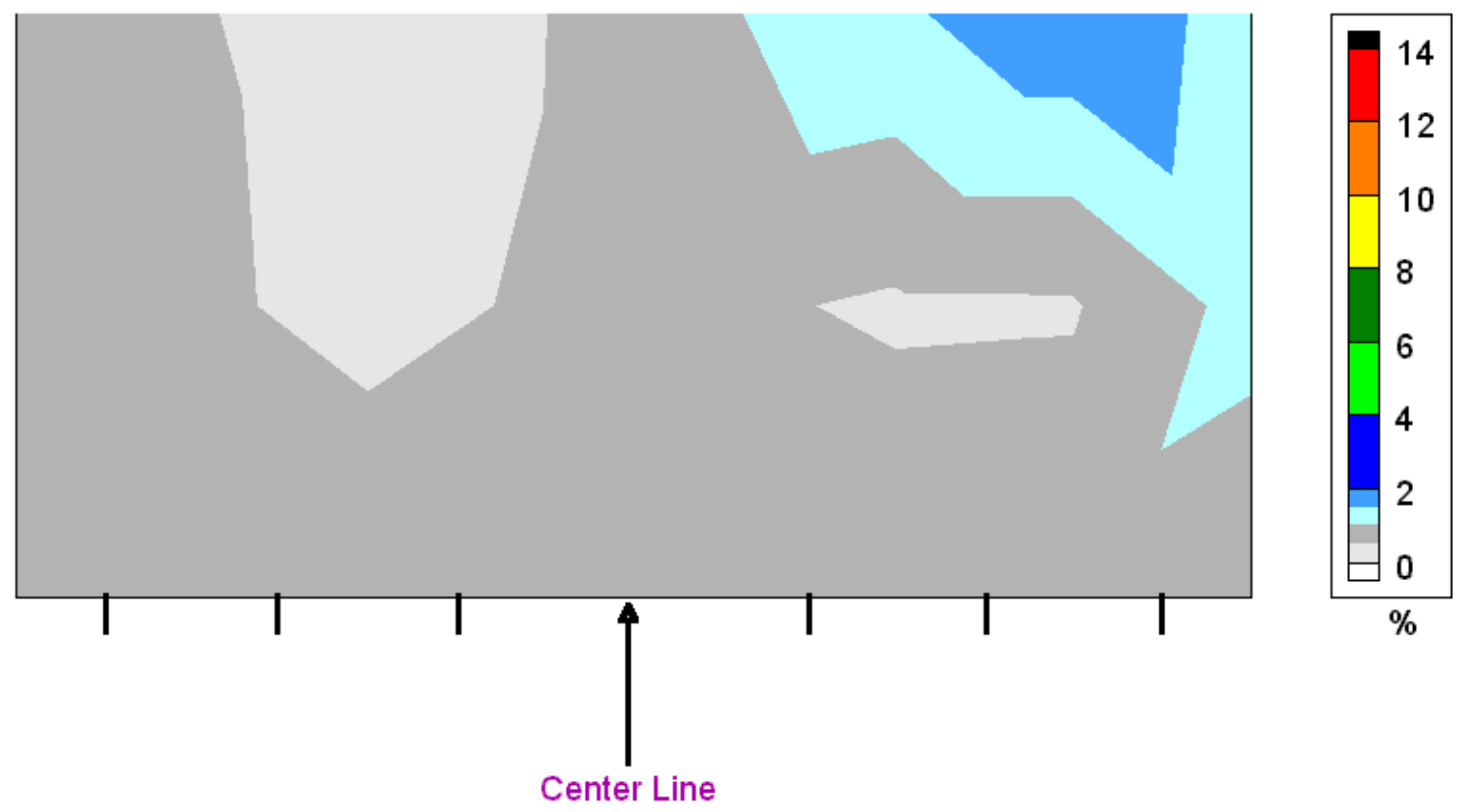

Figure 10 - Percentage of total salt recovered at 64 kilometers/hour (40 MPH) for Muncie System 


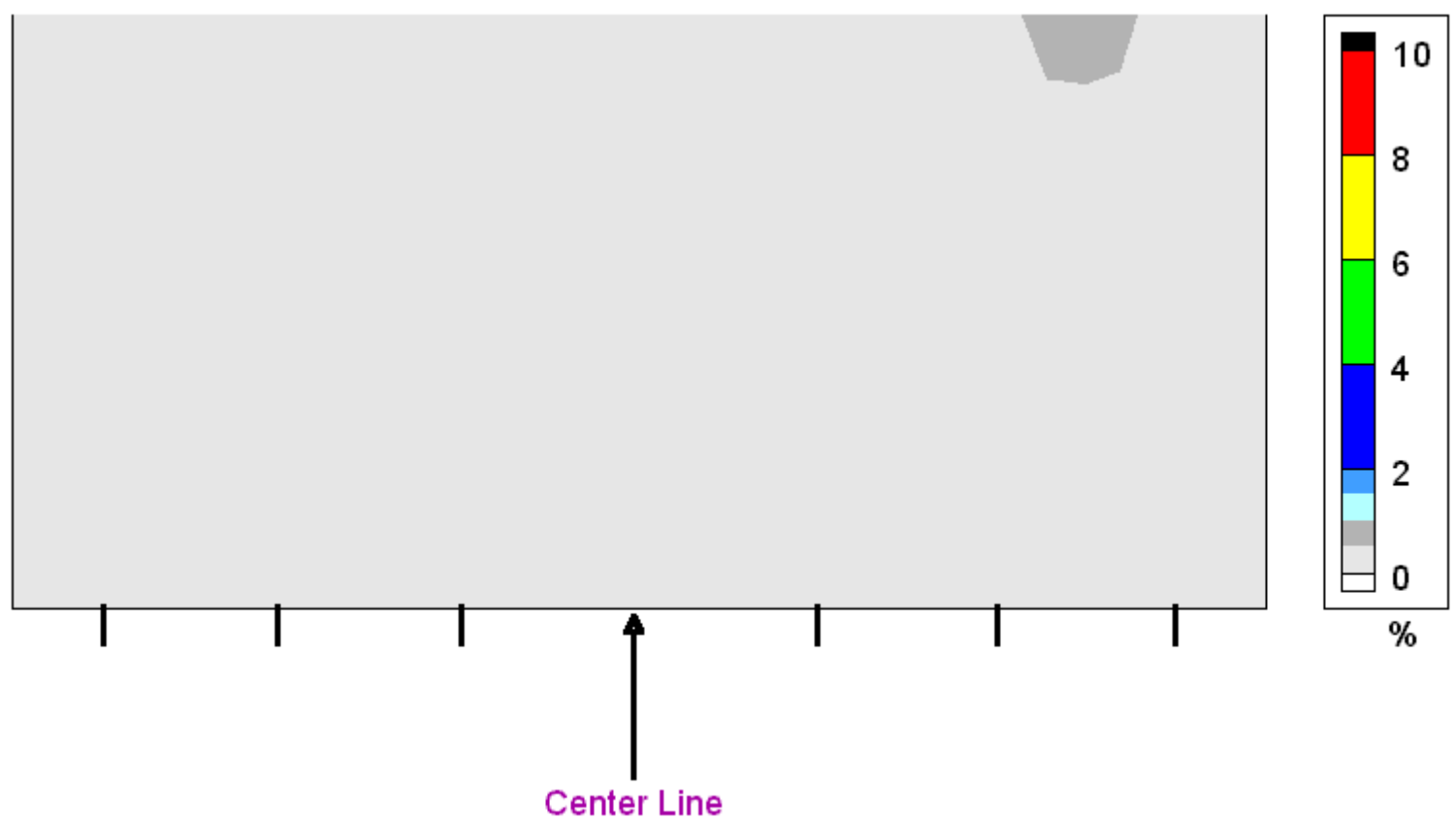

Figure 11 - Percentage of \#4 sieve salt recovered at 64 kilometers/hour (40 MPH) for Muncie System

5C. Pengwyn Zero Velocity
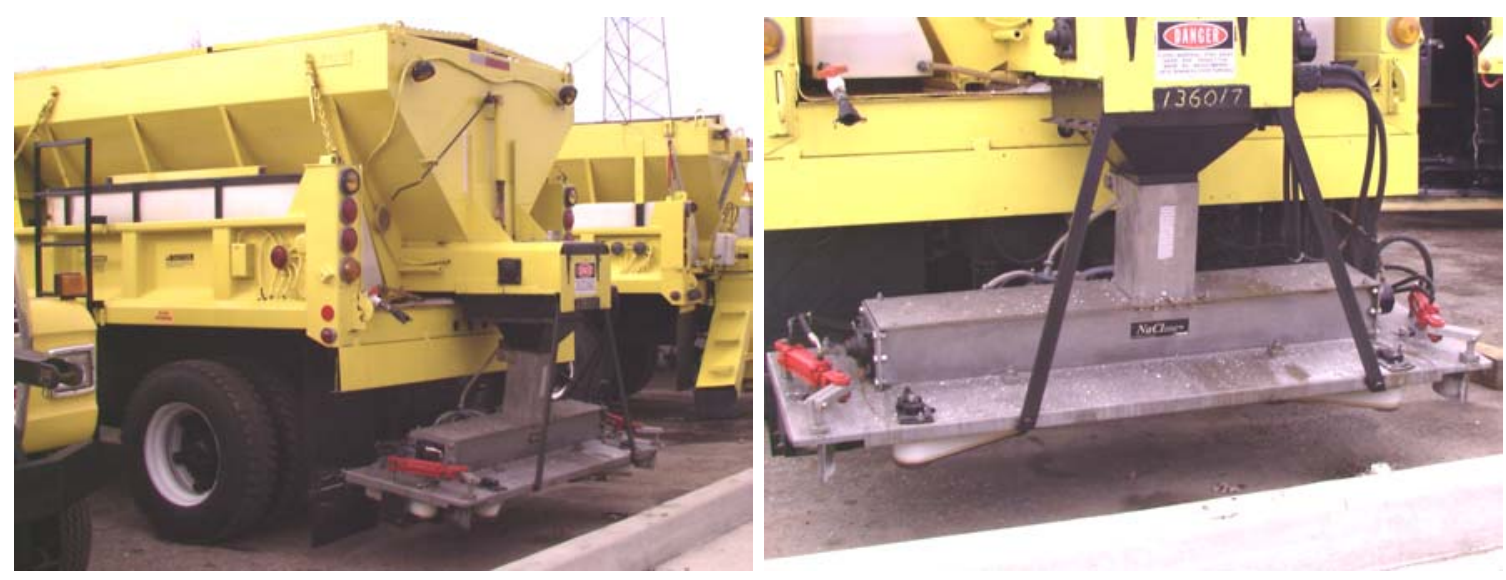

Figure 12 - Pengwyn Zero Velocity

Figure 13 - Pengwyn Dispensing Unit

This Pengwyn Model 2000 Central Hydraulic System Zero Velocity truck is equipped with a twin-zero velocity ejector consisting of a right and left wheel ejector. These ejectors are operator selectable in the cab on the fly for $100 \%$ right track application, 100\% left track application or 50-50 application. This will enable the truck 
driver to treat curved two lanes, straight two lanes in one pass, four lanes and interstate at the highest practical speed. Both ejectors have automatic wetting controls which dispense $\mathrm{CaCl}_{2}$ liquid directly on the stainless steel ejector plate of the active zero velocity unit. This wets all the material including the salt fines getting nearly $100 \%$ to stick to the pavement rather than losing the fines as dust in the turbulence behind the truck.

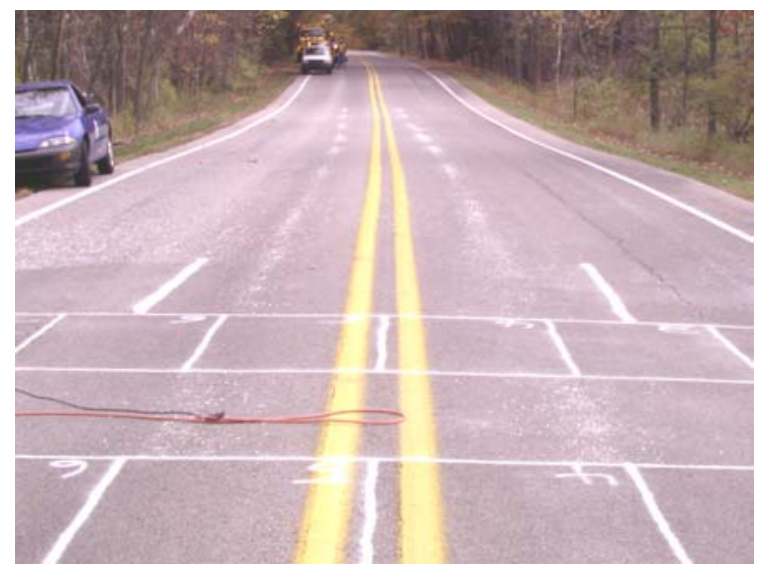

Figure 14 - Spread pattern at $20 \mathrm{MPH}$

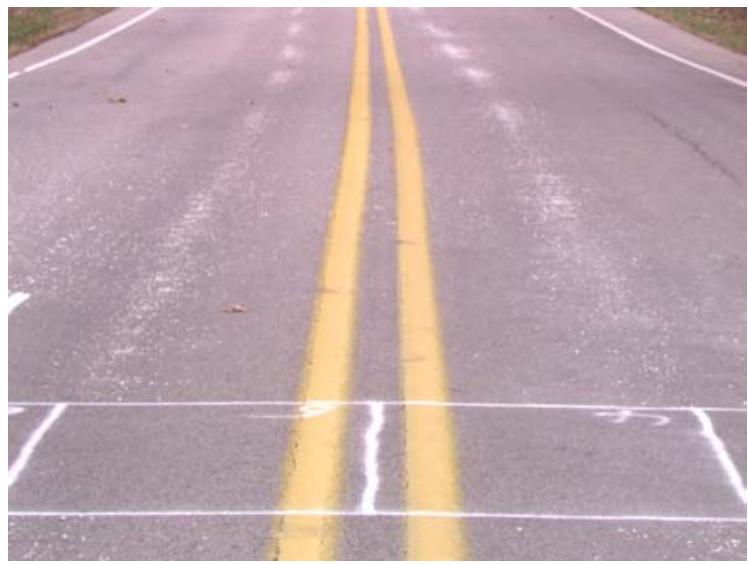

Figure 15 - Spread pattern at 40MPH

During the evaluation of this system, the salt was not pre-wetted. Therefore, direct comparison with other systems can be achieved. In addition, the two ejectors were set to 50-50 application as indicated in Figures 12 and 13. Figures 14 and 15 show the traces of salt particles at 32 kilometers/hour (20 MPH) and 64 kilometers/hour (40 MPH) with a feed rate of $56.37 \mathrm{~kg} / \mathrm{km}$ (200 lbs/mile). It appears clearly that both ejectors sucessfully "placed" the salt particles to the intended areas.

Figure 16 shows the spread pattern of the total salt particles from the Pengwyn Zero Velocity with a truck speed of 32 kilometers/hour (20 MPH) with a recovery rate of $59.48 \%$. Although some particles fell outside of the the target area due the configuration of the ejectors (the two ejectors are two meters apart) this system gives a more than satisfactory results. Figure 17 shows the spread pattern of the coarser salt particles retained on \#4 sieve. It is very obvious that the coarser salt particles fell in between of the 4 meter (13.12 foot) wide area. The recovery rate for these coarser salt particles is $28.64 \%$. 
Figure 18 shows the spread pattern of the total salt particles at 64 kilometers/hour (40 MPH) with a recovery rate of $55.07 \%$. This Pengwyn system consistently spread the target area with a small amount of salt particles fell on the right hand side of the direction of the truck. Comparing Figures 18 and 19, the salt particles that fell outside the target area to the right side of the truck were mostly fine salt particles. Therefore, turbulence on the tail of the truck was suspected as the cause.

Figure 19 shows the spread pattern of the coarser salt particles at 64 kilometers/hour (40 MPH). It is clear that the spreader consistently spread the target area more than satisfactory result. The recovery rate of $30.56 \%$ for the coarser particles at 64 kilometers/hour (40 MPH) is even a little bit higher than that of the lower speed.

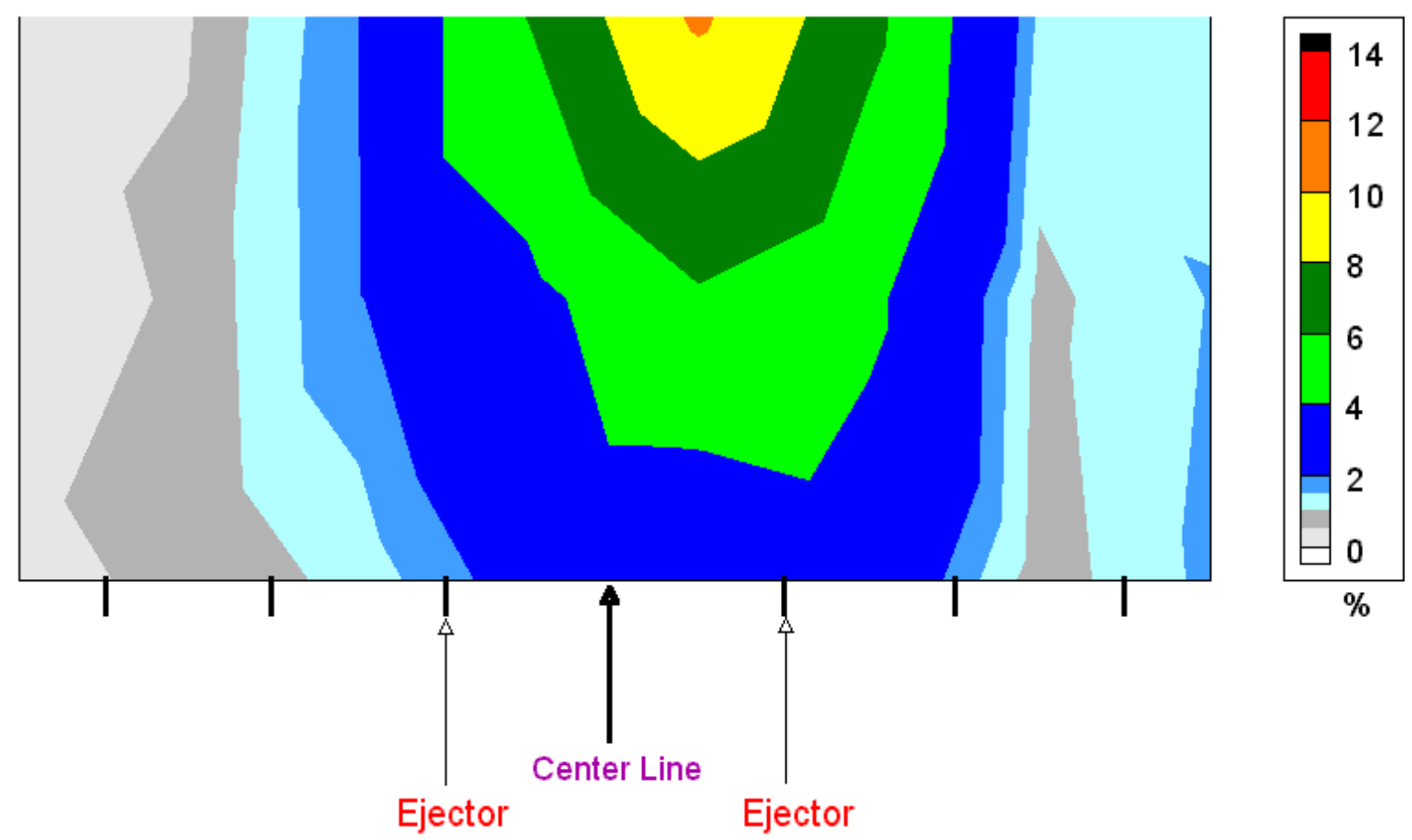

Figure 16 - Percentage of total salt recovered at 32 kilometers/hour (20 MPH) for Pengwyn System 


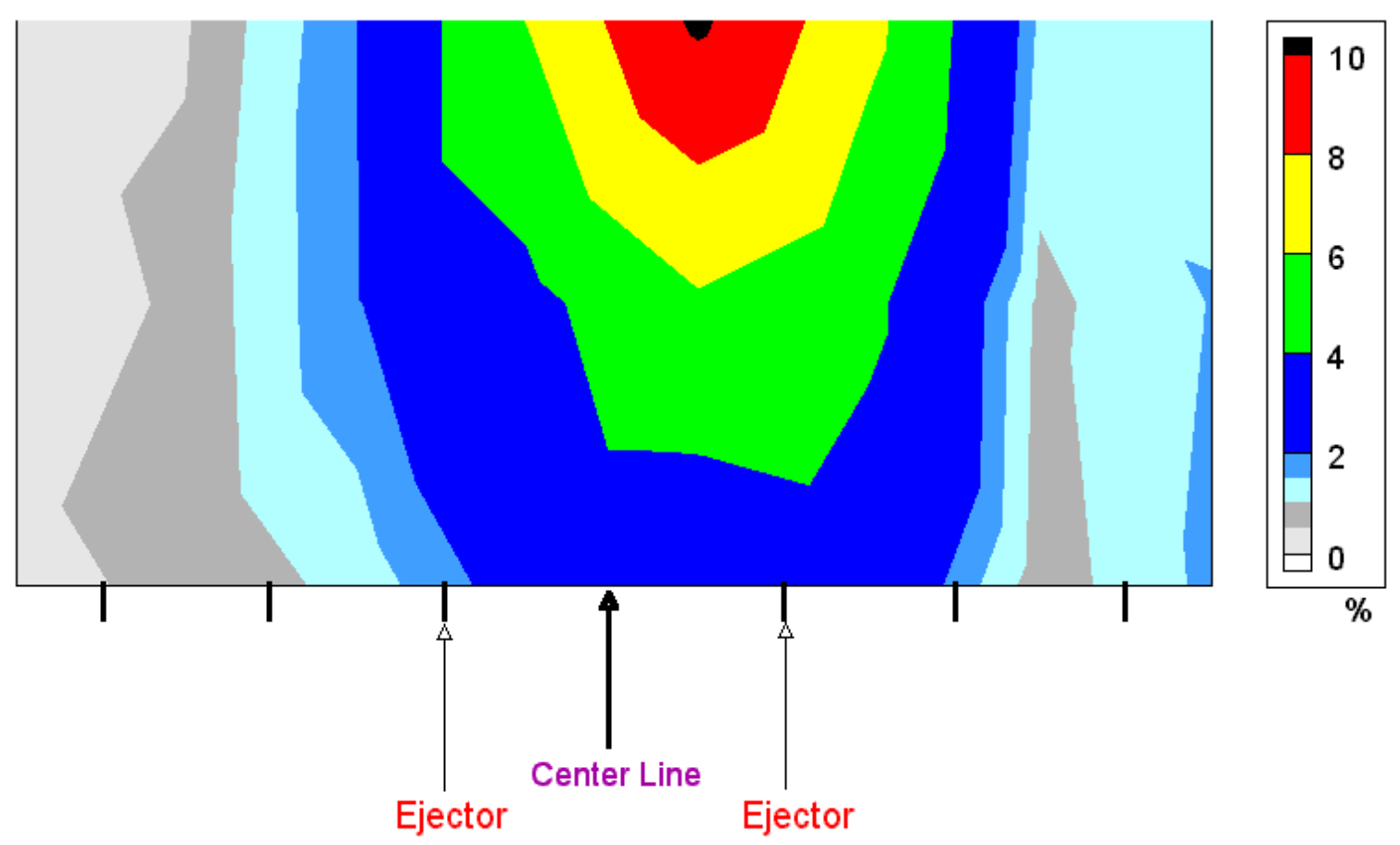

Figure 17 - Percentage of \#4 sieve salt recovered at 32 kilometers/hour (20 MPH) for Pengwyn System

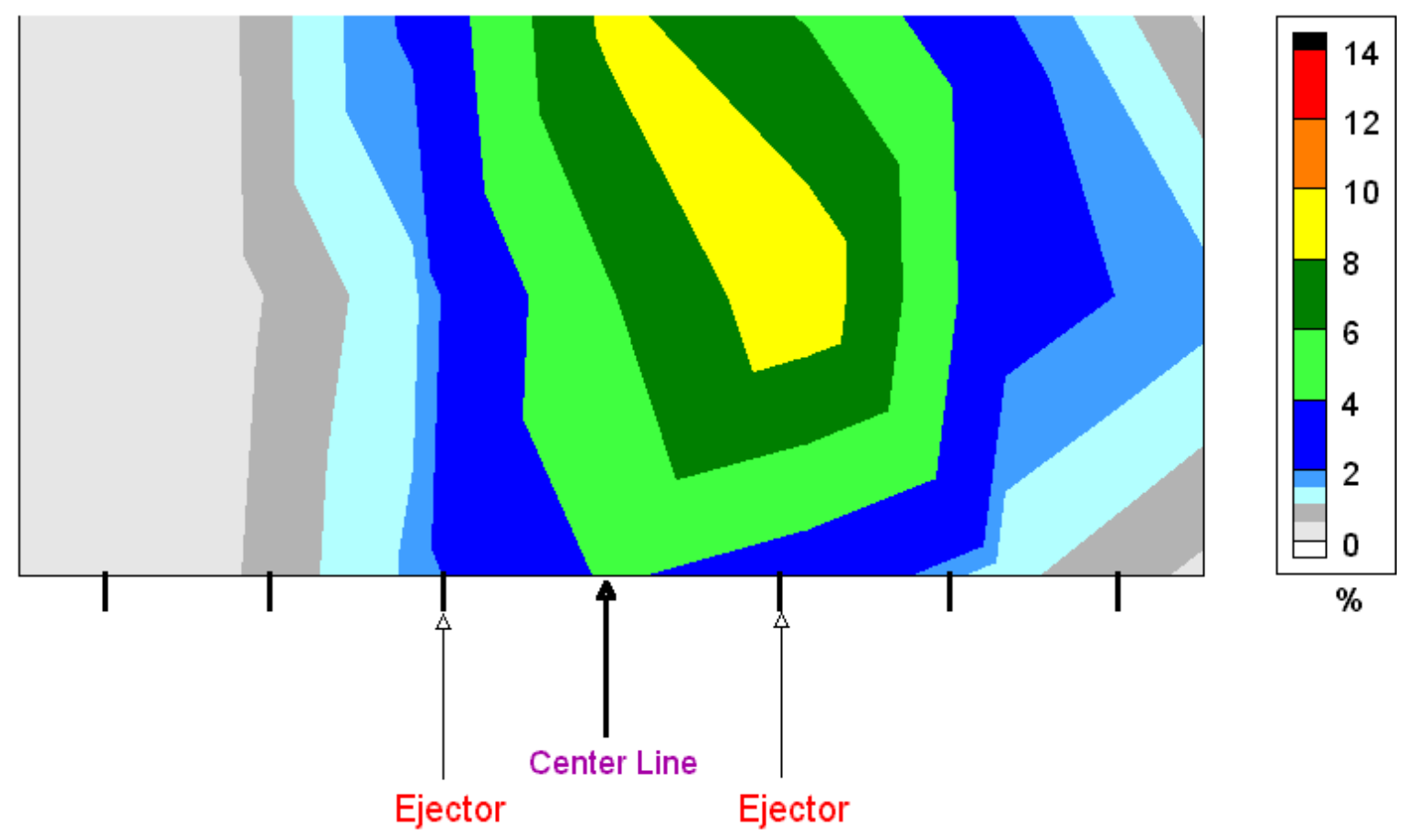

Figure 18 - Percentage of total salt recovered at 64 kilometers/hour (40 MPH) for Pengwyn System 


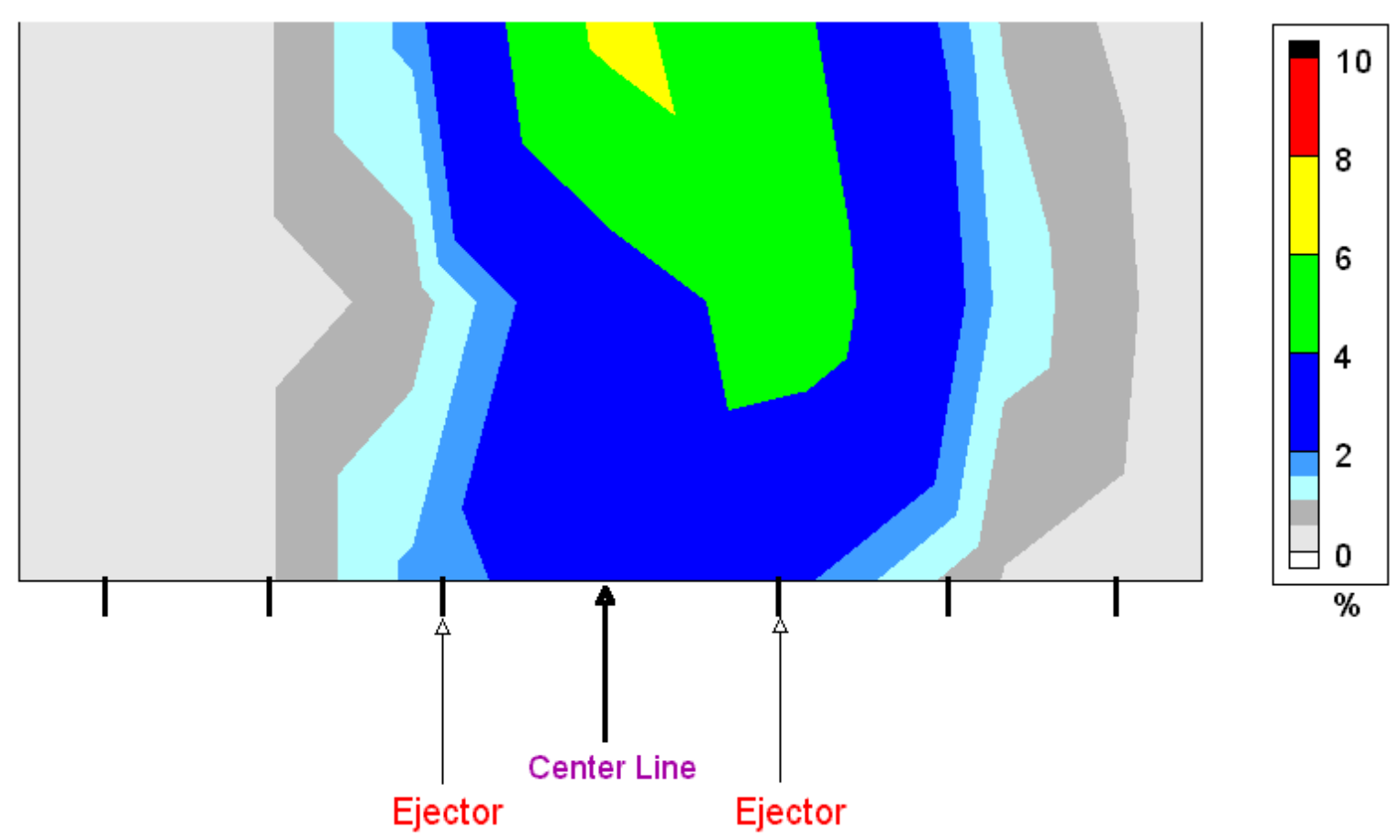

Figure 19 - Percentage of \#4 sieve salt recovered at 64 kilometers/hour (40 MPH) for Pengwyn System

\section{D. Swenson Zero Velocity System}

This Swenson Zero Velocity System or Precision Placement System has a spinner assembly constructed of 304 stainless steel and features a hydraulic cylinder actuated shroud which may be raised or lowered based on spreading requirements. In the shroud down mode, this unit applies in a four to six feet wide confined stream windrow with a rearward velocity equal to the forward velocity of the truck. With the shroud up, the unit may be used for multi-lane or spot broadcast applications. Figures 20 and 21 show the Swenson system and its dispensing unit or shroud.

At low and high speed, the feed rate was set to $70.46 \mathrm{~kg} / \mathrm{km}(250 \mathrm{lbs} / \mathrm{mile})$. Figure 22 shows the spread pattern of this Swenson system with a single ejector. It is very clear that this system is able to spread the salt in a narrow band of area. However, as indicated in Figure 22, the consistency of the feed rate is questionable. Figure 22 shows an interupted streak of salt band, this system lacks of steady flow of determined feed rate. 

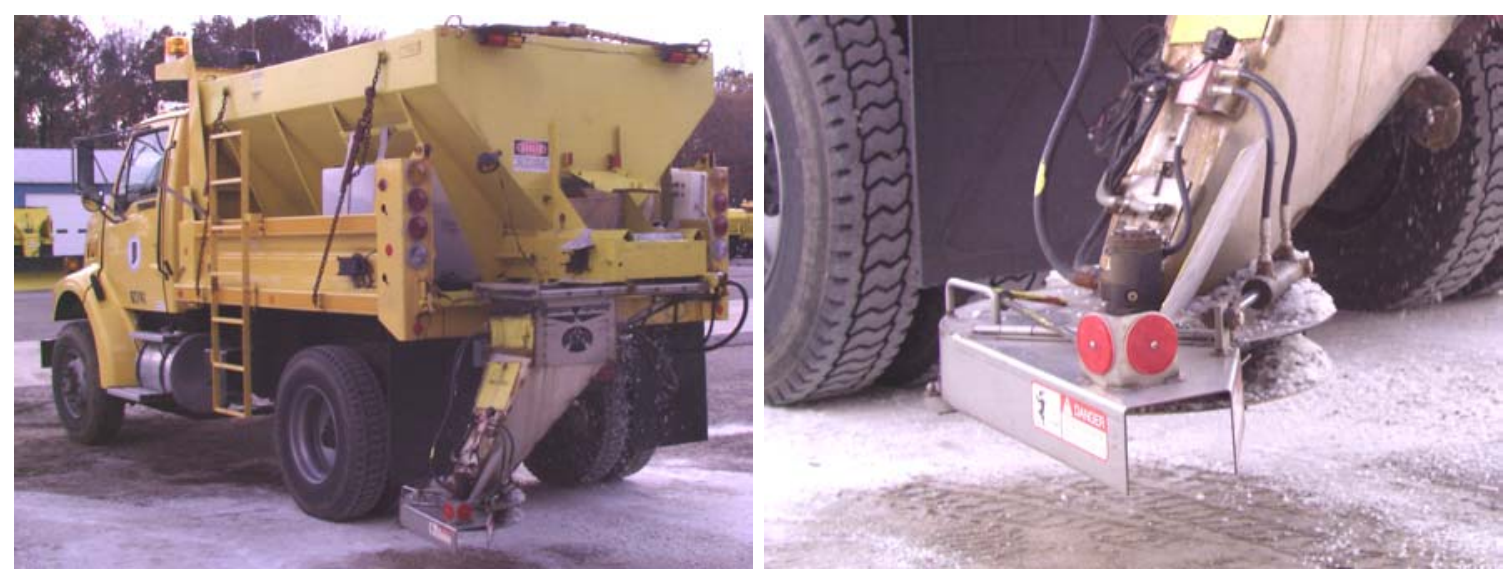

Figure 20 - Swenson Zero Velocity System Figure 21 - Dispensing Unit (Shroud)

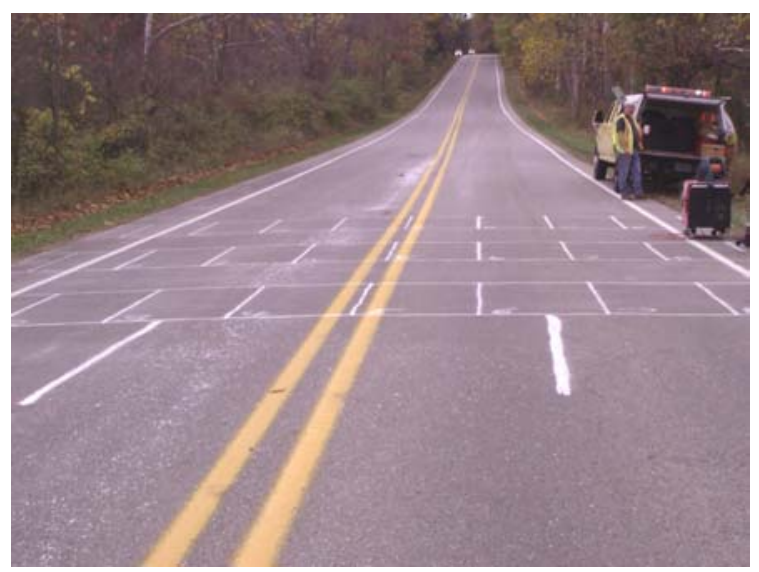

Figure 22 - Swenson Spread Pattern

The Swenson Zero Velocity system reviewed by INDOT Angola Sub-District was provided by the manufacturer for a trial basis. This unit might be a prototype unit that needs fine tuning of the salt feeder and coordination between the ground speed and the ejector speed.

Figure 23 shows the spread pattern of the Swenson unit at 32 kilometers/hour (20 $\mathrm{MPH})$. The recovery rate of the total salt particles is $28.49 \%$ which is almost identical to the Industrial Hydraulic System but far less than that of the Muncie System. Figure 23 also shows an excellent narrow band spread pattern. Figure 24 shows the spread pattern of the coarser salt particles with a recovery rate of $17.72 \%$, which is almost identical to 
the Muncie System. These results shows that this system has no advantage compared to the present system at INDOT. However, these results may be due to the inconsistency of the spread of the prototype unit.

Figure 25 shows the spread pattern of the total salt particles at 64 kilometers/hour (40 MPH) with a very high recovery rate of $79.56 \%$. With this very high recovery rate compared to that of the slower truck speed of 32 kilometers/hour (20 MPH), it solidify the conclusion that this Swenson System lacks consistency of feed rate.

Figure 26 shows the spread pattern of the coarser salt particles for a truck speed of 64 kilometers/hour (40 MPH) with a recovery rate of $44.06 \%$. This result is more than double that of the slower truck speed of $17.72 \%$ indicates the inconsistency of the feed rate. During the actual operation of this unit in two winter seasons, the truck operators indicated an excesive down-time for every cycle of snow removal operation. This problem had been reported to the manufacturer for modification of this unit. By this time, the manufacturer of this Swenson unit may already solved the problem.

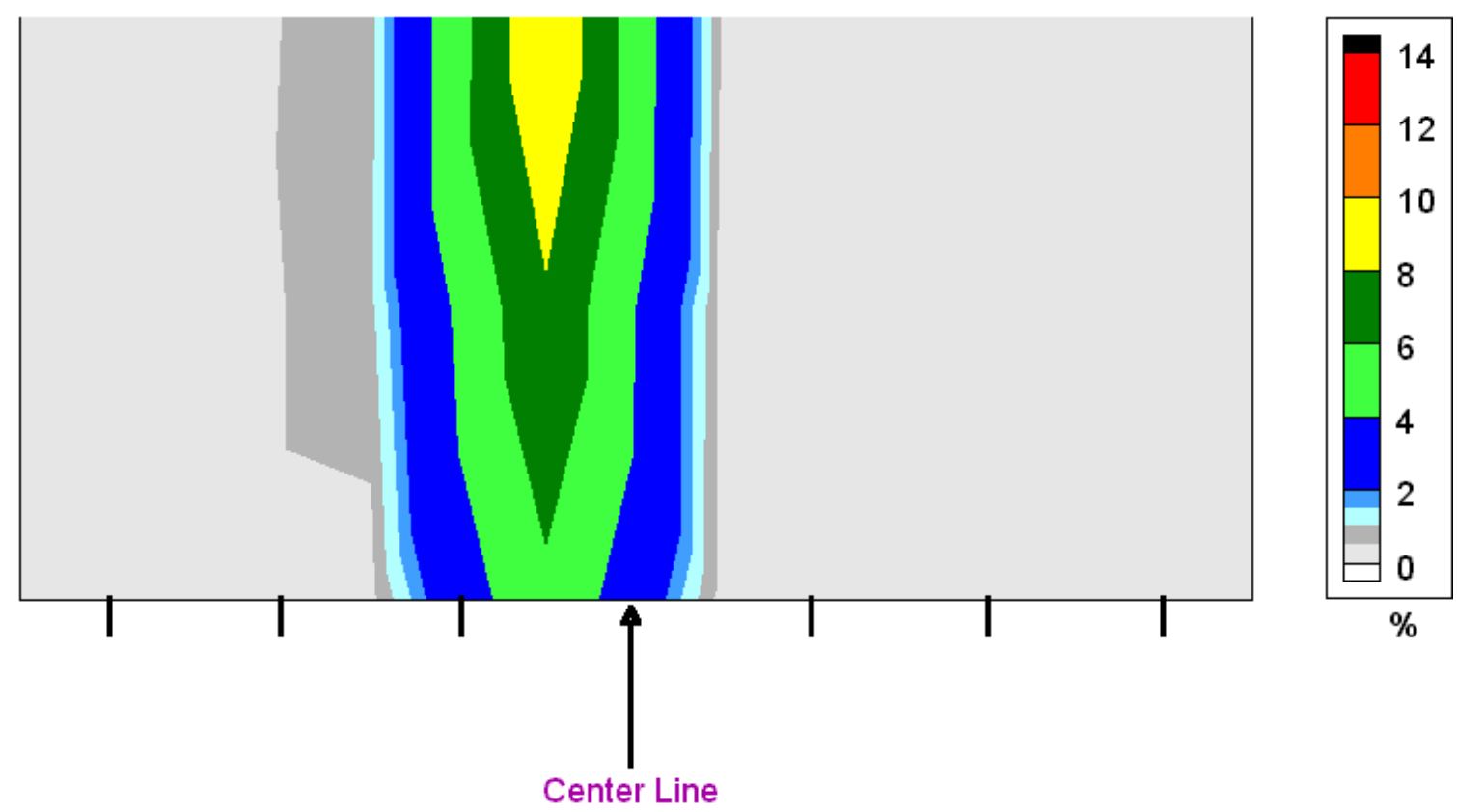

Figure 23 - Percentage of total salt recovered at 32 kilometers/hour (20 MPH) for Swenson System 


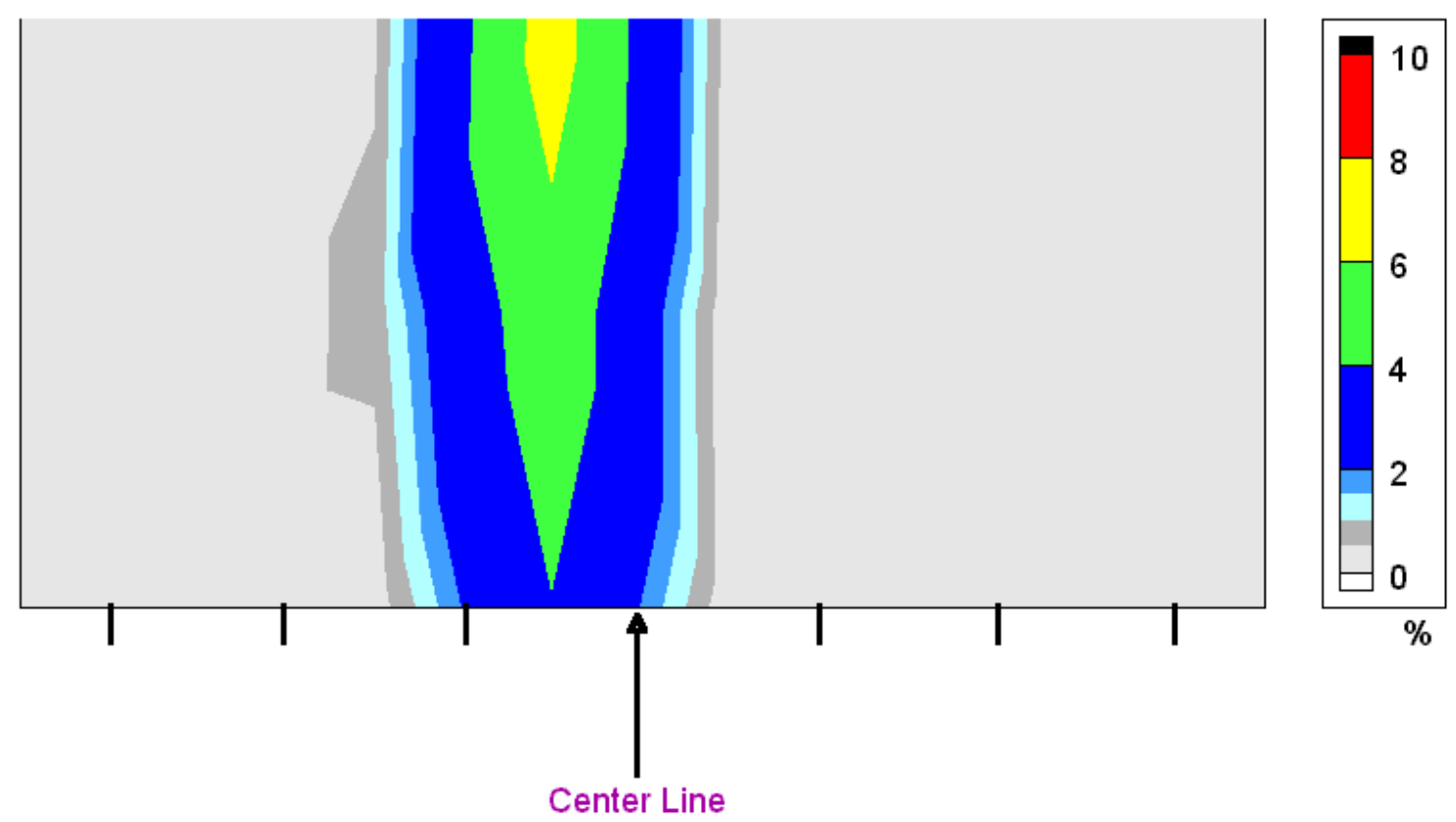

Figure 24 - Percentage of \#4 sieve salt recovered at 32 kilometers/hour (20 MPH) for Swenson System

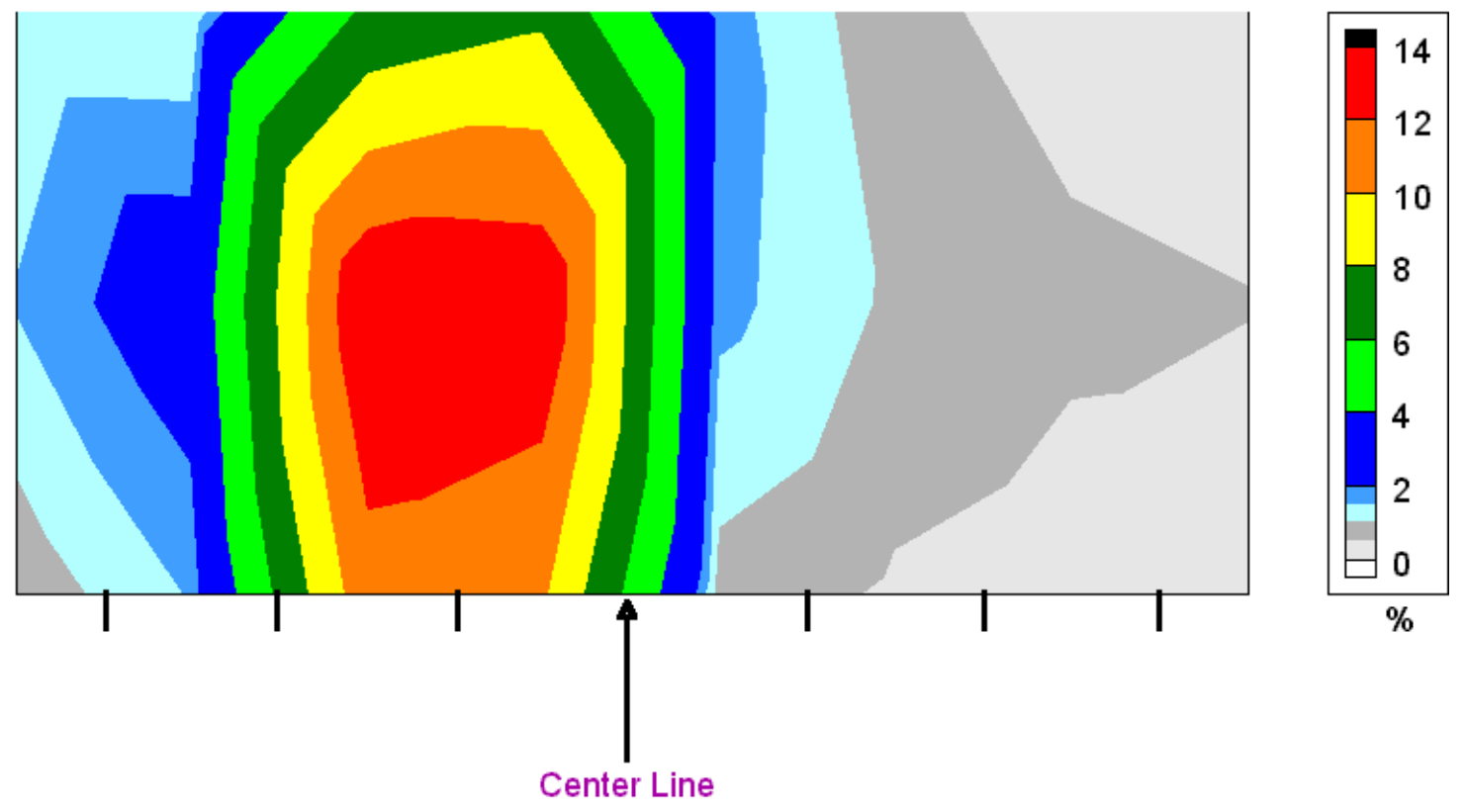

Figure 25 - Percentage of total salt recovered at 64 kilometers/hour (40 MPH) for Swenson System 


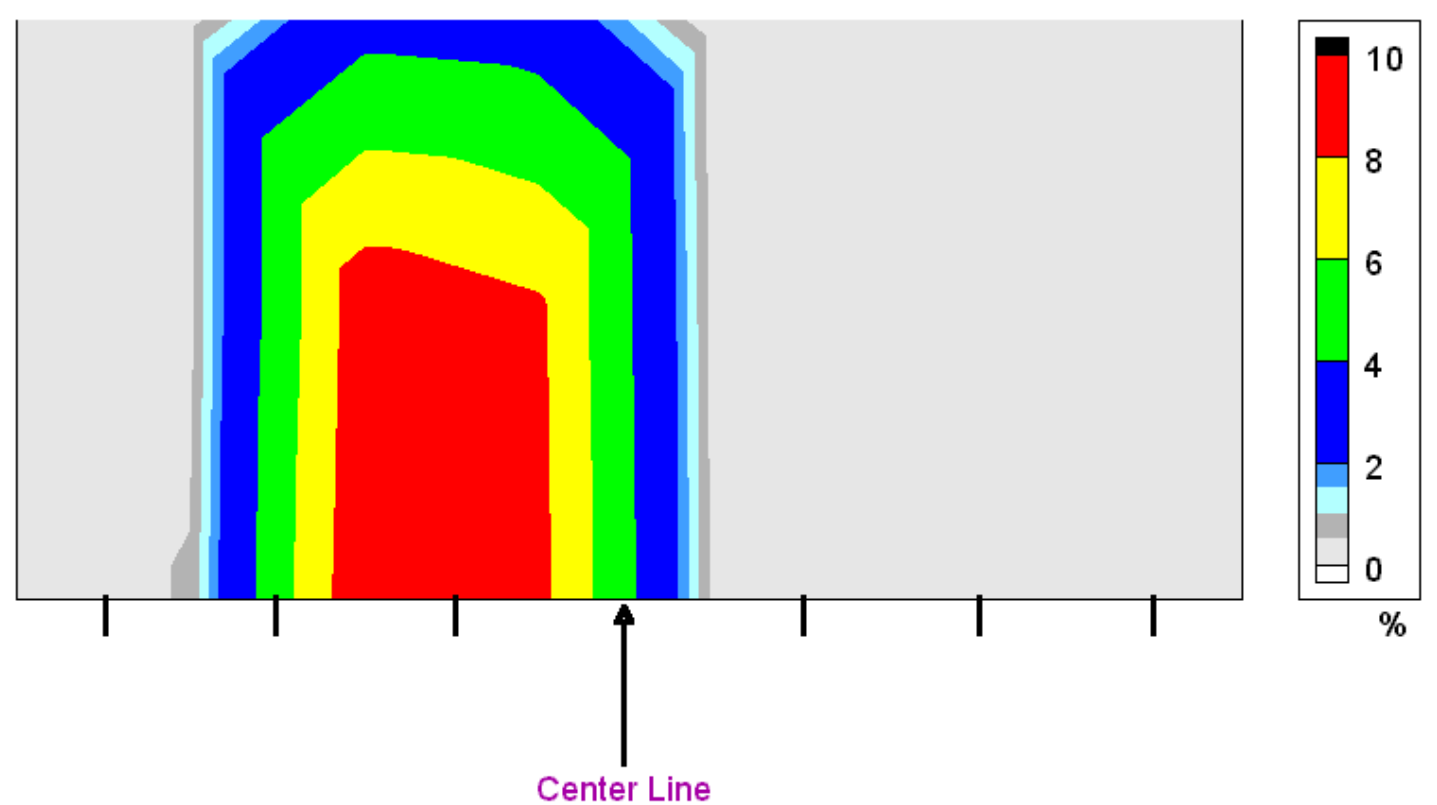

Figure 26 - Percentage of \#4 sieve salt recovered at 64 kilometers/hour (40 MPH) for Swenson System

\section{E. Tyler Zero Velocity System}

The Tyler Zero Velocity System is a very sophisticated system to spread the salt. The system's microprocessor-based, cab-mounted Quantum controller handles three control loops and generates Pulse Width Modulation command signals. To control the auger that delivers salt to the dispersal system, this system utilizes a closed control loop. A pulse pickup on the hydraulic motor that drives the auger provides speed feedback data to the controller. Both the fan that propels salt out of the system and the liquid-injection diaphragm pump (driven by a de motor) are controlled open-loop. According to the manufacturer, this system can spread very precisely from speeds right down to zero and up to $35 \mathrm{MPH}$, which is about the upper end. After that, the pattern starts to degrade because of vortices around the back of the truck. ${ }^{(5)}$

The working principle of the spreader unit in this zero velocity system is different from the two zero velocity systems discussed before. The spreader in the Pengwyn Zero Velocity System is a belt driven ejector, the spreader in the Swenson system is a disc driven, and the spreader in this Tyler unit is an air driven as shown in Figure 27. In this 
air driven system, the salt particles from the hopper are fed to a horizontal auger system and into a vertical drop chute and ejected by blown air.

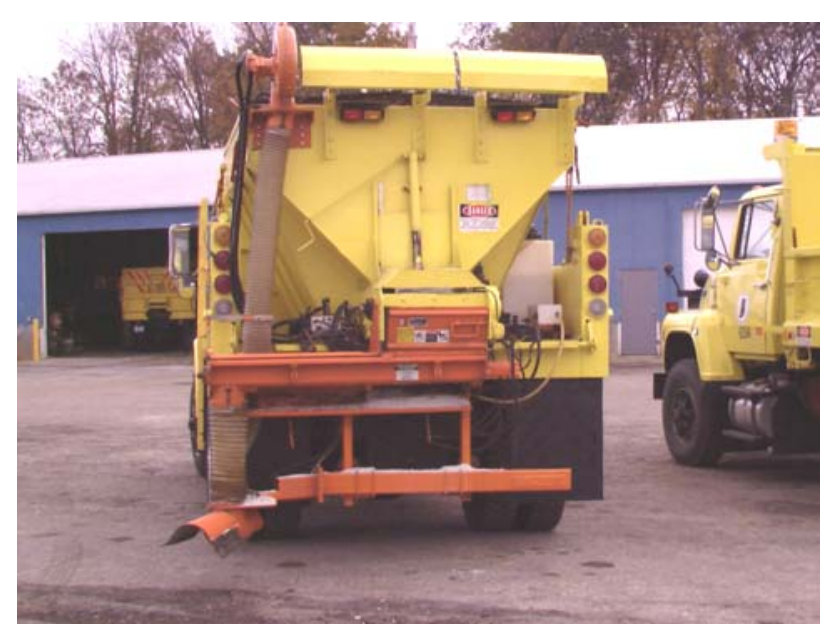

Figure 27 - Tyler Zero Velocity System

This Tyler system is proven to be the best system for a truck speed of 32 kilometers/hour (20 MPH). Figure 28 shows the spread patterns of the total salt particles at 32 kilometers/hour $(20 \mathrm{MPH})$ with a recovery rate of $72.73 \%$. Figure 29 shows the spread pattern of the coarser salt particles at 32 kilometers/hour (20 MPH) with an excellent recovery rate of $42 \%$.

At a higher truck speed, the performance of this Tyler system degrades. Figure 30 shows the spread pattern of total salt particles at 64 kilometers/hour (40 MPH) with a recovery rate $50.11 \%$ and Figure 31 shows the spread pattern of the coarser particles with a recovery rate of $20.02 \%$. However, this recovery rate at this truck speed is far more better than that of the Industrial Hydraulic System and the Muncie System.

Besides the down-time experienced with this Tyler System, a small problem occurred when spreading onto wet snow. Because the ejector is located right behind the wheels on the driver side of the truck, moisture went into the vertical drop chute and "caking" of salt particles jammed the flow of salt. It is an inconvinience to the truck operator to clear-up the drop chute every so often. 


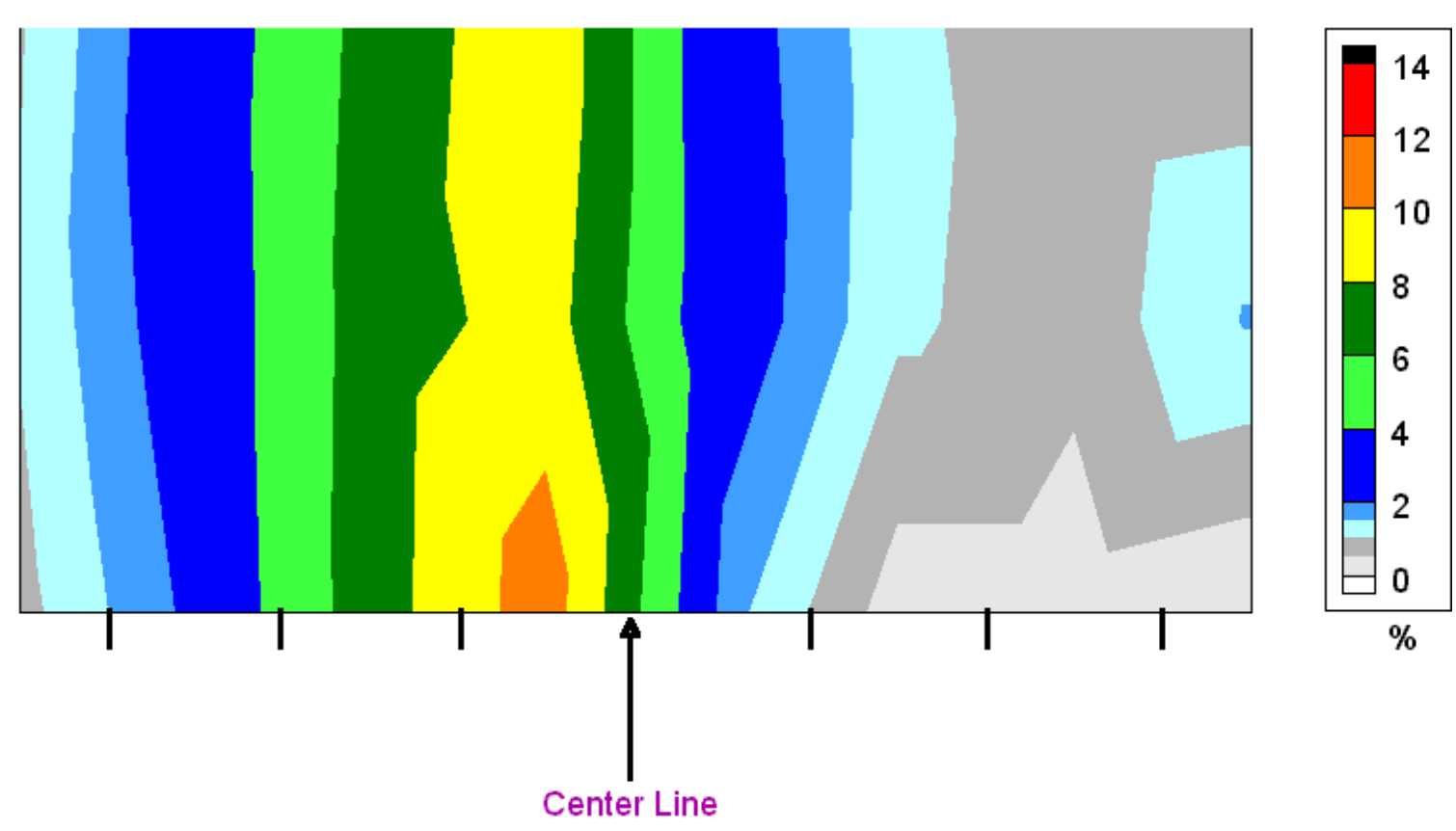

Figure 28 - Percentage of total salt recovered at 32 kilometers/hour (20 MPH) for Tyler System
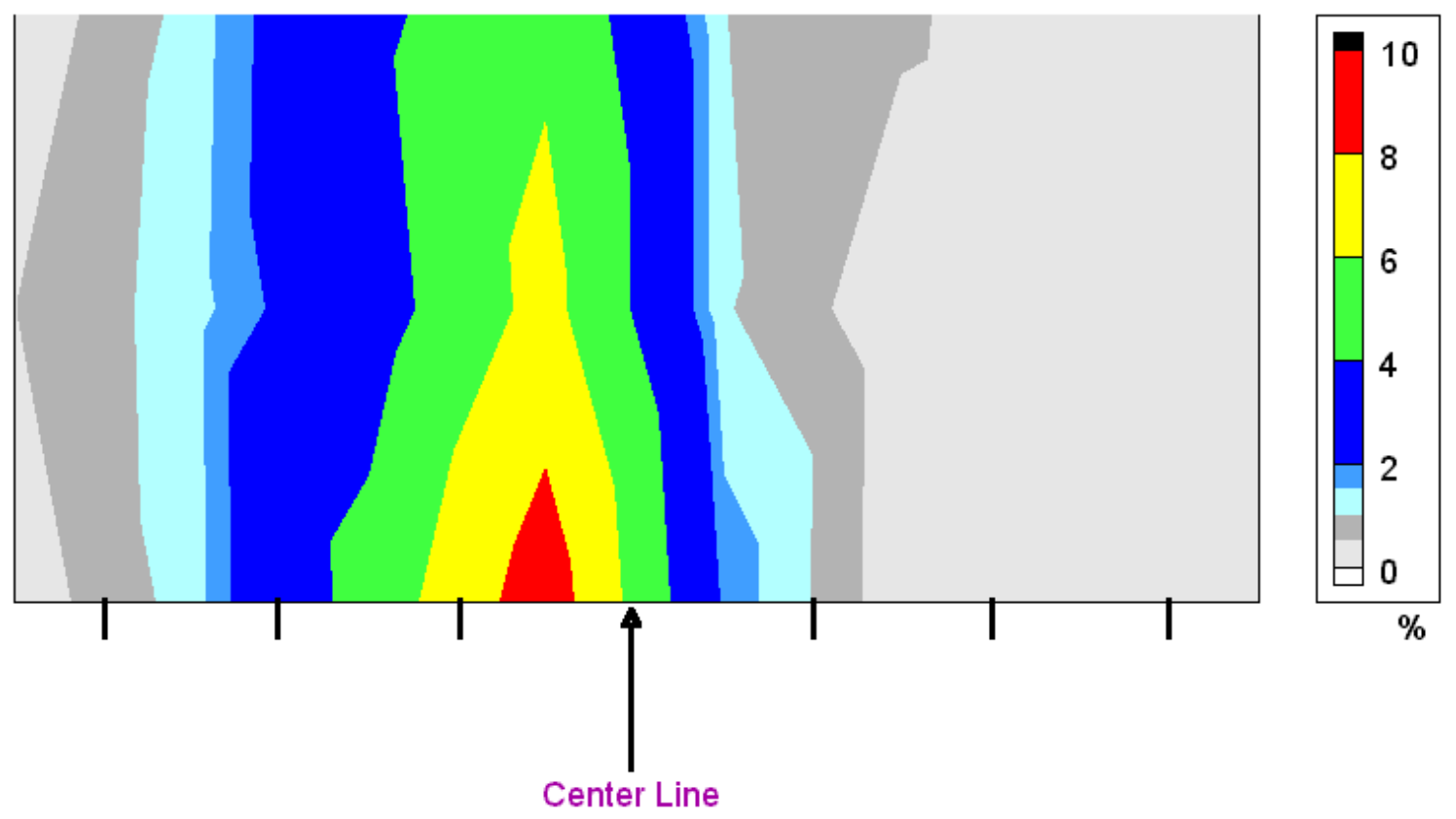

Figure 29 - Percentage of \#4 sieve salt recovered at 32 kilometers/hour (20 MPH) for Tyler System 


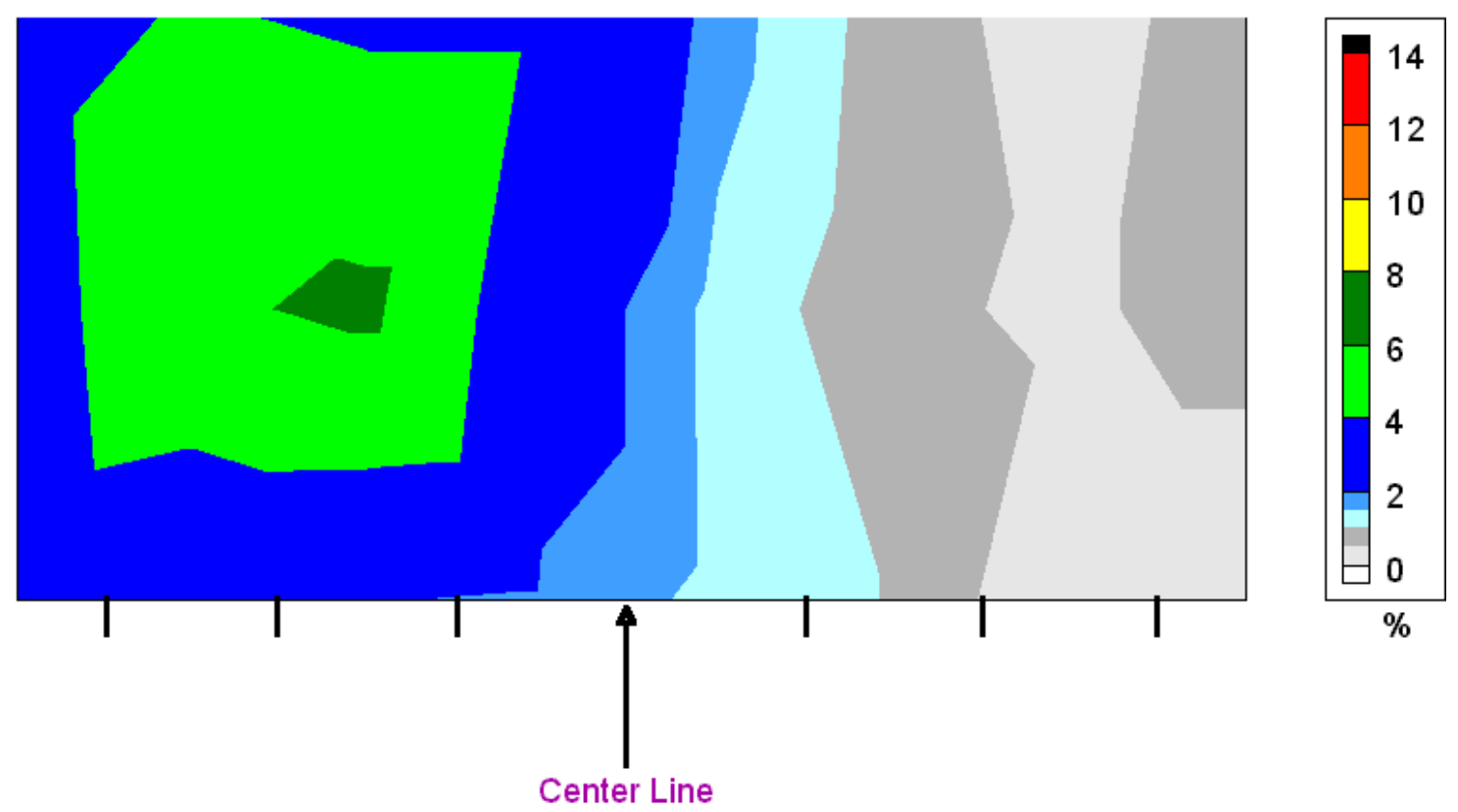

Figure 30 - Percentage of total salt recovered at 64 kilometers/hour (40 MPH) for Tyler System
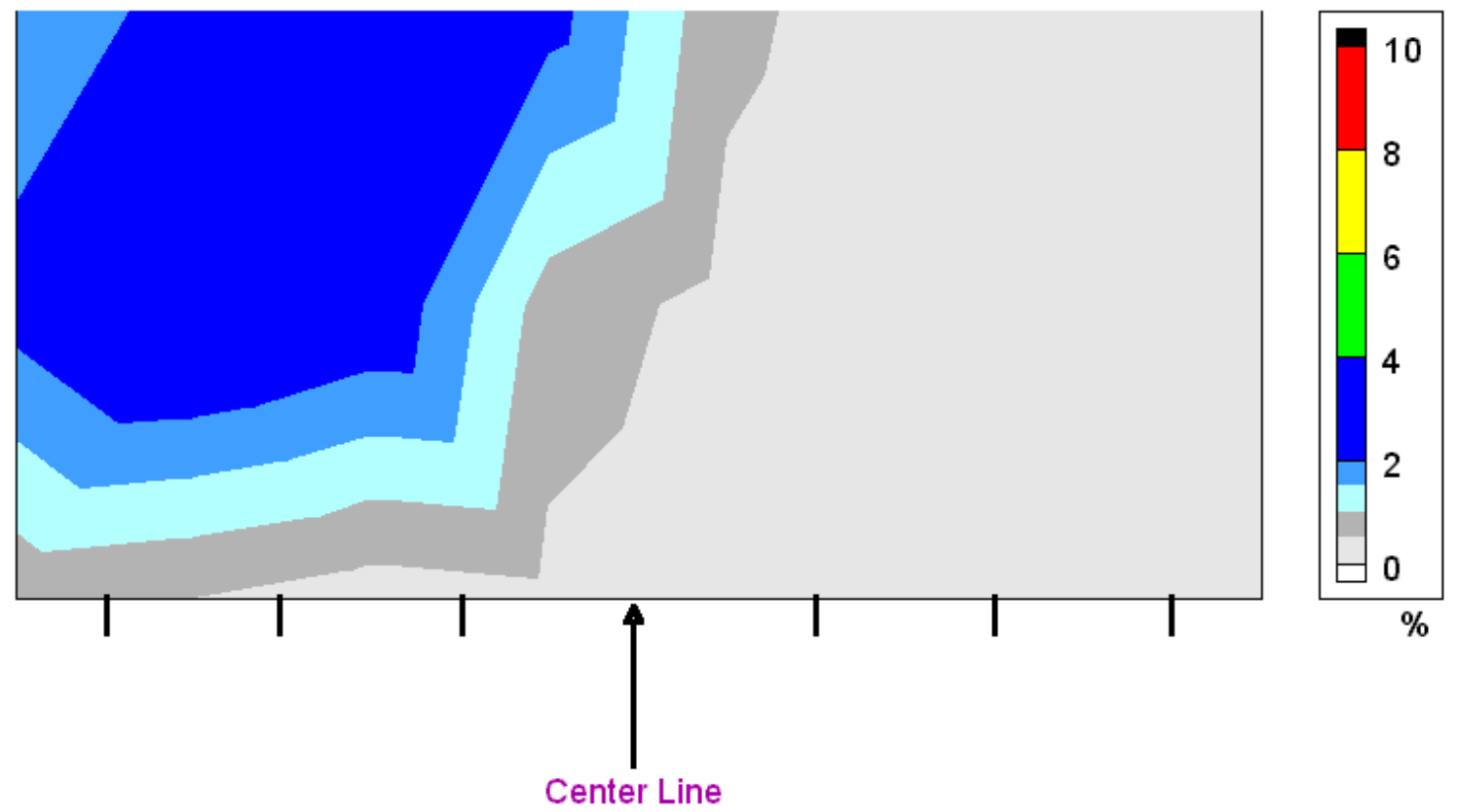

Figure 31 - Percentage of \#4 sieve salt recovered at 64 kilometers/hour (40 MPH) for Tyler System 


\section{F. Y Chute in the Industrial Hydraulic System}

This salt spreader has been used by the highway agencies for a few years now. It is becoming popular among operation engineers because of its effectiveness in spreading and keeping the salt on the road. Figure 32 shows the Y Chute with the Industrial Hydraulic System at INDOT Angola Subdistrict. The working principle of this salt spreader involves chanelling the salt to the conveyor or auger, to the hopper, and finally to the $\mathrm{Y}$ chutes. This unit delivers a preset amount per unit area regardless of truck speed. By keeping the chute openings low and close to the road, the salt particles are expected to drop in a small distance, hence fewer amount will fall outside the target area.

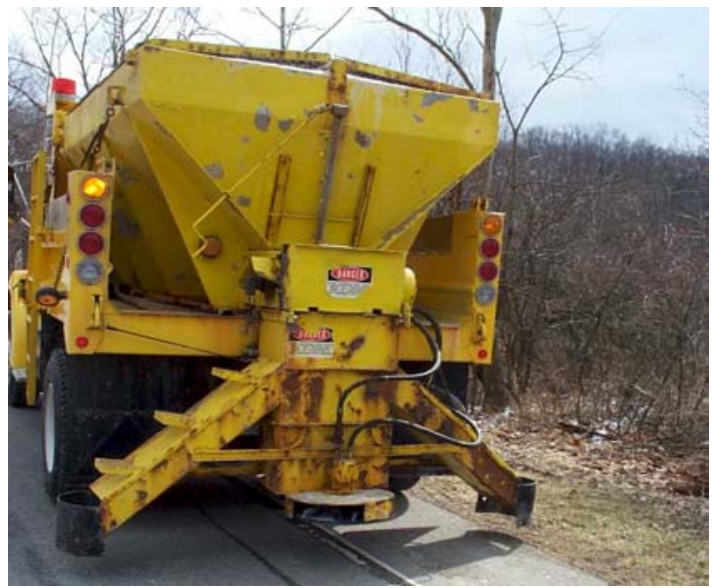

Figure $32-$ Y System

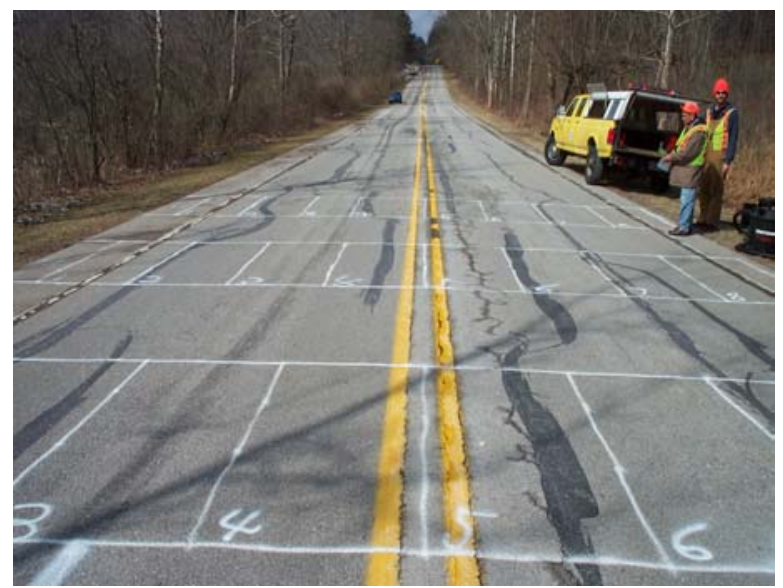

Figure 33 - Y System Spread Pattern

For this evaluation program, the Y System feed rate was set to $70.46 \mathrm{~kg} / \mathrm{km}(250$ lbs/mile). Figure 33 shows the Y System spread pattern running at 32 kilometers/hour $(20 \mathrm{mph})$. The chutes were aimed in symmetry to the center line of the roadway. The spread pattern shows that this system spread the salt particles in the intended area. However, traces of finer salt particles on the roadway were very scarce. Most of the salt particles are coarse particles.

Figure 34 shows the result of the spread pattern analysis with $68.88 \%$ recovery rate for the total salt particles. Figure 35 shows the spread pattern for salt particles retained on \#4 sieve (coarse salt particles). From the total salt amount, $64 \%$ of the salt particles belong to the coarse particle size and the recovery rate for this size is $90.20 \%$ of that $64 \%$. 
At a higher truck speed, the performance of this Y system degrades to a significant level but not for the coarser salt particles. Figure 36 shows the spread pattern of total salt particles at 64 kilometers/hour (40 MPH) with a recovery rate $35.38 \%$ and Figure 37 shows the spread pattern of the coarser particles with a recovery rate of $51.53 \%$ of the $64 \%$ coarse particles from the total salt particles. The recovery rate at this truck speed is better than that of the Industrial Hydraulic System and the Muncie System and comparable to the Zero Velocity Systems.

Based on the recovery rates, this Y System performs well in keeping the coarse particles on the road. These coarser salt particles are responsible to prolong the snow melting action from the salt particles, while the finer particles provide a quick action to melt the snow. The finer particles were loss because of the turbulence on the tail of the truck right on the back of the tires. Therefore, this equipment cannot provide quick reaction to melt the snow when needed.

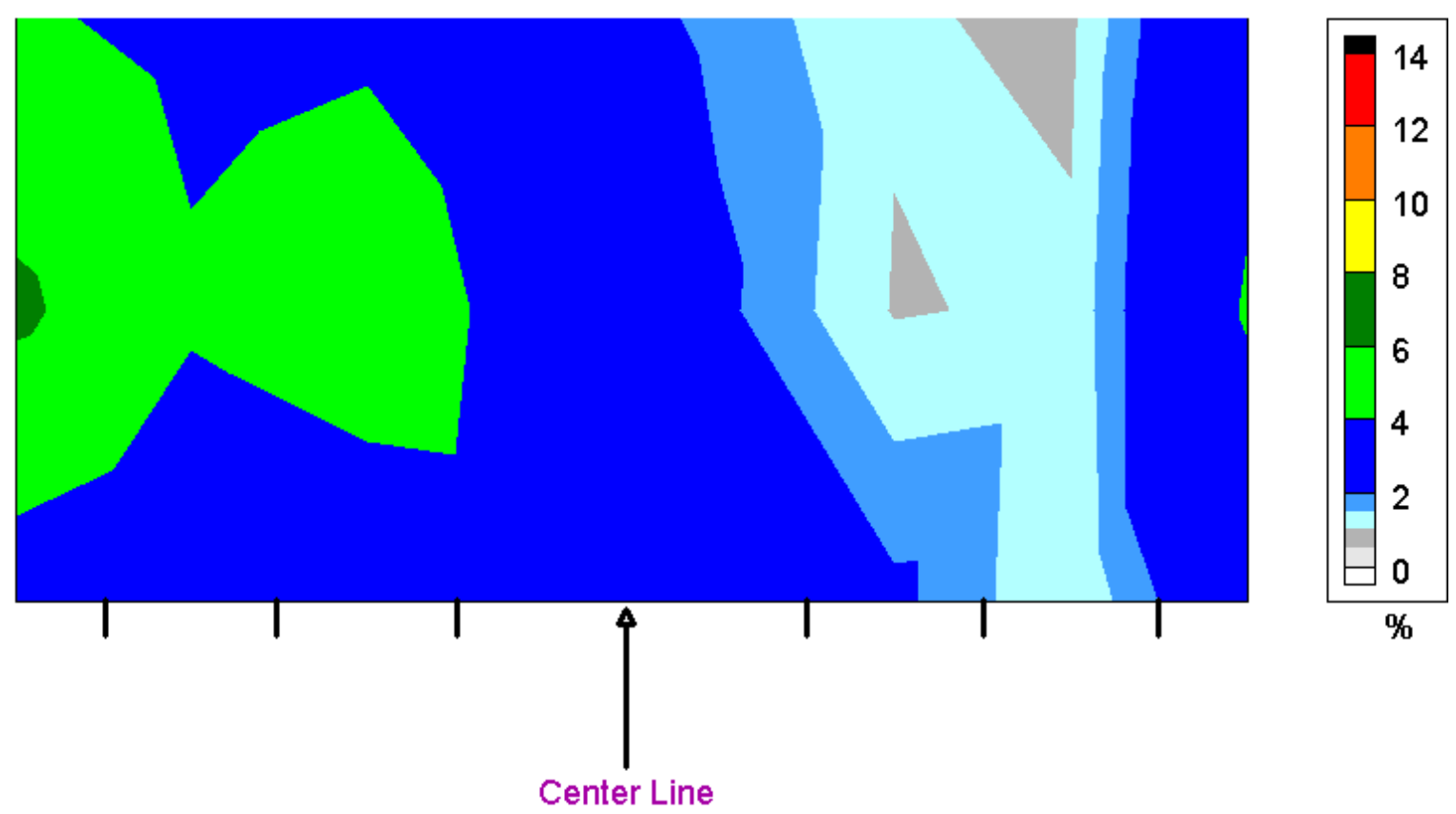

Figure 34 - Percentage of total salt recovered at 32 kilometers/hour (20 MPH) for Y System 


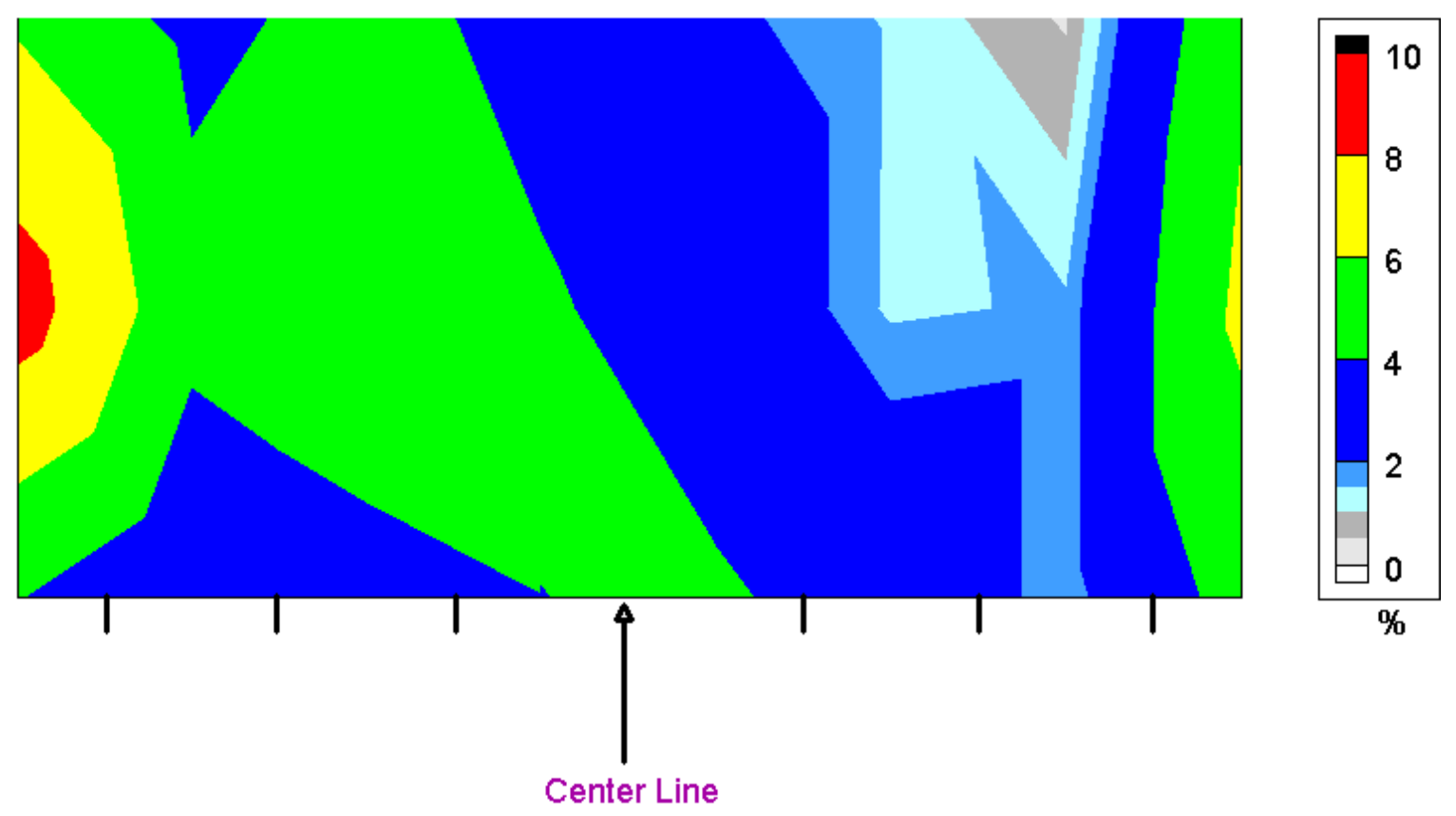

Figure 35 - Percentage of \#4 sieve salt recovered at 32 kilometers/hour (20 MPH) for Y System

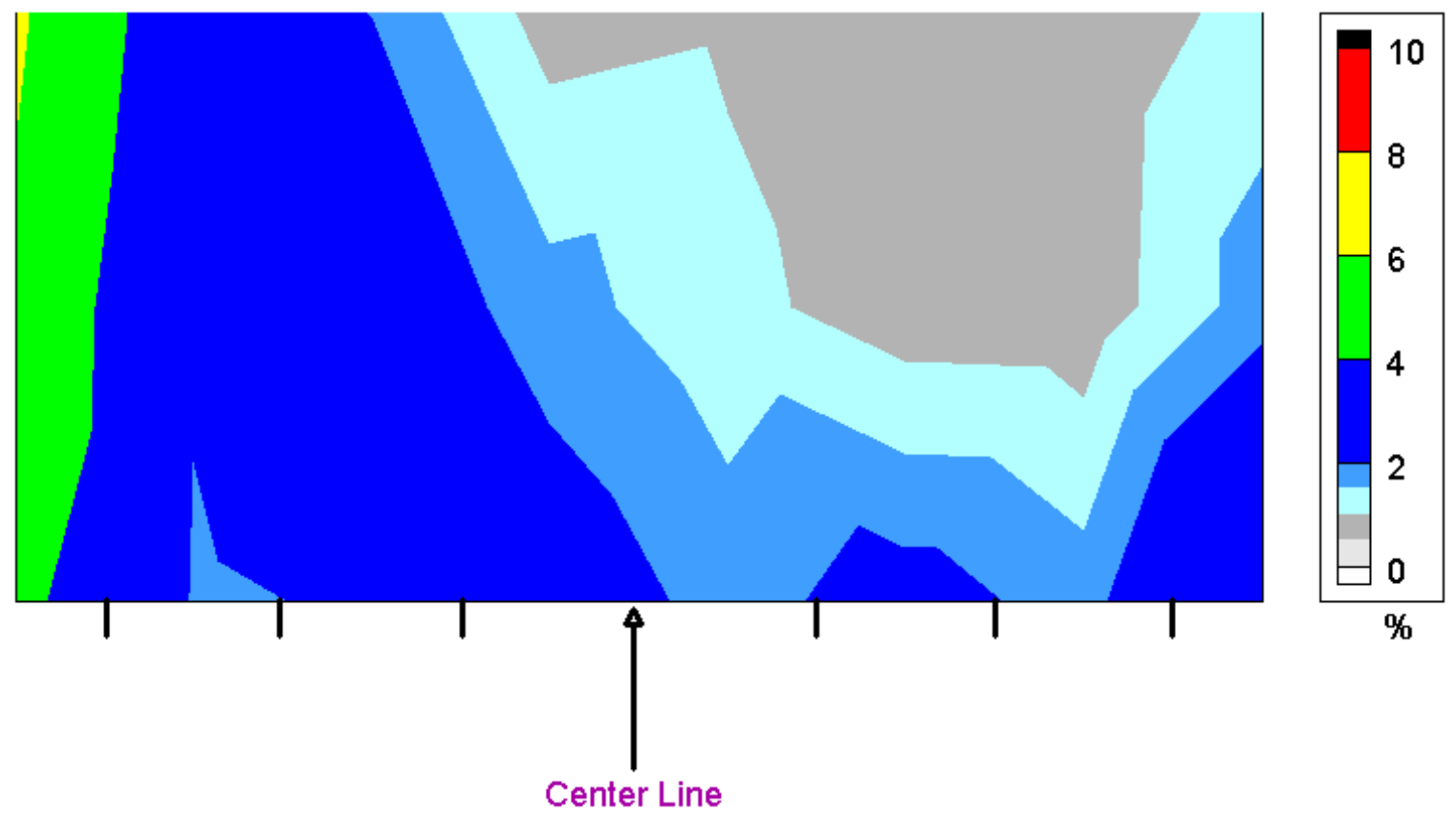

Figure 36 - Percentage of total salt recovered at 64 kilometers/hour (40 MPH) for Y System 


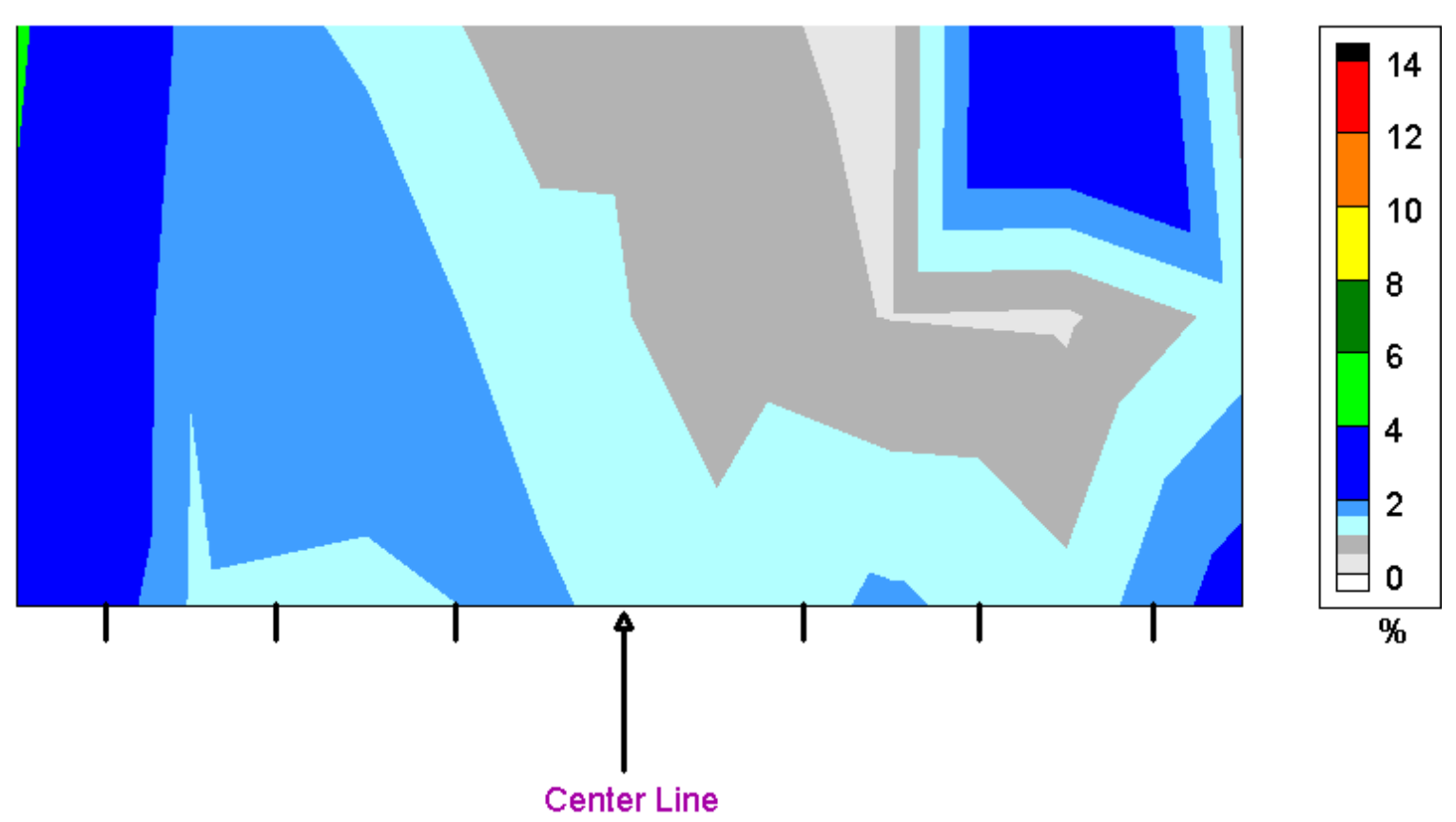

Figure 37 - Percentage of \#4 sieve salt recovered at 64 kilometers/hour (40 MPH) for Y System

\section{$\underline{\text { G. Economic Analysis }}$}

The objectives of operating the Zero Velocity Salt Spreader System are to cut salt cost while maintaining the level of service to the travelling public. As claimed by the manufacturers of the Zero Velocity System, the Zero Velocity System can have up to $40 \%$ saving in salt cost. This claim comes from the calculation of amount of salt particles which fall right on the target area. However, if the target level of service for the zero velocity system is the level of service of the Industrial Hydraulic System, using the Zero Velocity System will give more cost savings. This savings come from the fact that since the Zero Velocity System can spread the salt particles on small band or target area, further cut on the amount of salt per lane miles can be done to achieve satisfactory level of service.

Table 2 shows the salt usage by INDOT in the last four years for the six districts and the central office. On average, INDOT spend $\$ 10,895,265$ per year in salt cost. Table 3 shows the predicted savings on the amount of salt and the salt cost per year based on the spreader recovery rate data in Figure 38. At truck speed of 32 kilometers/hour (20 
MPH), the Tyler System will save $44.27 \%$ amount of salt and give $\$ 4,823,334$, the $\mathrm{Y}$ System will give $\$ 4,403,866$, and the Pengwyn system will give $\$ 3,379,711$ in cost saving. For truck speed of 64 kilometers/hour (40 MPH), the Pengwyn system will save $31.45 \%$ amount of salt use and give $\$ 3,426,561$ in cost saving.

Table 4 shows the predicted savings on the amount of salt use and the salt cost per year based on the mean spread density to maintain the same level of service as of the Industrial Hydraulic System as shown in Figure 39. The Zero Velocity Systems give approximately additional 7 to $15 \%$ in savings of salt use. The Y-System will give $\$ 6,395,939$ per year with the truck running at 32 kilometers/hour (20 MPH), the Tyler system gives $\$ 5,569,123$ cost saving per year. At 64 kilometers/hour (40 MPH), the Pengwyn system will give \$5,056,224 cost saving while the Tyler System will give $\$ 4,473,833$ in cost saving.

The Swenson System indicated a tremendous cost saving but due to the inconsistency of the equipment, the cost saving cannot be materialized. Figure 38 shows that the recovery rate of the system at a slower 32 kilometers/hour (20 MPH) truck speed is a lot higher than that of at 64 kilometers/hour (40 MPH). This indicate the inconsistency of the feed rate.

Tables 3 and 4 show that the Pengwyn system gives more consistent savings and results compared to other systems in any given truck speeds. This particular system is suitable to quickly clear the roadway for traveling public during the winter season, especially for areas those in need of quick snow removal such as cities and business areas. The result will be higher productivity per truck over a period of time. Snow trucks with this system do not have to go back to the unit to load more salt, and also save fuel cost, maintenance cost, and overtime pay for the operator.

For areas in the secondary priority, the Tyler System, Muncie system, and the Pengwyn system will give a very large cost savings as well. Based on these data, the decision makers and the budget department have to analyze the cost savings versus the investment cost for the systems and also the equipment maintenance cost. 
Table 2 - Salt Costs for INDOT in the Last Four Years by Locations

\begin{tabular}{|l|r|r|r|r|r|}
\hline \multicolumn{1}{|c|}{ Location } & \multicolumn{1}{c|}{ FY 97 } & \multicolumn{1}{c|}{ FY 98 } & \multicolumn{1}{c|}{ FY 99 } & \multicolumn{1}{c|}{ FY00 } & \multicolumn{1}{c|}{ Average } \\
\hline \hline Central Office & $\$ 785,045$ & $\$ 50,883$ & $\$ 0$ & $\$ 0$ & $\$ 208,982$ \\
\hline Crawfordsville & $\$ 1,937,266$ & $\$ 1,297,656$ & $\$ 1,576,772$ & $\$ 1,701,333$ & $\$ 1,628,257$ \\
\hline Ft. Wayne & $\$ 2,568,150$ & $\$ 1,991,500$ & $\$ 2,277,980$ & $\$ 2,031,266$ & $\$ 2,217,224$ \\
\hline Greenfield & $\$ 2,343,607$ & $\$ 1,570,336$ & $\$ 1,926,364$ & $\$ 2,135,319$ & $\$ 1,993,907$ \\
\hline LaPorte & $\$ 2,324,108$ & $\$ 3,239,708$ & $\$ 3,090,955$ & $\$ 2,868,839$ & $\$ 2,880,903$ \\
\hline Seymour & $\$ 1,291,213$ & $\$ 1,012,795$ & $\$ 986,160$ & $\$ 940,985$ & $\$ 1,057,788$ \\
\hline Vincennes & $\$ 1,077,899$ & $\$ 1,012,632$ & $\$ 734,790$ & $\$ 807,500$ & $\$ 908,205$ \\
\hline \hline Totals & $\$ 12,327,288$ & $\$ 10,175,510$ & $\$ 10,593,021$ & $\$ 10,485,242$ & $\$ 10,895,265$ \\
\hline
\end{tabular}

Table 3 - Predicted Savings on Amount of Salt and Salt Cost Per Year based on the Spreader Recovery Rate of the Industrial Hydraulic System

\begin{tabular}{|c|c|c|c|c|}
\hline \multirow{2}{*}{ System } & \multicolumn{2}{|c|}{$\begin{array}{c}\text { Truck Speed at } 32 \mathrm{Km} / \mathrm{Hr} \\
\text { (20 MPH) }\end{array}$} & \multicolumn{2}{|c|}{$\begin{array}{c}\text { Truck Speed at } 64 \mathrm{Km} / \mathrm{Hr} \\
(40 \mathrm{MPH})\end{array}$} \\
\hline & $\begin{array}{l}\text { Total Salt } \\
\text { Particles }\end{array}$ & $\begin{array}{l}\text { Coarser Salt } \\
\text { Particles }\end{array}$ & $\begin{array}{l}\text { Total Salt } \\
\text { Particles }\end{array}$ & $\begin{array}{c}\text { Coarser Salt } \\
\text { Particles }\end{array}$ \\
\hline \multirow{2}{*}{ Muncie } & $22.58 \%$ & \multirow{2}{*}{$11.83 \%$} & $-5.83 \%$ & \multirow{2}{*}{$0.16 \%$} \\
\hline & $\$ 2,460,151$ & & $-\$ 635,194$ & \\
\hline \multirow{2}{*}{ Pengwyn } & $31.02 \%$ & \multirow{2}{*}{$17.86 \%$} & $31.45 \%$ & \multirow{2}{*}{$28.19 \%$} \\
\hline & $\$ 3,379,711$ & & $\$ 3,426,561$ & \\
\hline \multirow{2}{*}{ Swenson *) } & $0.03 \%$ & \multirow{2}{*}{$6.94 \%$} & $55.94 \%$ & \multirow{2}{*}{$41.69 \%$} \\
\hline & $\$ 3,269$ & & $\$ 6,094,811$ & \\
\hline \multirow{2}{*}{ Tyler } & $44.27 \%$ & \multirow{2}{*}{$31.22 \%$} & $26.49 \%$ & \multirow{2}{*}{$17.65 \%$} \\
\hline & $\$ 4,823,334$ & & $\$ 2,886,156$ & \\
\hline \multirow{2}{*}{ Y-System } & $40.42 \%$ & \multirow{2}{*}{$79.42 \%$} & 11.76 & \multirow{2}{*}{49.16} \\
\hline & $\$ 4,403,866$ & & $\$ 1,281,283$ & \\
\hline
\end{tabular}

*) Inconsistent result 
36

Table 4 - Predicted Savings on Amount of Salt and Salt Cost Per Year based on the Mean Spread Density of the Industrial Hydraulic System to Maintain Level of Service

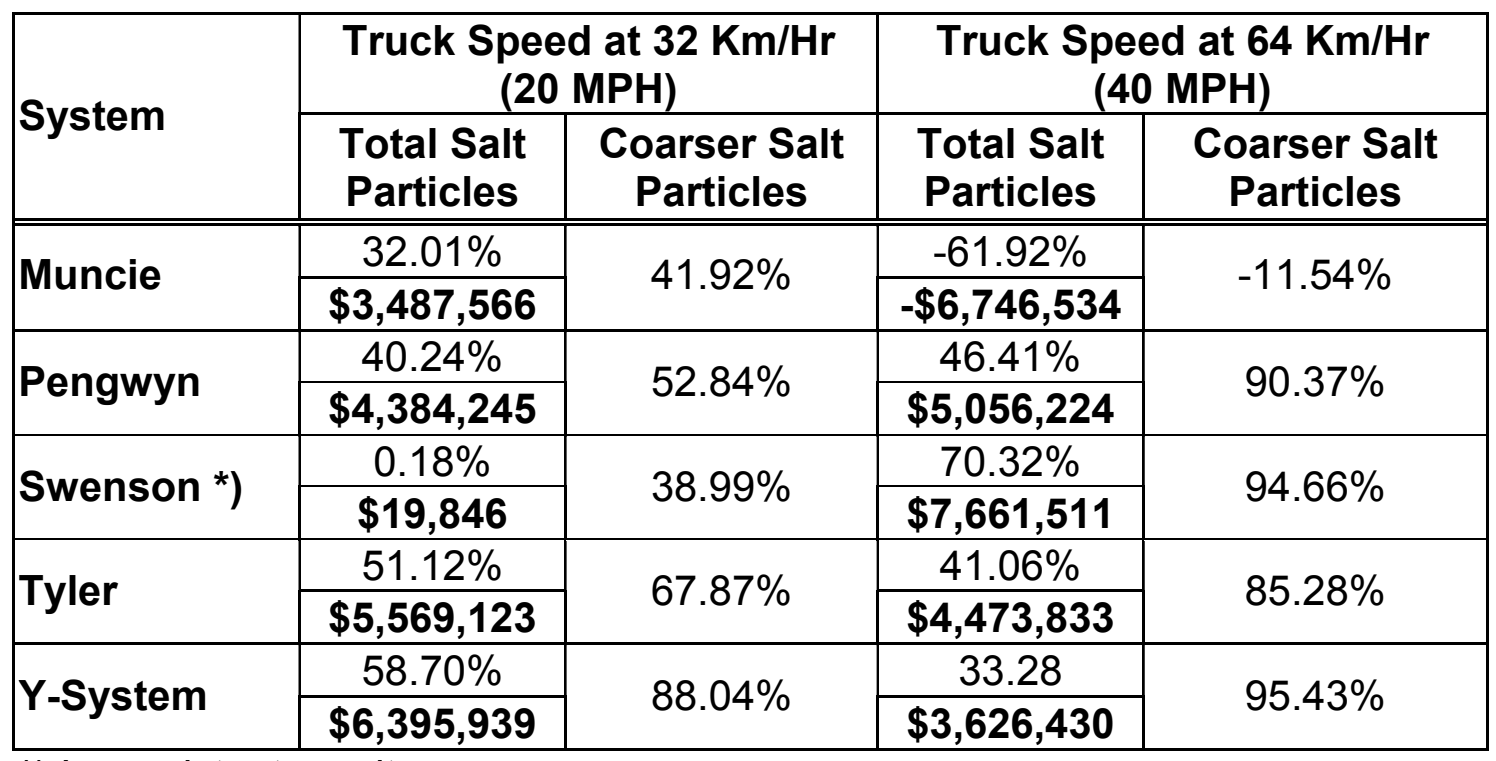

$\left.{ }^{*}\right)$ Inconsistent result 


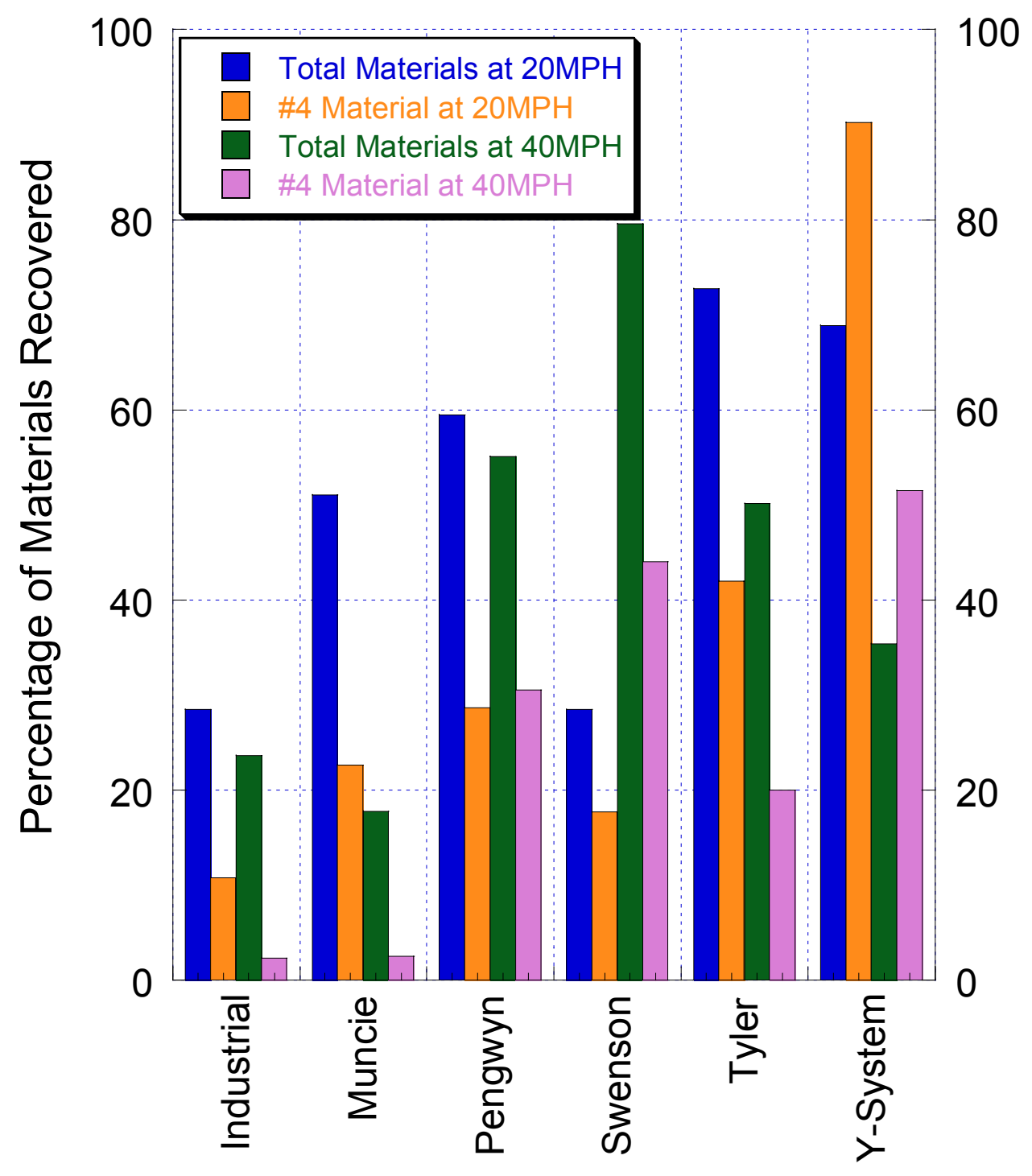

Salt Spreader System

Figure 38 - Percentage Recovery Rate of the Evaluated Salt Spreader Systems 




Salt Spreader System

Figure 39 - Mean Spread Density of the Evaluated Salt Spreader Systems 


\section{Conclusions}

The basic principle of the zero velocity spreader is rather simple. The zero velocity spreader ejects salt particles at zero velocity relative to the roadway. With this principle, salt particles are "placed" to the intended area on the roadway and a lot less to the area outside the roadway. However, performance differences between the zero velocity spreaders depend primarily on:

1. The effectiveness of the auger system and the drop chute to feed the salt particles from the hopper to the dispensing unit on the tail of the truck. During the actual operation of the systems in the two winter seasons, salt particles in one system jammed the drop chute due to the caking of the salt. Moisture apparently went to the drop chute and created salt cakes. Although this is not a serious problem but it creates an inconvenience to the spreader operator to clean up the salt cakes and continue the operation every 10 to 20 minutes.

2. The ability of the dispensing unit to maintain a spread pattern at a higher truck speed. Consistency in maintaining the spread pattern in a higher speed is very crucial to the advantage of the zero velocity system compared to the conventional system. Vortices on the back of the truck are the primary causes of the inconsistency of the spread pattern. During the dry run spread pattern test at 64 kilometers/hour (40 mph), one zero velocity system gave a spread pattern only a very little advantage to that of the conventional system. Vortices on the back of the truck made the dispensing system spread the salt particles in a very large area, therefore defeated the purpose of using the zero velocity system.

3. The ability of the dispensing unit to maintain spread quantities or feed rate at lower and higher truck speeds. Consistency of the feed rate is very crucial in the performance of the salt spreaders. As indicated in the analysis by one of the Zero Velocity Systems, a system can perform poorly and has no cost saving at all with a degrading spread density of salt that can result in unsafe roadway to travel.

4. The Y-System gives good results comparable to the Zero Velocity Systems when the truck runs at a slower speed. However, most of the salts particles that stay on the 
pavement surface are coarse particles. Therefore, an immediate thawing action to clear the pavement surface from snow and ice because of the finer salt particles is almost none.

Maintenance of the Zero Velocity System also should be taken into account in selecting a salt spreader system. A salt spreader system, with a longer down-time per operation or period of time, will defeat the advantage of using the system. With a more complicated hydraulic system in the Zero Velocity System it is expected that the downtime for system maintenance will be longer than that of the Industrial Hydraulic System. However, a better system should have a minimum down-time per operation. A downtime per period of use, such as maintenance after the winter season, will not have a very important effect to the selection of a Zero Velocity System.

The protocol suggested by the Strategic Highway Research Program (SHRP) is very good in reviewing the performance of salt spreader. The only adjustment to be made is the speed of the truck. The protocol suggested truck speeds of $20 \mathrm{Km} / \mathrm{Hr}(12.4$ $\mathrm{MPH})$ and $40 \mathrm{Km} / \mathrm{Hr}(24.8 \mathrm{MPH})$. Although these truck speeds are good enough for evaluating ordinary salt spreaders, they are too slow to evaluate the Zero Velocity Systems based on the speed claimed by the Zero Velocity Systems manufacturers. Based on INDOT experience, truck speeds of 32 kilometers/hour (20 MPH) and 64 kilometers/hour (40 MPH) are suggested.

During the experimental design stage, a visual evaluation of the performance of the salt spreaders was proposed. In addition, a maintenance log book was given to each truck operator to record the down-time and the maintenance costs. Appendix B shows the evaluation forms for the truck operators and for an evaluator. After two winter seasons, conclusions cannot be drawn from the visual evaluation because the visual inspection of roadway is a very subjective interpretation. Therefore, the performance of the spreaders during operation cannot be compared. The down-time and the maintenance costs also cannot be recorded because all of the Zero Velocity Systems were under the manufacturers' warranty.

Based on the dry-run tests, the Zero Velocity Systems will give excellent performance with a large number of cost savings due to the accurate placement of salt 
particles on the roadway. However, on the slower truck speed, a modified system such as the Y system or Muncie system, can give a satisfactory result as well. 


\section{References:}

1. National Cooperative Highway Research Program, Synthesis of Highway Practice No. 24, "Minimizing Deicing Chemical Use," Transportation Research Board, National Research Council, Washington, D.C., 1974

2. Keranen, Paul F., Fourth International Symposium on Snow and Ice Control Technology, August 11-16, 1996, Reno, Nevada.

3. Strategic Highway Research Program, National Research Council, "Development of Anti-Icing Technology," Washington, D.C., 1994

4. Commonwealth of Pennsylvania, Department of Transportation, "District 4-3 DS2 Ground Control; Zero Velocity (Project \#013-95), 1995.

5. "Particle Velocity Control Places Salt Accurately," Design News Online, March 4, 1996. 


\section{Appendix A}

Spread Pattern Performance Test and

Discharge Performance Test (SHRP Test Protocols) 


\section{American Testing Protocol for Winter Maintenance Spreaders}

\section{Spread Pattern Performance Test}

General. The spread pattern test should be conducted at a speed of $20 \mathrm{~km} / \mathrm{h}(12.4 \mathrm{mph})$ and $40 \mathrm{~km} / \mathrm{hr}(24.8 \mathrm{mph})$ with controls set to deliver approximately $20 \mathrm{~g} / \mathrm{m}^{2}$ (260 lb/lane-mile) of spread material and the spinner setting dispersing the spread material over approximately two lanes $(6 \mathrm{~m}$ or $19.7 \mathrm{ft})$.

With the hopper loaded to approximately half capacity, the spreader should be driven over a marked grid system spreading dry salt. The salt samples should be vacuumed into paper filters from the surface of the grid system, and the mass of the salt vacuumed from each sampling rectangle should be weighed to an accuracy of $0.1 \mathrm{~g}(.004 \mathrm{oz})$ and recorded. The data should then be analyzed to determine the characteristics of the longitudinal and transverse distribution pattern. The tests should consist of two runs at each speed.

Test Site. The test should be conducted on a straight length of roadway. The roadway should be as flat as possible, with a cross slope not exceeding 1 in 40 , to avoid distortion and the rolling of large particles. The recommended minimum length of the roadway is $320 \mathrm{~m}$ $(1,049.9 \mathrm{ft})$. The roadway should be long enough for the spreader to accelerate to and maintain test spreads of 20 and $40 \mathrm{~km} / \mathrm{hr}$ (12.4 and $24.8 \mathrm{mph}$ ) before entering the first test strip. The roadway should also be long enough for the spreader to stop after leaving the third test strip. The surface of the test area should be made of asphalt-concrete, exhibiting a macroroughness such as that experienced in the middle of the roadway.

A grid system consisting of strips should be marked out on the test area in accordance with figure 35. The width of the strips should be $6 \mathrm{~m}(19.7 \mathrm{ft})$ for the nominal spread width and $1 \mathrm{~m}(3.3 \mathrm{ft})$ for the overspreading rectangles, for a total width of $8 \mathrm{~m}(26.2 \mathrm{ft})$. Capture walls (with a dimension of $2.5 \mathrm{~m}$ long by $300 \mathrm{~mm}$ high [ $8.2 \mathrm{ft}$ by $1 \mathrm{ft}$ ]) should be placed along the outer edge of the overspreading rectangles. The breadth of the strips should be $2 \mathrm{~m}(6.6 \mathrm{ft})$.

Test Material. The testing material should be rock salt which meets ASTM D632 Grade 1 at a moisture content of less than $3 \%$. 


\section{Procedure.}

1. Mark out the test site as indicated in figure 35. Erect capture walls along the outer edges of the overspreading rectangles $(\mathrm{U})$. Ensure that the surface of each test strip is dry.

2. Sweep the transverse strips and adjacent areas until a negligible amount of salt is left on the surface, and then vacuum the transverse strips.

3. Set the spread controls for a delivery rate of $20 \mathrm{~g} / \mathrm{m}^{2}(260 \mathrm{lb} / \mathrm{lane}-\mathrm{mile})$ and a spread width of $6 \mathrm{~m}(19.7 \mathrm{ft})$. Fill the hopper to approximately half capacity. With tailgate spreaders, fill the auger box completely.

4. The spinner displacement setting (asymmetry) should be set so that when the vehicle's right side is driven along the left edge of the rectangle designated as $\left(\mathrm{R}_{\mathrm{r}}\right)$, the spread material is covering the right-edge stripe $\left(\mathrm{R}_{\mathrm{r}}\right)$.

5. Drive the spreader vehicle straight along the test area with the vehicle's right side along the left edge of the right-edge stripe $\left(\mathrm{R}_{\mathrm{r}}\right)$ of the grid layout at the speeds of $20 \mathrm{~km} / \mathrm{hr}$ (12.4 mph) and $40 \mathrm{~km} / \mathrm{hr}(24.8 \mathrm{mph})$.

6. The amount of spread material deposited in the individual rectangles should be carefully removed by vacuuming the material into paper filters. Weigh the material to the nearest $0.1 \mathrm{~g}(.004 \mathrm{oz})$, and record the weights on a form similar to that shown in figure 37 .

7. Perform the various computations to measure the spreader performance for the following capabilities:

- Accuracy of longitudinal coverage

Compare the total mass of material collected on any one transverse strip to the mean mass of material collected on all three strips. Also, the total mass of material collected from all three strips should be compared for each of the speeds, $20 \mathrm{~km} / \mathrm{hr}(12.4 \mathrm{mph})$ and $40 \mathrm{~km} / \mathrm{hr}$ (24.8 $\mathrm{mph})$.

- Accuracy of coverage on side strips 


\begin{tabular}{|c|c|c|c|c|c|c|c|c|c|c|c|}
\hline & & \multicolumn{8}{|c|}{ Collected spread material amount (g) } & \multirow{2}{*}{$\begin{array}{l}\text { Lateral } \\
\text { strip } \\
\sum \Omega \\
\end{array}$} & \multirow{2}{*}{$\begin{array}{c}\text { Deviation from } \\
\text { average value } \\
(\%)\end{array}$} \\
\hline & & $\mathrm{O}_{1}$ & $\mathrm{R}_{1}$ & i.. & i.. & i.. & i.. & $\mathrm{R}_{\mathrm{r}}$ & $\mathrm{O}_{\mathrm{t}}$ & & \\
\hline \multicolumn{2}{|r|}{ Column } & 1 & 2 & 3 & 4 & 5 & 6 & 7 & 8 & 9 & 10 \\
\hline \multicolumn{2}{|c|}{ Strip width (m) } & 1 & 1 & & & & & 1 & 1 & - & - \\
\hline \multirow{3}{*}{$\begin{array}{l}\text { 을 } \\
\text { 문 } \\
\text { 芯 } \\
\text { 苛 }\end{array}$} & \multicolumn{11}{|l|}{ III } \\
\hline & \multicolumn{11}{|l|}{ II } \\
\hline & \multicolumn{11}{|l|}{ I } \\
\hline \multicolumn{2}{|r|}{$\sum_{\text {Total }}$} & & & & & & & & & \multicolumn{2}{|c|}{$\stackrel{3}{\rightarrow}$} \\
\hline \multicolumn{2}{|c|}{$\begin{array}{c}\text { Percent of the } \\
\text { total amount } \\
\left(\sum_{\text {Total }} \text { Column } 9\right)\end{array}$} & & & - & - & - & - & & & & \\
\hline \multicolumn{2}{|c|}{$\begin{array}{l}\text { (1) Spread density } y_{\mathrm{ix}} \\
{\left[\mathrm{g} / \mathrm{m}^{2}\right)}\end{array}$} & - & - & & & & & - & - & & \\
\hline \multicolumn{2}{|c|}{ (2) $\mathrm{A}_{\text {Qix }}(\%)$} & - & - & & & & & - & - & & \\
\hline
\end{tabular}

(1) Spread thickness in the test longitudinal strip ix

$(\mathrm{x}=1 ; 2 ; 3 \ldots$ Number of the test longitudinal strip as per selected number)

$$
\mathrm{SD}_{\mathrm{ix}}=\frac{\sum_{\text {Total }}(\text { Col. 3...6) }}{6 \cdot \mathrm{b}_{\text {Tix }} \dagger}=\left[\mathrm{g} / \mathrm{m}^{2}\right]
$$

(2) Deviation of spread thickness in the test longitudinal strip ix

$$
A_{Q_{i x}}=\frac{\left(S_{i x}-S_{m}\right)}{S D_{m}} \cdot 100=[\%]
$$

$\mathrm{SD}_{\mathrm{m}}$ is the mean spread density in the nominal spread track including overspread amount

$$
\mathrm{SD}_{\mathrm{m}}=\frac{\sum_{\text {Total }}(\text { Col. 9) }}{6 \cdot \mathrm{b}_{\mathrm{H}} \dagger}=\left[\mathrm{g} / \mathrm{m}^{2}\right]
$$

† Factor 6 is the total length of the test longitudinal strip $3 \cdot 2 \mathrm{~m}$.

Figure 37 Computation form. 
Compare the mass of material collected on either side strip $\left(\mathrm{R}_{\mathrm{l}}, \mathrm{R}_{\mathrm{r}}\right)$ to the total mass collected.

- Accuracy of coverage on inner test strips

Compare the computed spread density for the inner lengthwise strips (those between the side strips) to the average spread density of all the rectangles in the grid system.

- Wastage

Compare the total mass of material collected on either overspread strip $\left(\mathrm{U}_{1}, \mathrm{U}_{\mathrm{r}}\right)$ to the total mass collected.

\section{Discharge Performance Test}

General. The amount of spread material released from the spreader vehicle in a unit of time depends on the setting that controls the auger or belt speed and on the speed of the vehicle. The discharge test measures the accuracy of releasing material in accordance with the normal operational range of the spreader. This test also attempts to reflect the actual amount of material applied to the roadway.

For dry salt, the values of the operating ranges for output and speed follow:

\begin{tabular}{lcc}
\hline Output & Amount discharged & Speed \\
\hline Lowest & $30 \mathrm{~kg} / \mathrm{km}$ & $10 \mathrm{~km} / \mathrm{hr}$ \\
& $(106 \mathrm{lb} / \mathrm{mile})$ & $(6.2 \mathrm{mph})$ \\
Most frequent & $120 \mathrm{~kg} / \mathrm{km}$ & $30 \mathrm{~km} / \mathrm{hr}$ \\
& $(426 \mathrm{lb} / \mathrm{mile})$ & $(18.6 \mathrm{mph})$ \\
Highest & $240 \mathrm{~kg} / \mathrm{km}$ & $40 \mathrm{~km} / \mathrm{hr}$ \\
& $(852 \mathrm{lb} / \mathrm{mile})$ & $(24.8 \mathrm{mph})$ \\
\hline
\end{tabular}


The tests should be conducted under the following conditions developed from the above tabulations:

- $30 \mathrm{~kg} / \mathrm{km}(106 \mathrm{lb} / \mathrm{mile})$ at $10 \mathrm{~km} / \mathrm{hr}(6.2 \mathrm{mph})$

- $120 \mathrm{~kg} / \mathrm{km}(426 \mathrm{lb} / \mathrm{mile})$ at $30 \mathrm{~km} / \mathrm{hr}(18.6 \mathrm{mph})$

- $120 \mathrm{~kg} / \mathrm{km}(426 \mathrm{lb} / \mathrm{mile})$ at $40 \mathrm{~km} / \mathrm{hr}(24.8 \mathrm{mph})$

- $240 \mathrm{~kg} / \mathrm{km}(852 \mathrm{lb} / \mathrm{mile})$ at $30 \mathrm{~km} / \mathrm{hr}(18.6 \mathrm{mph})$

- $240 \mathrm{~kg} / \mathrm{km}(852 \mathrm{lb} / \mathrm{mile})$ at $40 \mathrm{~km} / \mathrm{hr}(24.8 \mathrm{mph})$

\section{Discharge Test}

1. Fill the spreader to half capacity with dry salt.

2. Start and end the measurement by activating the on and off control.

3. The control setting values should correspond to the test conditions given above.

4. Establish a distance for the spreader vehicle to travel during the discharge test operation. The recommended quantity of spread material collected during each test is $24 \mathrm{~kg}$ $(52.9 \mathrm{lb})$. The minimum quantity collected should not be less than $10 \mathrm{~kg}(22.1 \mathrm{lb})$.

5. Remove the spinner from the truck bracket. Relocate the spinner to a position that is not hazardous to the operator, the truck, or itself. Mount a drum and bracket assembly, similar to that in figure 38 , on the truck in the area previously occupied by the spinner.

6. Allow the vehicle to idle long enough to warm the hydraulic oil to a normal working temperature with the spreader system running. Set the spinner controls to a midrange setting to allow hydraulic fluid to flow.

7. Drive the spreader vehicle over the test distance and collect the discharge material in the barrel. At least two separate discharge tests should be made for each test condition. The maximum and minimum weights of the discharge material collected for each test condition must satisfy the following expression:

$$
\frac{\text { Maximum }- \text { Minimum }}{0.5 \text { (Maximum }+ \text { Minimum })} \leq 0.1
$$

8. Evaluate the discharge results for the various truck speeds to determine the accuracy of released material. 


\title{
Appendix B
}

\author{
Field Evaluation Form for \\ Zero Velocity Spreader Evaluation
}




\begin{tabular}{|l|l|}
\hline Date & \\
\hline
\end{tabular}

Please Put a Check Mark

\begin{tabular}{|c|c|}
\hline \\
\hline \multicolumn{2}{|l|}{\begin{tabular}{c|c}
\multicolumn{2}{|c}{ Weather } \\
Clear
\end{tabular}} \\
\hline Partly Cloudy & Light Snow \\
\hline Cloudy & Moderate Snow \\
\hline Raining & Heavy Snow \\
\hline Freezing Rain & Storm Over \\
\hline
\end{tabular}

\begin{tabular}{|l|l|}
\hline Driver & \\
\hline
\end{tabular}

\begin{tabular}{|l|l|}
\hline Start Mile & \\
\hline
\end{tabular}

\begin{tabular}{|l|l|}
\hline Truck No & \\
\hline
\end{tabular}

\begin{tabular}{|l|l|}
\hline End Mile & \\
\hline
\end{tabular}

\begin{tabular}{|l|l|}
\hline \multicolumn{1}{|l|}{ Wind } \\
\hline & Light \\
\hline & Moderate \\
\hline & Strong \\
& Gale \\
\hline & Huricane \\
\hline
\end{tabular}

\begin{tabular}{|c|}
\hline Operations \\
\hline Patrolling \\
\hline Plowing \\
\hline Sand \& Chlorides \\
\hline Pushing Back \\
\hline Loading \& Hauling Snow \\
\hline
\end{tabular}

\begin{tabular}{|c|c|c|}
\hline Storm & Time & Wind \\
\hline \multirow{2}{*}{ Began } & & North \\
\hline & $\mathrm{AM}$ or $\mathrm{PM}$ & South \\
\hline \multirow[t]{2}{*}{ Stopped } & & West \\
\hline & $\mathrm{AM}$ or $\mathrm{PM}$ & East \\
\hline
\end{tabular}

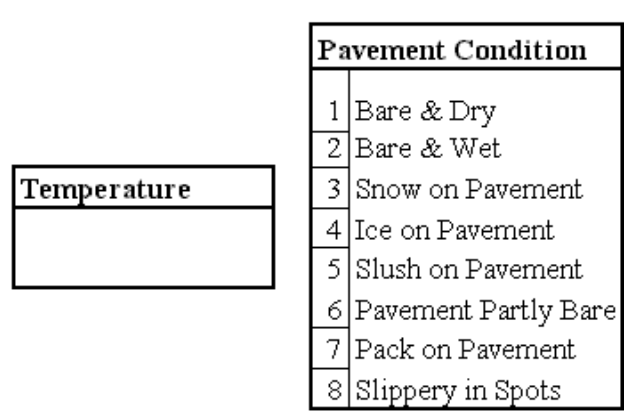

\begin{tabular}{|c|c|c|c|c|c|c|c|c|c|c|}
\hline $\begin{array}{l}\text { Stock } \\
\text { Pile No. }\end{array}$ & \begin{tabular}{|l|} 
Route No. or Name \\
$\begin{array}{l}\text { Start Time and } \\
\text { Direction }\end{array}$ \\
\end{tabular} & \begin{tabular}{|l|} 
es Sand / Salt / \\
Calc./Liquid \\
tons / yard / gal \\
\end{tabular} & \begin{tabular}{|l|} 
Sand / Salt / \\
Calc./Liquid \\
tons / yard/gal \\
\end{tabular} & \begin{tabular}{|l|} 
Sand / Salt / \\
Calc./Liquid \\
tons/yard/gal \\
\end{tabular} & \begin{tabular}{|l} 
Rate of \\
Application \\
(pounds/mile)
\end{tabular} & \begin{tabular}{|l|}
$\begin{array}{l}\text { Distance } \\
\text { Spread } \\
\text { (miles) }\end{array}$ \\
\end{tabular} & $\begin{array}{l}\text { Treatment } \\
\text { (1st, 2nd,...) }\end{array}$ & $\begin{array}{l}\text { Accident } \\
\text { Observed }\end{array}$ & \begin{tabular}{|l|} 
Pavement \\
Condition
\end{tabular} & Remarks \\
\hline & & & & & & & & & & \\
\hline & & & & & & & & & & \\
\hline & & & & & & & & & & \\
\hline & & & & & & & & & & \\
\hline & & & & & & & & & & \\
\hline & & & & & & & & & & \\
\hline & & & & & & & & & & \\
\hline & & & & & & & & & & \\
\hline
\end{tabular}




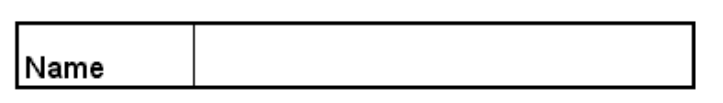

\section{District/Sub}

\begin{tabular}{|c|c|c|c|c|c|c|c|c|c|c|c|c|c|c|c|c|c|c|c|c|c|c|c|c|c|c|c|}
\hline \multirow[t]{3}{*}{ Date } & \multirow[t]{3}{*}{ Time } & \multirow{2}{*}{\multicolumn{6}{|c|}{ Type of Precipitation }} & \multicolumn{2}{|c|}{ Section Observed } & \multirow[t]{3}{*}{ Route No. } & \multirow[t]{3}{*}{$\begin{array}{l}\text { Lane No. } \\
\text { \& Direction }\end{array}$} & \multirow[t]{3}{*}{$\begin{array}{l}\text { Type of } \\
\text { Pavement }\end{array}$} & \multicolumn{15}{|c|}{\begin{tabular}{|l|} 
Observed Pavement \\
Condition
\end{tabular}} \\
\hline & & & & & & & & \multirow[t]{2}{*}{ Test } & \multirow[t]{2}{*}{ Control } & & & & \multicolumn{7}{|c|}{ Wheel Track } & \multicolumn{8}{|c|}{ Outside Wheel Track } \\
\hline & & $\mid$\begin{tabular}{|l}
$\mathrm{D}$ \\
$\mathrm{r}$ \\
$\mathrm{i}$ \\
$\mathrm{z}$ \\
$\mathrm{z}$ \\
$\mathrm{z}$ \\
$\mathrm{e}$ \\
$\mathrm{e}$
\end{tabular} & $\begin{array}{c}\mathrm{R} \\
\mathrm{a} \\
\mathrm{i} \\
\mathrm{n}\end{array}$ & 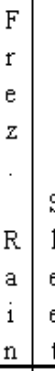 & 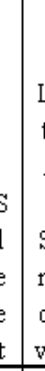 & $\begin{array}{c}\mathrm{B} \\
1 \\
0 \\
\mathrm{w} \\
\mathrm{D} \\
\mathrm{s} \\
\mathrm{n} \\
0 \\
\mathrm{w}\end{array}$ & \begin{tabular}{|c|}
$\mathrm{N}$ \\
$\mathrm{o}$ \\
$\mathrm{n}$ \\
$\mathrm{e}$ \\
\end{tabular} & & & & & & $\begin{array}{l}D \\
r \\
y\end{array}$ & $\begin{array}{c}W \\
\mathrm{e} \\
\mathrm{t}\end{array}$ & $\begin{array}{c}\mathrm{s} \\
\mathrm{n} \\
0 \\
\mathrm{w}\end{array}$ & $\begin{array}{l}\mathrm{I} \\
\mathrm{c} \\
\mathrm{e}\end{array}$ & $\begin{array}{l}\mathrm{s} \\
1 \\
\mathrm{u} \\
\mathrm{s} \\
\mathrm{h}\end{array}$ & $\begin{array}{l}\mathrm{P} \\
\mathrm{a} \\
\mathrm{r} \\
\mathrm{t} \\
. \\
\mathrm{b} \\
\mathrm{a} \\
\mathrm{r} \\
\mathrm{e} \\
\end{array}$ & $\begin{array}{l}\text { S } \\
\text { n } \\
0 \\
W \\
\text { W } \\
P \\
\text { a } \\
c \\
\text { k }\end{array}$ & 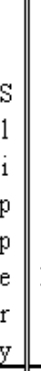 & $\begin{array}{l}D \\
\mathrm{r} \\
\mathrm{y}\end{array}$ & $\begin{array}{l}w \\
\mathrm{w} \\
\mathrm{t}\end{array}$ & & 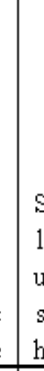 & 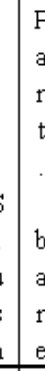 & $\begin{array}{l}\mathrm{s} \\
\mathrm{n} \\
0 \\
\mathrm{w} \\
\mathrm{P} \\
\mathrm{a} \\
\mathrm{c} \\
\mathrm{k}\end{array}$ & $\begin{array}{l}\mathrm{s} \\
\mathrm{s} \\
\mathrm{i} \\
\mathrm{p} \\
\mathrm{p} \\
\mathrm{e} \\
\mathrm{r} \\
\mathrm{y}\end{array}$ \\
\hline & & & & & & & & & & & & & & & & & & & & & & & & & & & \\
\hline & & & & & & & & & & & & & & & & & & & & & & & & & & & \\
\hline & & & & & & & & & & & & & & & & & & & & & & & & & & & \\
\hline & & & & & & & & & & & & & & & & & & & & & & & & & & & \\
\hline & & & & & & & & & & & & & & & & & & & & & & & & & & & \\
\hline & & & & & & & & & & & & & & & & & & & & & & & & & & & \\
\hline & & & & & & & & & & & & & & & & & & & & & & & & & & & \\
\hline & & & & & & & & & & & & & & & & & & & & & & & & & & & \\
\hline
\end{tabular}




\begin{tabular}{|l|l|l|l|l|}
\hline Month of & Driver & & Truck No \\
\hline
\end{tabular}

\begin{tabular}{|c|c|c|c|c|c|c|c|c|}
\hline Date & Reference & $\begin{array}{r}\text { Labor } \\
\text { Cost } \\
\end{array}$ & $\begin{array}{c}\text { Materials } \\
\text { Cost }\end{array}$ & $\begin{array}{l}\text { Supplies } \\
\text { Cost }\end{array}$ & $\begin{array}{l}\text { Charges for } \\
\text { Equipment }\end{array}$ & \begin{tabular}{|c|}
$\begin{array}{c}\text { Contractual } \\
\text { Services }\end{array}$ \\
\end{tabular} & $\begin{array}{c}\text { Other } \\
\text { Services }\end{array}$ & Overhead \\
\hline & & $\$$ & $\$$ & $\$$ & $\$$ & $\$$ & $\$$ & $\$$ \\
\hline & & & & & & & & \\
\hline & & & & & & & & \\
\hline & & & & & & & & \\
\hline & & & & & & & & \\
\hline & & & & & & & & \\
\hline & & & & & & & & \\
\hline & & & & & & & & \\
\hline & & & & & & & & \\
\hline & & & & & & & & \\
\hline & & & & & & & & \\
\hline
\end{tabular}




\section{Appendix C}

Zero Velocity Spreader Evaluation Field Data 
Table C1 - Percentage of total salt recovered at 32 kilometers/hour (20 MPH) for Industrial Hydraulic System

\begin{tabular}{|c|c|c|c|c|c|c|c|c|c|c|c|}
\hline & & \multicolumn{8}{|c|}{ Collected spread material amount (grams) } & \multirow{2}{*}{$\begin{array}{l}\text { Lateral } \\
\text { strip } \\
\text { (grams) }\end{array}$} & \multirow{2}{*}{$\begin{array}{c}\text { Deviation } \\
\text { from } \\
\text { average } \\
(\%)\end{array}$} \\
\hline & & $\mathrm{O}_{1}$ & $\mathrm{R}_{\mathrm{l}}$ & $\mathrm{i}_{3}$ & $\mathrm{i}_{4}$ & $\mathrm{i}_{5}$ & $\mathrm{i}_{6}$ & $\mathrm{R}_{\mathrm{r}}$ & $\mathrm{O}_{\mathrm{r}}$ & & \\
\hline \multicolumn{2}{|l|}{ Column } & 1 & 2 & 3 & 4 & 5 & 6 & 7 & 8 & - & - \\
\hline \multicolumn{2}{|c|}{ Strip width (meters) } & 1 & 1 & 1 & 1 & 1 & 1 & 1 & 1 & - & - \\
\hline \multirow{3}{*}{$\begin{array}{l}\text { Lateral } \\
\text { strip }\end{array}$} & III & 2.84 & 6.48 & 7.60 & 7.95 & 5.66 & 3.61 & 3.51 & 5.08 & 42.73 & -51 \\
\hline & II & 5.89 & 6.62 & 9.19 & 16.93 & 15.13 & 14.56 & 14.28 & 10.54 & 93.14 & 6 \\
\hline & I & 6.13 & 8.63 & 11.20 & 15.78 & 22.52 & 30.22 & 17.72 & 15.06 & 127.26 & 45 \\
\hline \multicolumn{2}{|c|}{ Total (grams) } & 14.86 & 21.73 & 27.99 & 40.66 & 43.31 & 48.39 & 35.51 & 30.68 & 263.13 & 87.71 \\
\hline \multicolumn{2}{|c|}{ Percent of total amount } & 6 & 8 & 11 & 15 & 16 & 18 & 13 & 12 & \multicolumn{2}{|c|}{$\begin{array}{c}\text { Total Spread } \\
\text { (grams) }\end{array}$} \\
\hline \multicolumn{2}{|c|}{$\begin{array}{l}\text { Spread Thickness } \\
(\text { SDix) }(g / m 2)\end{array}$} & - & - & 4.67 & 6.78 & 7.22 & 8.07 & - & - & \multicolumn{2}{|c|}{924.71} \\
\hline \multicolumn{2}{|c|}{$\begin{array}{l}\text { Deviation of Spread } \\
\text { Thickness (AQix) (\%) }\end{array}$} & - & - & -14.90 & 23.62 & 31.68 & 47.12 & - & - & \multicolumn{2}{|c|}{$\%$ Recovered } \\
\hline \multicolumn{2}{|c|}{$\begin{array}{l}\text { Mean Spread Density } \\
(\mathrm{SDm})(\mathrm{g} / \mathrm{m} 2)\end{array}$} & \multicolumn{8}{|c|}{5.48} & \multicolumn{2}{|c|}{28.46} \\
\hline
\end{tabular}


Table C2 - Percentage of \#4 sieve salt recovered at 32 kilometers/hour (20 MPH) for Industrial Hydraulic System

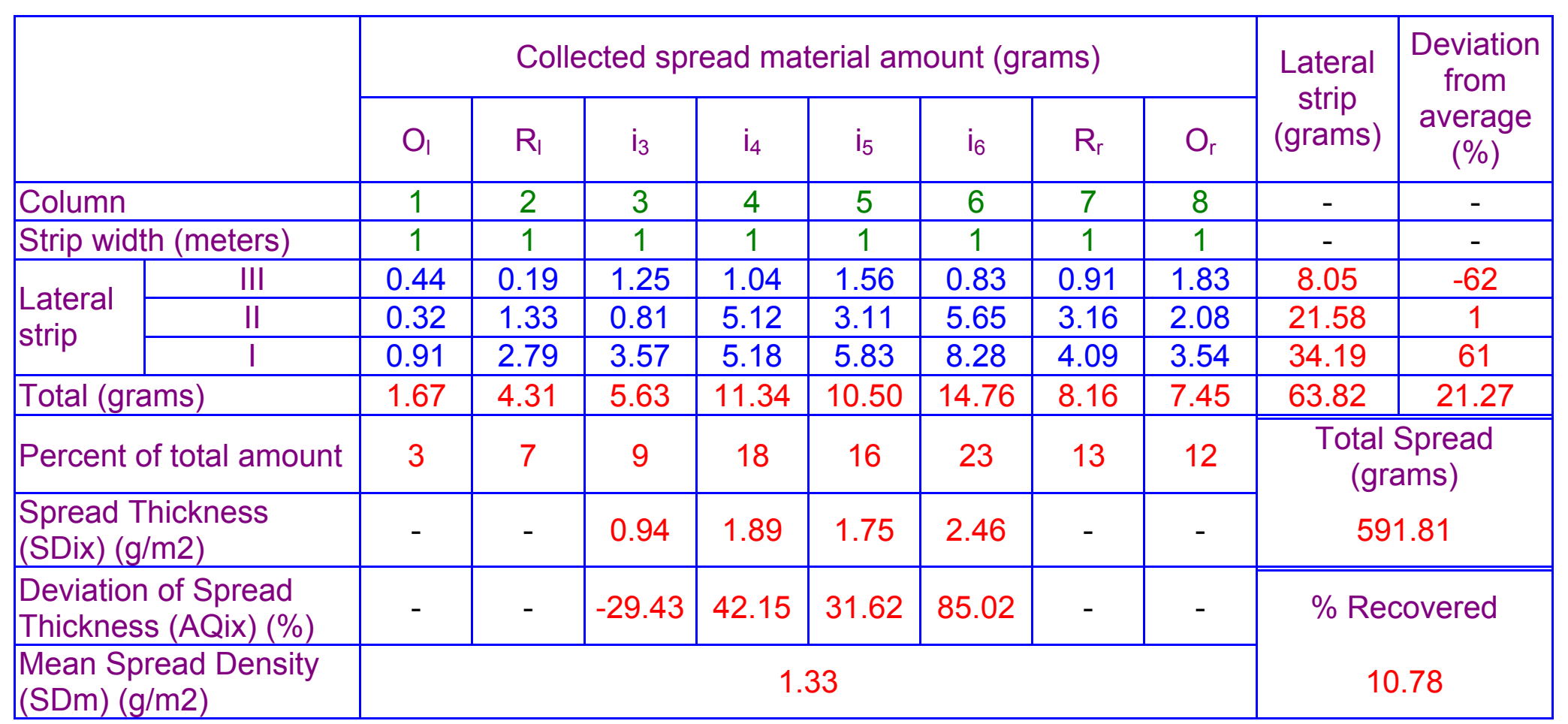


Table C3 - Percentage of total salt recovered at 64 kilometers/hour (40 MPH) for Industrial Hydraulic System

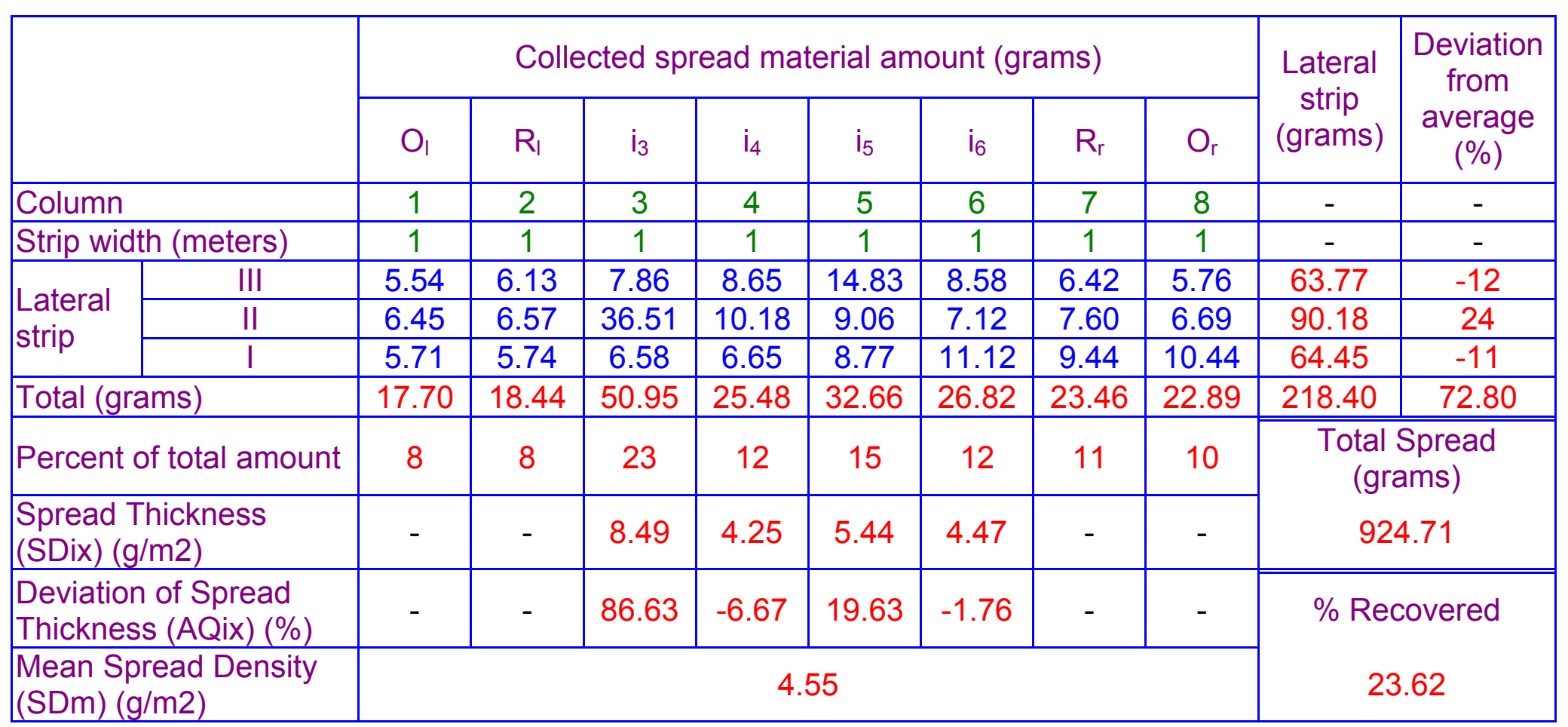


Table C4 - Percentage of \#4 sieve salt recovered at 64 kilometers/hour (40 MPH) for Industrial Hydraulic System

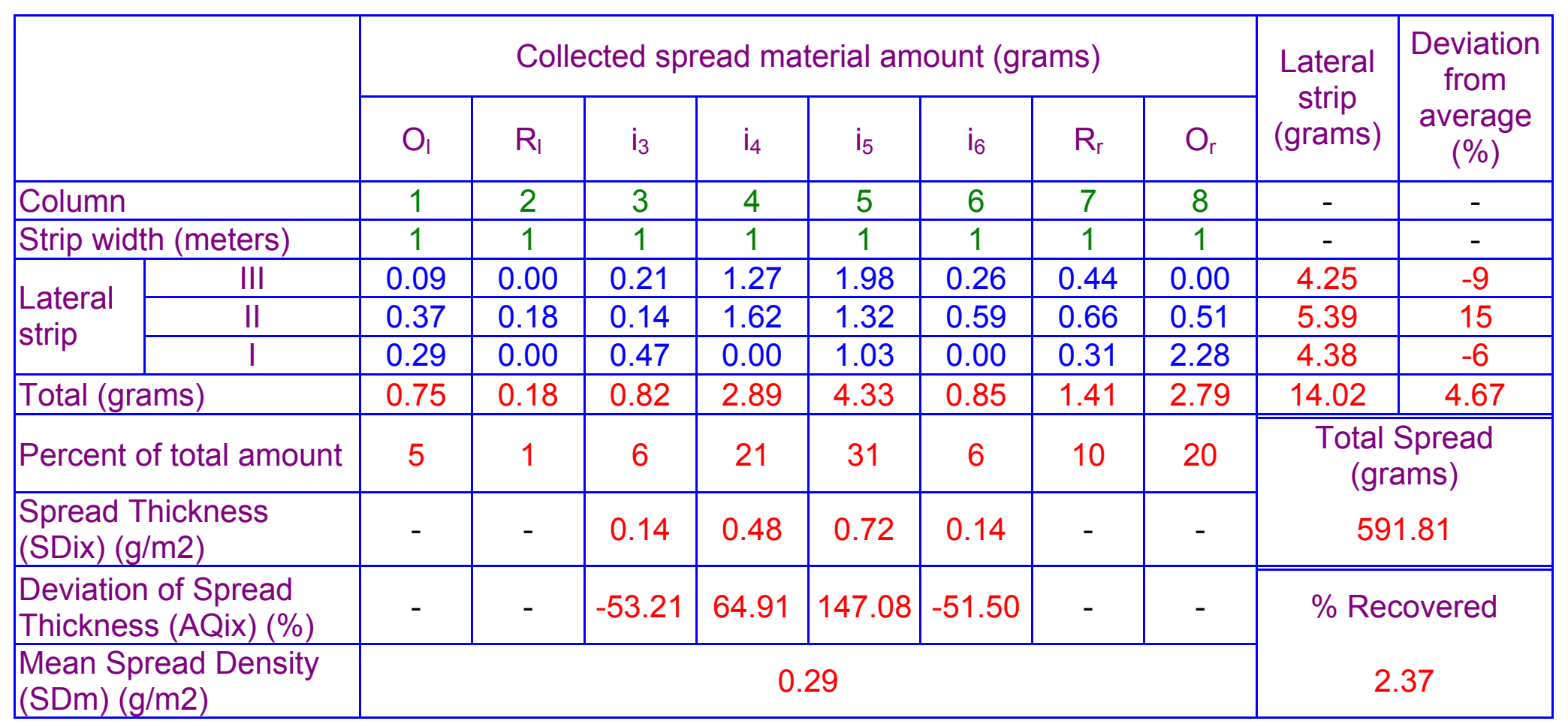


Table C5 - Percentage of total salt recovered at 32 kilometers/hour (20 MPH) for Muncie System

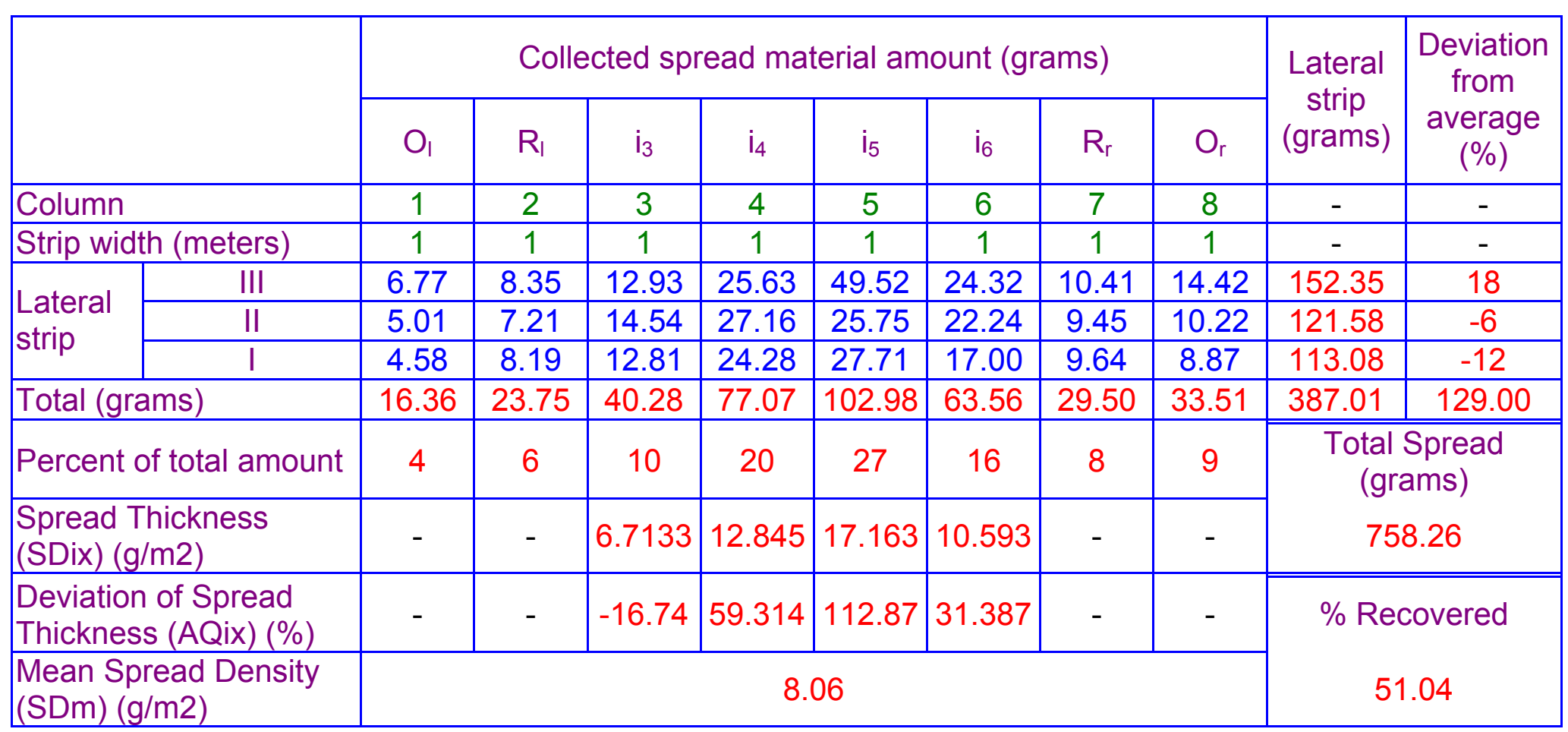


Table C6 - Percentage of \#4 sieve salt recovered at 32 kilometers/hour (20 MPH) for Muncie System

\begin{tabular}{|c|c|c|c|c|c|c|c|c|c|c|c|}
\hline & & \multicolumn{8}{|c|}{ Collected spread material amount (grams) } & \multirow{2}{*}{$\begin{array}{l}\text { Lateral } \\
\text { strip } \\
\text { (grams) }\end{array}$} & \multirow{2}{*}{$\begin{array}{l}\text { Deviation } \\
\text { from } \\
\text { average } \\
(\%)\end{array}$} \\
\hline & & $\mathrm{O}_{1}$ & $\mathrm{R}_{\mathrm{l}}$ & $\dot{i}_{3}$ & $\mathrm{i}_{4}$ & $\mathrm{i}_{5}$ & $\mathrm{i}_{6}$ & $\mathrm{R}_{\mathrm{r}}$ & $\mathrm{O}_{\mathrm{r}}$ & & \\
\hline \multicolumn{2}{|l|}{ Column } & 1 & 2 & 3 & 4 & 5 & 6 & 7 & 8 & - & - \\
\hline \multicolumn{2}{|c|}{ Strip width (meters) } & 1 & 1 & 1 & 1 & 1 & 1 & 1 & 1 & - & - \\
\hline \multirow{3}{*}{$\begin{array}{l}\text { Lateral } \\
\text { strip }\end{array}$} & III & 0.32 & 1.83 & 3.55 & 8.91 & 13.81 & 6.60 & 3.61 & 5.35 & 43.98 & 20 \\
\hline & II & 0.22 & 1.14 & 3.72 & 6.00 & 0.83 & 10.26 & 3.15 & 1.88 & 27.2 & -26 \\
\hline & 1 & 0.86 & 2.24 & 2.97 & 7.96 & \begin{tabular}{|l|}
10.76 \\
\end{tabular} & 6.82 & 4.35 & 2.60 & 38.56 & 5 \\
\hline \multicolumn{2}{|c|}{ Total (grams) } & 1.40 & 5.21 & 10.24 & 22.87 & 25.40 & 23.68 & 11.11 & 9.83 & 109.74 & 36.58 \\
\hline \multicolumn{2}{|c|}{ Percent of total amount } & 1 & 5 & 9 & 21 & 23 & 22 & 10 & 9 & \multicolumn{2}{|c|}{$\begin{array}{c}\text { Total Spread } \\
\text { (grams) }\end{array}$} \\
\hline \multicolumn{2}{|c|}{$\begin{array}{l}\text { Spread Thickness } \\
\text { (SDix) (g/m2) }\end{array}$} & - & - & 1.7067 & 3.8117 & 4.2333 & 3.9467 & - & - & \multicolumn{2}{|c|}{485.29} \\
\hline \multicolumn{2}{|c|}{$\begin{array}{l}\text { Deviation of Spread } \\
\text { Thickness (AQix) (\%) }\end{array}$} & - & - & -25.35 & 66.721 & 85.165 & 72.626 & - & - & \multicolumn{2}{|c|}{$\%$ Recovered } \\
\hline \multicolumn{2}{|c|}{$\begin{array}{l}\text { Mean Spread Density } \\
(\mathrm{SDm})(\mathrm{g} / \mathrm{m} 2)\end{array}$} & \multicolumn{8}{|c|}{2.29} & \multicolumn{2}{|c|}{22.61} \\
\hline
\end{tabular}


Table C7 - Percentage of total salt recovered at 64 kilometers/hour (40 MPH) for Muncie System

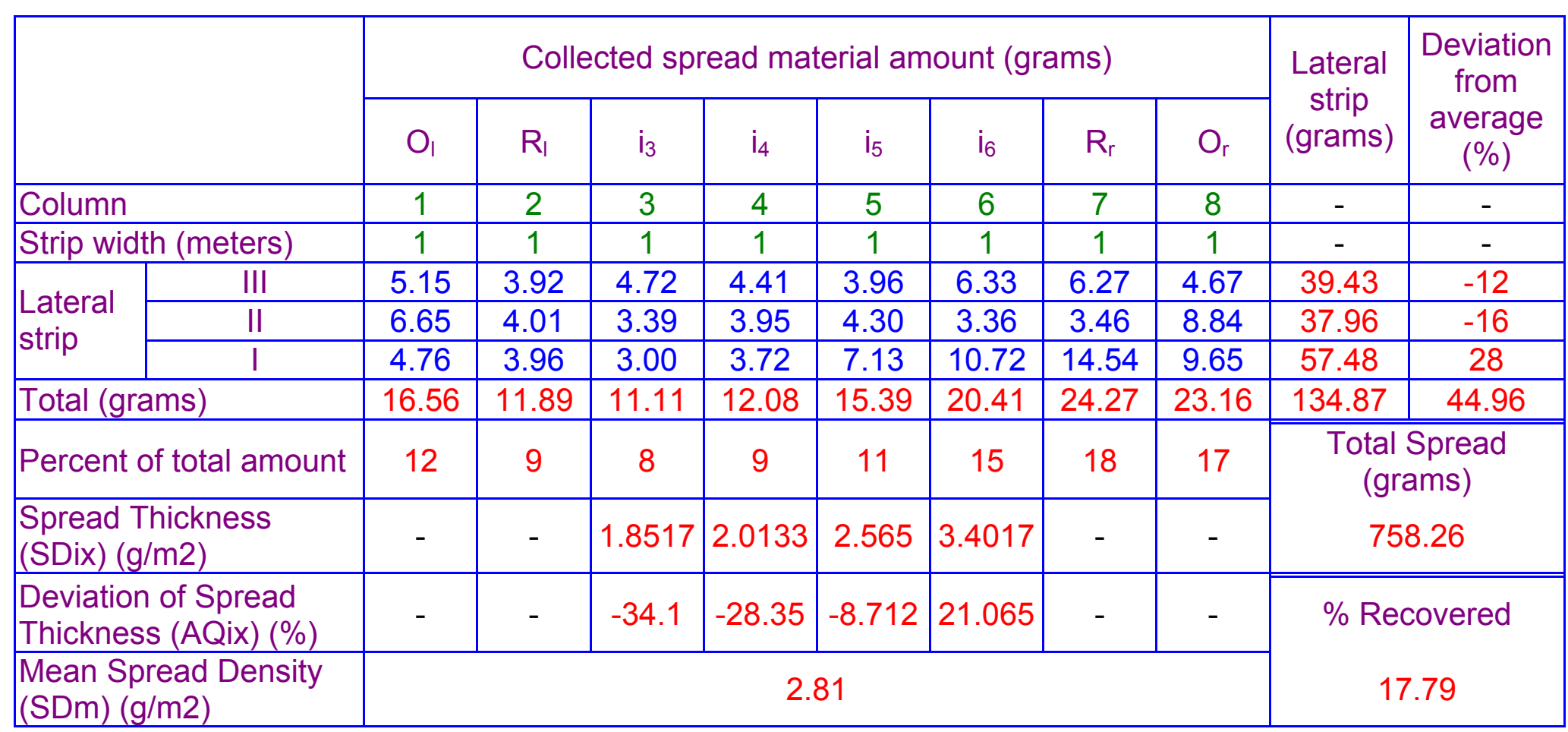


Table C8 - Percentage of \#4 sieve salt recovered at 64 kilometers/hour (40 MPH) for Muncie System

\begin{tabular}{|c|c|c|c|c|c|c|c|c|c|c|c|}
\hline & & \multicolumn{8}{|c|}{ Collected spread material amount (grams) } & \multirow{2}{*}{$\begin{array}{l}\text { Lateral } \\
\text { strip } \\
\text { (grams) }\end{array}$} & \multirow{2}{*}{$\begin{array}{l}\text { Deviation } \\
\text { from } \\
\text { average } \\
(\%)\end{array}$} \\
\hline & & $\mathrm{O}_{1}$ & $\mathrm{R}_{\mathrm{l}}$ & $\dot{i}_{3}$ & $\mathrm{i}_{4}$ & $\mathrm{i}_{5}$ & $\mathrm{i}_{6}$ & $\mathrm{R}_{\mathrm{r}}$ & $\mathrm{O}_{\mathrm{r}}$ & & \\
\hline \multicolumn{2}{|l|}{ Column } & 1 & 2 & 3 & 4 & 5 & 6 & 7 & 8 & - & - \\
\hline \multicolumn{2}{|c|}{ Strip width (meters) } & 1 & 1 & 1 & 1 & 1 & 1 & 1 & 1 & - & - \\
\hline \multirow{3}{*}{$\begin{array}{l}\text { Lateral } \\
\text { strip }\end{array}$} & III & 0.13 & 0.26 & 0.07 & 0.61 & 0.12 & 0.44 & 0.19 & 0.00 & 1.82 & -56 \\
\hline & II & 0.07 & 0.33 & 0.20 & 0.00 & 0.90 & 0.34 & 0.58 & 0.00 & 2.42 & -41 \\
\hline & 1 & 0.31 & 0.32 & 0.45 & 0.46 & 1.08 & 1.37 & 3.03 & 1.01 & 8.03 & 96 \\
\hline \multicolumn{2}{|c|}{ Total (grams) } & 0.51 & 0.91 & 0.72 & 1.07 & 2.10 & 2.15 & 3.80 & 1.01 & 12.27 & 4.09 \\
\hline \multicolumn{2}{|c|}{ Percent of total amount } & 4 & 7 & 6 & 9 & 17 & 18 & 31 & 8 & \multicolumn{2}{|c|}{$\begin{array}{c}\text { Total Spread } \\
\text { (grams) }\end{array}$} \\
\hline \multicolumn{2}{|c|}{$\begin{array}{l}\text { Spread Thickness } \\
\text { (SDix) (g/m2) }\end{array}$} & - & - & 0.12 & 0.1783 & 0.35 & 0.3583 & - & - & \multicolumn{2}{|c|}{485.29} \\
\hline \multicolumn{2}{|c|}{$\begin{array}{l}\text { Deviation of Spread } \\
\text { Thickness (AQix) (\%) }\end{array}$} & - & - & -53.06 & -30.24 & 36.919 & 40.179 & - & - & \multicolumn{2}{|c|}{$\%$ Recovered } \\
\hline \multicolumn{2}{|c|}{$\begin{array}{l}\text { Mean Spread Density } \\
(\mathrm{SDm})(\mathrm{g} / \mathrm{m} 2)\end{array}$} & \multicolumn{8}{|c|}{0.26} & \multicolumn{2}{|c|}{2.53} \\
\hline
\end{tabular}


Table C9 - Percentage of total salt recovered at 32 kilometers/hour (20 MPH) for Pengwyn Zero Velocity System

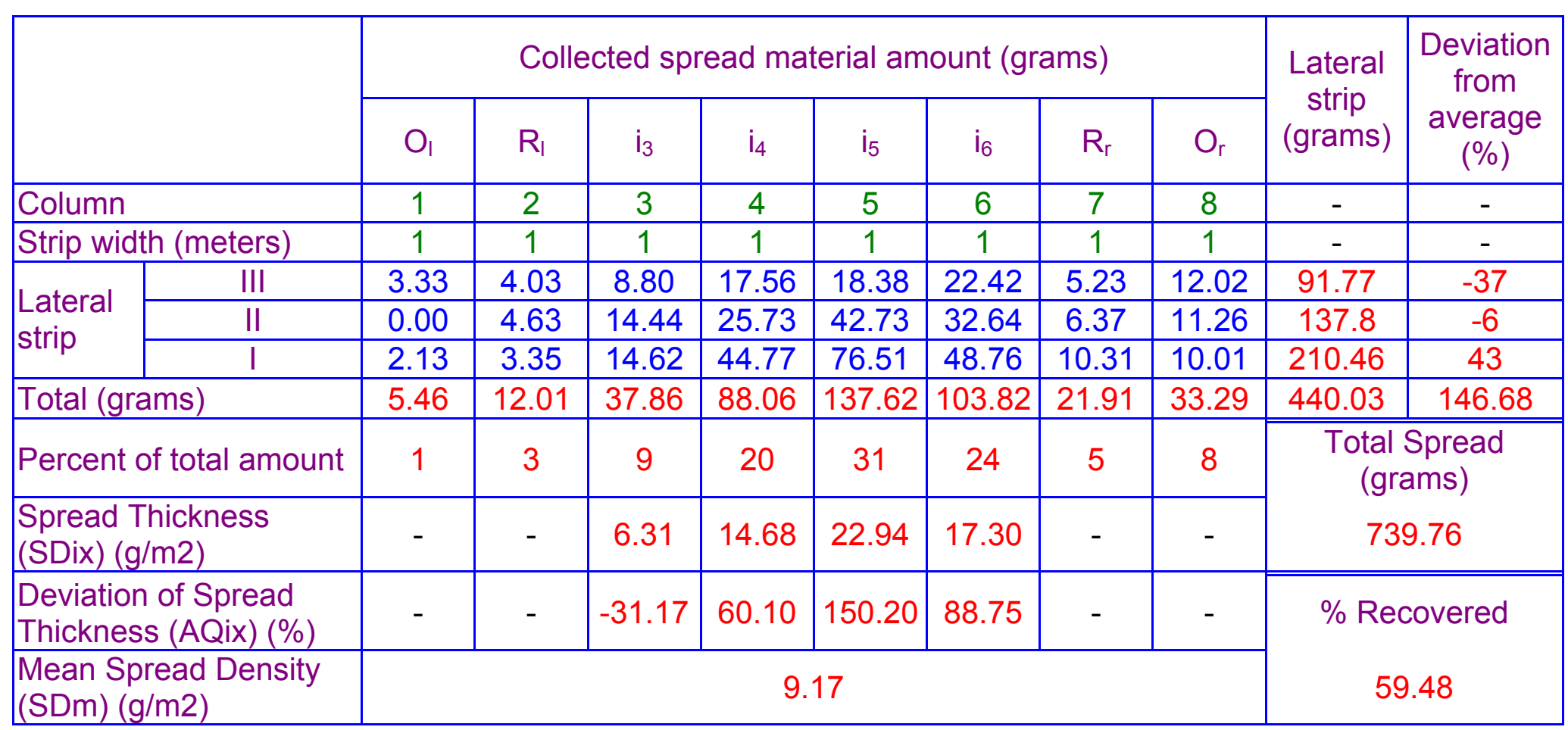


Table C10 - Percentage of \#4 sieve salt recovered at 32 kilometers/hour (20 MPH) for Pengwyn Zero Velocity System

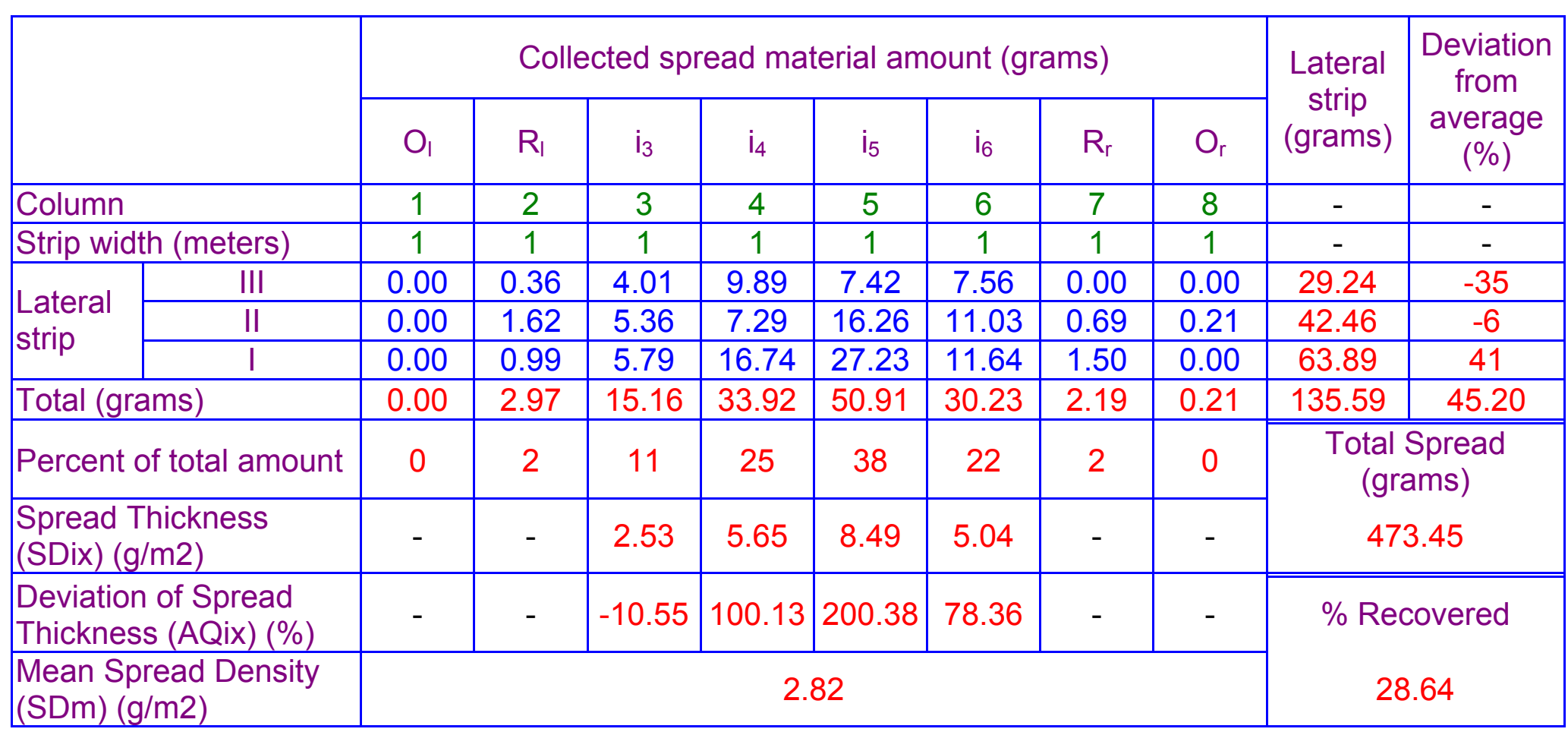


Table C11 - Percentage of total salt recovered at 64 kilometers/hour (40 MPH) for Pengwyn Zero Velocity System

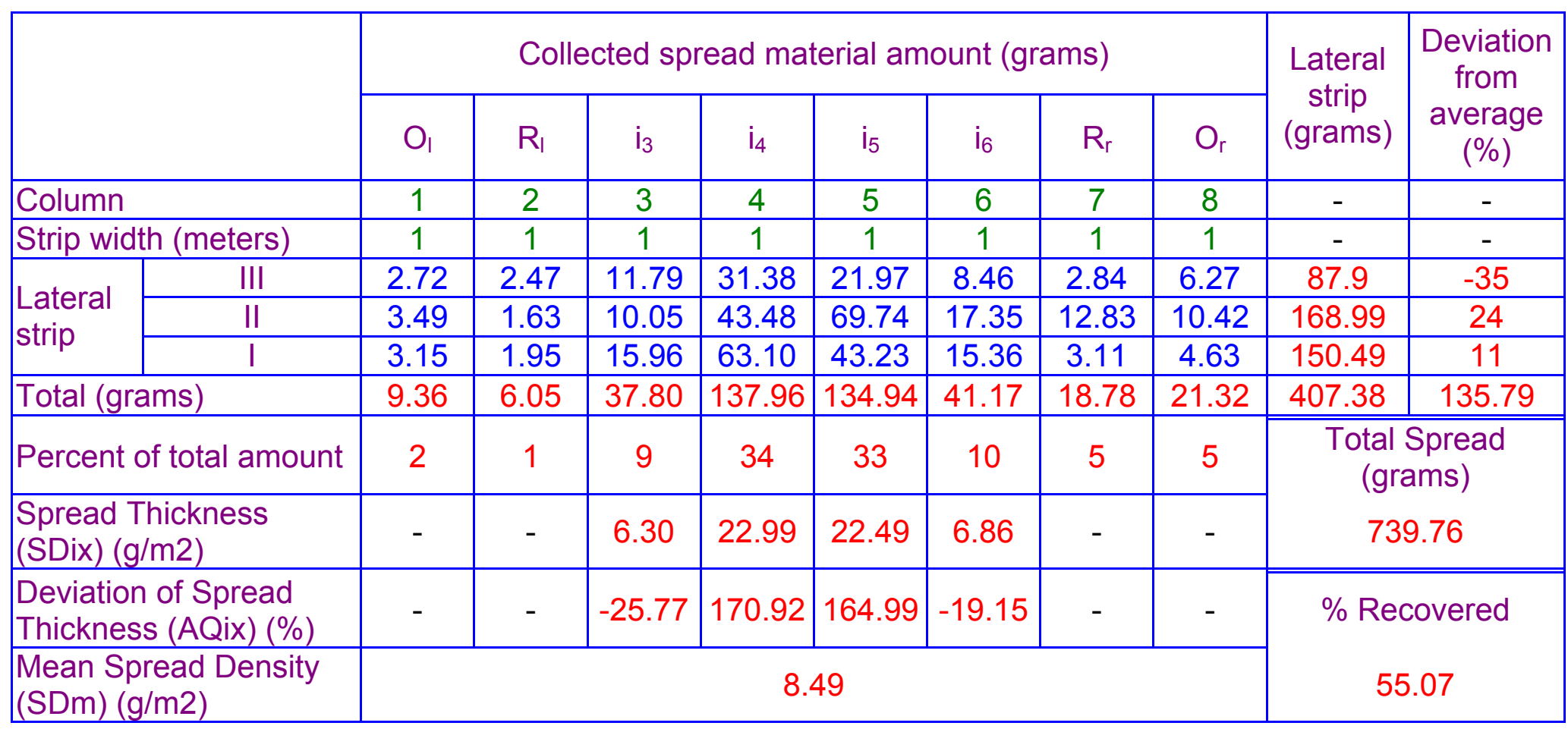


Table C12 - Percentage of \#4 sieve salt recovered at 64 kilometers/hour (40 MPH) for Pengwyn Zero Velocity System

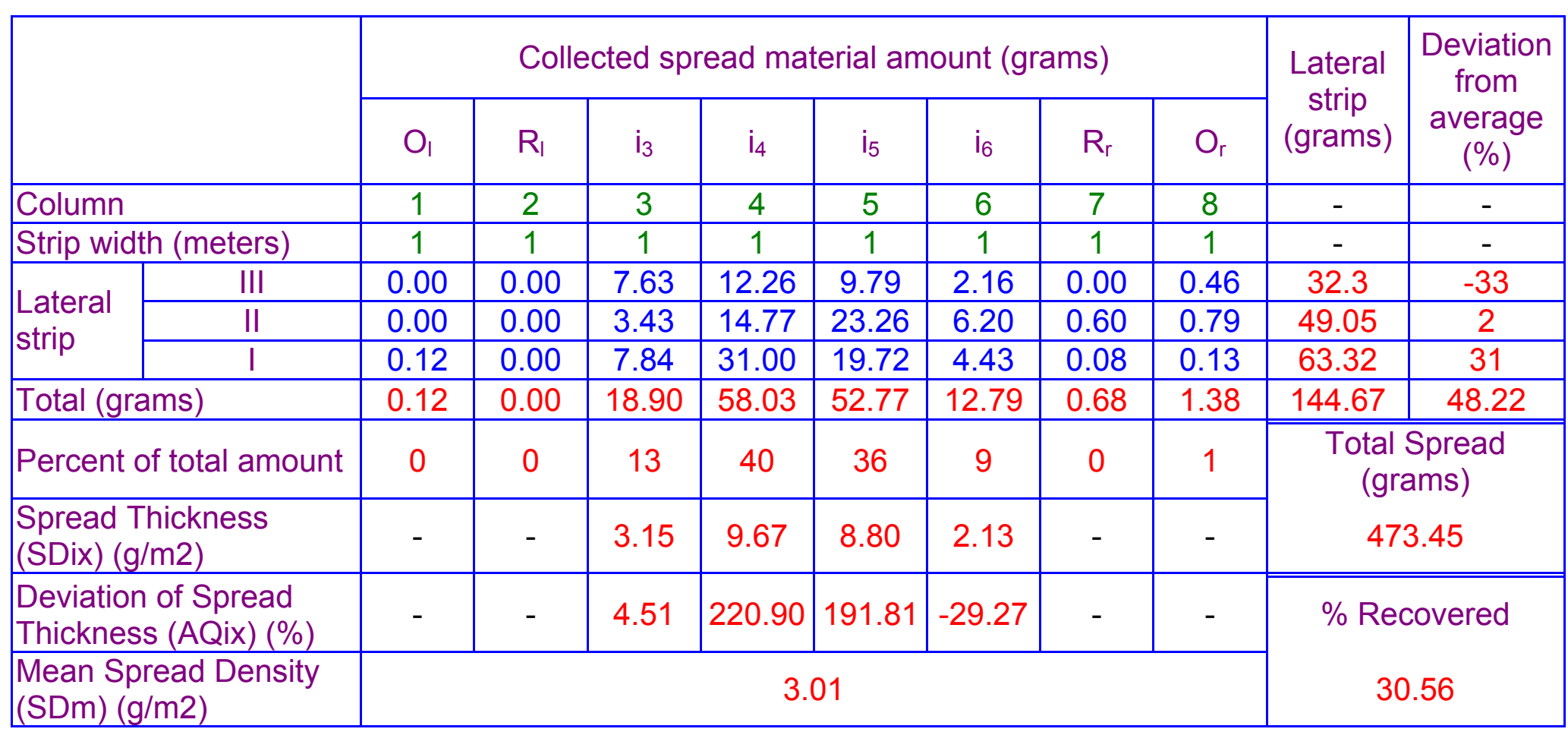


Table C13 - Percentage of total salt recovered at 32 kilometers/hour (20 MPH) for Swenson Zero Velocity System

\begin{tabular}{|c|c|c|c|c|c|c|c|c|c|c|c|}
\hline & & \multicolumn{8}{|c|}{ Collected spread material amount (grams) } & \multirow{2}{*}{$\begin{array}{l}\text { Lateral } \\
\text { strip } \\
\text { (grams) }\end{array}$} & \multirow{2}{*}{$\begin{array}{c}\text { Deviation } \\
\text { from } \\
\text { average } \\
(\%)\end{array}$} \\
\hline & & $\mathrm{O}_{1}$ & $\mathrm{R}_{\mathrm{l}}$ & $\mathrm{i}_{3}$ & $\mathrm{i}_{4}$ & $\mathrm{i}_{5}$ & $\mathrm{i}_{6}$ & $\mathrm{R}_{\mathrm{r}}$ & $\mathrm{O}_{\mathrm{r}}$ & & \\
\hline \multicolumn{2}{|c|}{ Column } & 1 & 2 & 3 & 4 & 5 & 6 & 7 & 8 & - & - \\
\hline \multicolumn{2}{|c|}{ Strip width (meters) } & 1 & 1 & 1 & 1 & 1 & 1 & 1 & 1 & - & - \\
\hline \multirow{3}{*}{$\begin{array}{l}\text { Lateral } \\
\text { strip }\end{array}$} & III & 0.94 & 1.44 & 2.67 & 52.07 & 2.24 & 1.00 & 1.01 & 3.31 & 64.68 & -26 \\
\hline & II & 1.37 & 1.36 & 7.62 & 71.64 & 2.41 & 1.29 & 0.77 & 1.56 & 88.02 & 0 \\
\hline & $\mathrm{I}$ & 2.71 & 2.01 & 7.35 & 91.66 & 3.77 & 1.16 & 0.88 & 1.24 & 110.78 & 26 \\
\hline \multicolumn{2}{|c|}{ Total (grams) } & 5.02 & 4.81 & \begin{tabular}{|l|}
17.64 \\
\end{tabular} & 215.37 & 8.42 & 3.45 & 2.66 & 6.11 & 263.48 & 87.83 \\
\hline \multicolumn{2}{|c|}{ Percent of total amount } & 2 & 2 & 7 & 82 & 3 & 1 & 1 & 2 & \multicolumn{2}{|c|}{$\begin{array}{l}\text { Total Spread } \\
\text { (grams) }\end{array}$} \\
\hline \multicolumn{2}{|c|}{$\begin{array}{l}\text { Spread Thickness } \\
\text { (SDix) (g/m2) }\end{array}$} & - & - & 2.94 & 35.90 & 1.40 & 0.58 & - & - & \multicolumn{2}{|c|}{924.71} \\
\hline \multicolumn{2}{|c|}{$\begin{array}{l}\text { Deviation of Spread } \\
\text { Thickness (AQix) (\%) }\end{array}$} & - & - & -46.44 & 553.92 & -74.43 & -89.52 & - & - & \multicolumn{2}{|c|}{$\%$ Recovered } \\
\hline \multicolumn{2}{|c|}{$\begin{array}{l}\text { Mean Spread Density } \\
(\mathrm{SDm})(\mathrm{g} / \mathrm{m} 2)\end{array}$} & \multicolumn{8}{|c|}{5.49} & \multicolumn{2}{|c|}{28.49} \\
\hline
\end{tabular}


Table C14 - Percentage of \#4 sieve salt recovered at 32 kilometers/hour (20 MPH) for Swenson Zero Velocity System

\begin{tabular}{|c|c|c|c|c|c|c|c|c|c|c|c|}
\hline & & \multicolumn{8}{|c|}{ Collected spread material amount (grams) } & \multirow{2}{*}{$\begin{array}{l}\text { Lateral } \\
\text { strip } \\
\text { (grams) }\end{array}$} & \multirow{2}{*}{$\begin{array}{c}\text { Deviation } \\
\text { from } \\
\text { average } \\
(\%)\end{array}$} \\
\hline & & $\mathrm{O}_{1}$ & $\mathrm{R}_{\mathrm{l}}$ & $\mathrm{i}_{3}$ & $\mathrm{i}_{4}$ & $\mathrm{i}_{5}$ & $\mathrm{i}_{6}$ & $\mathrm{R}_{\mathrm{r}}$ & $\mathrm{O}_{\mathrm{r}}$ & & \\
\hline \multicolumn{2}{|l|}{ Column } & 1 & 2 & 3 & 4 & 5 & 6 & 7 & 8 & - & - \\
\hline \multicolumn{2}{|c|}{ Strip width (meters) } & 1 & 1 & 1 & 1 & 1 & 1 & 1 & 1 & - & - \\
\hline \multirow{3}{*}{$\begin{array}{l}\text { Lateral } \\
\text { strip }\end{array}$} & III & 0.00 & 0.18 & 0.83 & 23.31 & 0.23 & 0.00 & 0.00 & 0.16 & 24.71 & -29 \\
\hline & II & 0.00 & 0.00 & 3.96 & 31.42 & 0.00 & 0.00 & 0.00 & 0.00 & 35.38 & 1 \\
\hline & $\mathrm{I}$ & 0.14 & 0.00 & 2.38 & 41.01 & 0.96 & 0.14 & 0.12 & 0.00 & 44.75 & 28 \\
\hline \multicolumn{2}{|c|}{ Total (grams) } & 0.14 & 0.18 & 7.17 & 95.74 & 1.19 & 0.14 & 0.12 & 0.16 & 104.84 & 34.95 \\
\hline \multicolumn{2}{|c|}{ Percent of total amount } & 0 & 0 & 7 & 91 & 1 & 0 & 0 & 0 & \multicolumn{2}{|c|}{$\begin{array}{l}\text { Total Spread } \\
\text { (grams) }\end{array}$} \\
\hline \multicolumn{2}{|c|}{$\begin{array}{l}\text { Spread Thickness } \\
\text { (SDix) }(\mathrm{g} / \mathrm{m} 2)\end{array}$} & - & - & 1.20 & 15.96 & 0.20 & 0.02 & - & - & \multicolumn{2}{|c|}{591.81} \\
\hline \multicolumn{2}{|c|}{\begin{tabular}{|l|} 
Deviation of Spread \\
Thickness (AQix) (\%) \\
\end{tabular}} & - & - & -45.29 & 630.56 & -90.92 & -98.93 & - & - & \multicolumn{2}{|c|}{$\%$ Recovered } \\
\hline \multicolumn{2}{|c|}{$\begin{array}{l}\text { Mean Spread Density } \\
(\mathrm{SDm})(\mathrm{g} / \mathrm{m} 2)\end{array}$} & \multicolumn{8}{|c|}{2.18} & \multicolumn{2}{|c|}{17.72} \\
\hline
\end{tabular}


Table C15 - Percentage of total salt recovered at 64 kilometers/hour (40 MPH) for Swenson Zero Velocity System

\begin{tabular}{|c|c|c|c|c|c|c|c|c|c|c|c|}
\hline & & \multicolumn{8}{|c|}{ Collected spread material amount (grams) } & \multirow{2}{*}{$\begin{array}{l}\text { Lateral } \\
\text { strip } \\
\text { (grams) }\end{array}$} & \multirow{2}{*}{$\begin{array}{c}\text { Deviation } \\
\text { from } \\
\text { average } \\
(\%)\end{array}$} \\
\hline & & $\mathrm{O}_{1}$ & $\mathrm{R}_{\mathrm{l}}$ & $\mathrm{i}_{3}$ & $\mathrm{i}_{4}$ & $\mathrm{i}_{5}$ & $\mathrm{i}_{6}$ & $\mathrm{R}_{\mathrm{r}}$ & $\mathrm{O}_{\mathrm{r}}$ & & \\
\hline \multicolumn{2}{|l|}{ Column } & 1 & 2 & 3 & 4 & 5 & 6 & 7 & 8 & - & - \\
\hline \multicolumn{2}{|c|}{ Strip width (meters) } & 1 & 1 & 1 & 1 & 1 & 1 & 1 & 1 & - & - \\
\hline \multirow{3}{*}{$\begin{array}{l}\text { Lateral } \\
\text { strip }\end{array}$} & III & 5.94 & 14.24 & 104.00 & 95.01 & 7.53 & 3.96 & 2.37 & 2.15 & 235.2 & -4 \\
\hline & II & 14.25 & 23.70 & 128.40 & 125.69 & 15.39 & 8.42 & 5.70 & 4.80 & 326.35 & 33 \\
\hline & $\mathrm{I}$ & 9.78 & 9.40 & 59.31 & \begin{tabular}{|l|}
69.75 \\
\end{tabular} & 15.90 & 5.88 & 2.66 & 1.47 & 174.15 & -29 \\
\hline \multicolumn{2}{|c|}{ Total (grams) } & 29.97 & 47.34 & 291.71 & 290.45 & 38.82 & 18.26 & 10.73 & 8.42 & 735.70 & 245.23 \\
\hline \multicolumn{2}{|c|}{ Percent of total amount } & 4 & 6 & 40 & 39 & 5 & 2 & 1 & 1 & \multicolumn{2}{|c|}{$\begin{array}{l}\text { Total Spread } \\
\text { (grams) }\end{array}$} \\
\hline \multicolumn{2}{|c|}{$\begin{array}{l}\text { Spread Thickness } \\
\text { (SDix) }(\mathrm{g} / \mathrm{m} 2)\end{array}$} & - & - & 48.62 & 48.41 & 6.47 & 3.04 & - & - & \multicolumn{2}{|c|}{924.71} \\
\hline \multicolumn{2}{|c|}{$\begin{array}{l}\text { Deviation of Spread } \\
\text { Thickness (AQix) (\%) }\end{array}$} & - & - & 217.21 & 215.84 & -57.79 & -80.14 & - & - & \multicolumn{2}{|c|}{$\%$ Recovered } \\
\hline \multicolumn{2}{|c|}{$\begin{array}{l}\text { Mean Spread Density } \\
(\mathrm{SDm})(\mathrm{g} / \mathrm{m} 2)\end{array}$} & \multicolumn{8}{|c|}{15.33} & \multicolumn{2}{|c|}{79.56} \\
\hline
\end{tabular}


Table C16 - Percentage of \#4 sieve salt recovered at 64 kilometers/hour (40 MPH) for Swenson Zero Velocity System

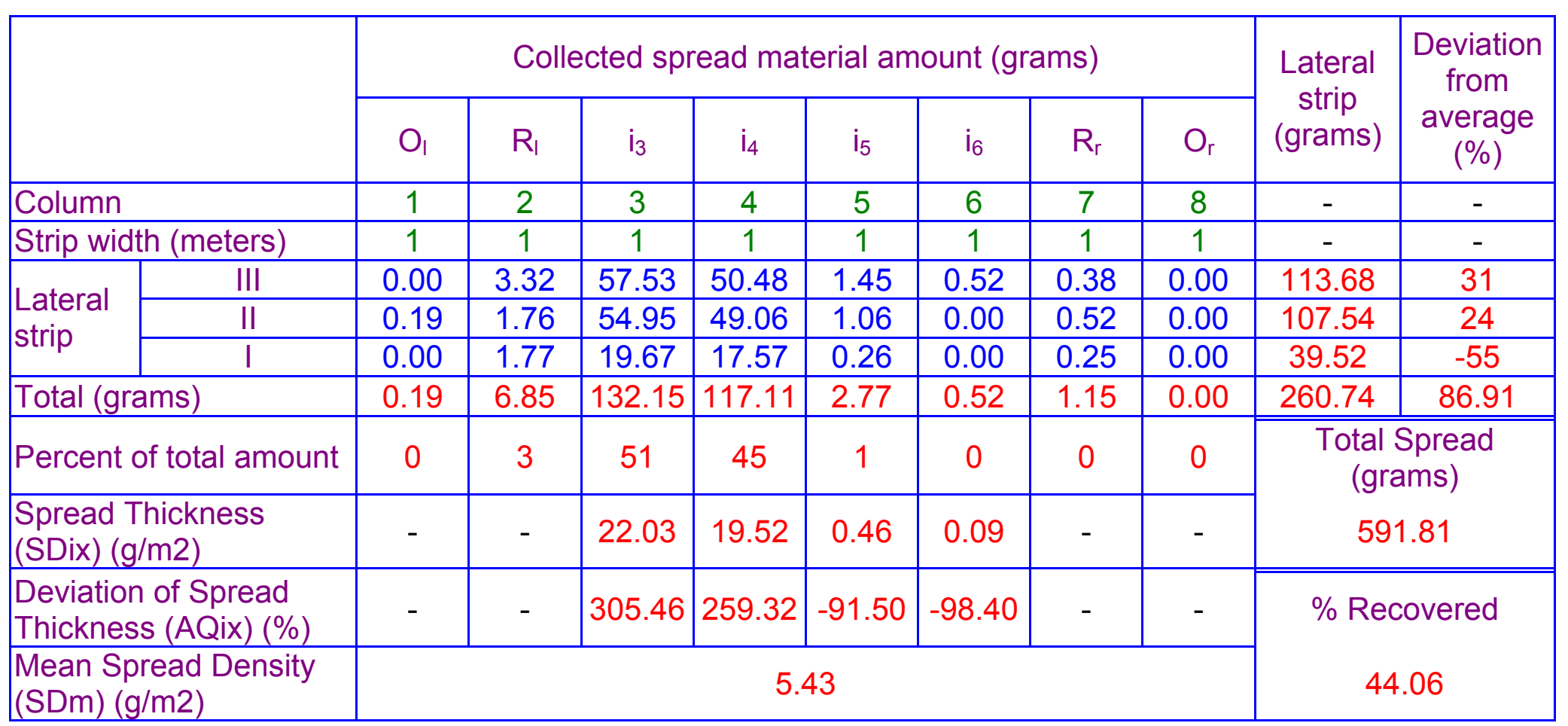


Table C17 - Percentage of total salt recovered at 32 kilometers/hour (20 MPH) for Tyler Zero Velocity System

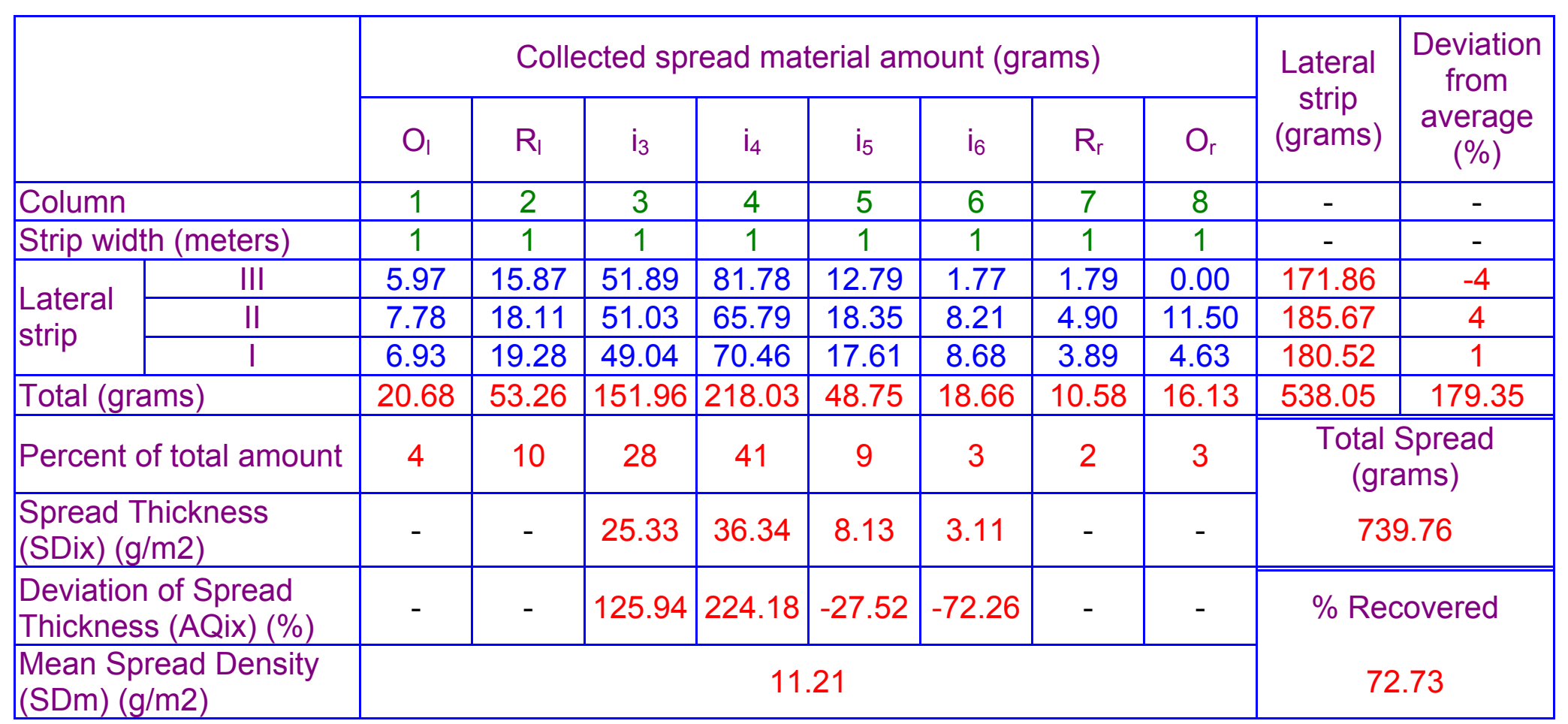


Table C18 - Percentage of \#4 sieve salt recovered at 32 kilometers/hour (20 MPH) for Tyler Zero Velocity System

\begin{tabular}{|c|c|c|c|c|c|c|c|c|c|c|c|}
\hline & & \multicolumn{8}{|c|}{ Collected spread material amount (grams) } & \multirow{2}{*}{$\begin{array}{c}\text { Lateral } \\
\text { strip } \\
\text { (grams) }\end{array}$} & \multirow{2}{*}{$\begin{array}{l}\text { Deviatior } \\
\text { from } \\
\text { average } \\
(\%)\end{array}$} \\
\hline & & $\mathrm{O}_{1}$ & $\mathrm{R}_{\mathrm{l}}$ & $\mathrm{i}_{3}$ & $\mathrm{i}_{4}$ & $\mathrm{i}_{5}$ & $\mathrm{i}_{6}$ & $\mathrm{R}_{\mathrm{r}}$ & $\mathrm{O}_{\mathrm{r}}$ & & \\
\hline \multicolumn{2}{|l|}{ Column } & 1 & 2 & 3 & 4 & 5 & 6 & 7 & 8 & - & - \\
\hline \multicolumn{2}{|c|}{ Strip width (meters) } & 1 & 1 & 1 & 1 & 1 & 1 & 1 & 1 & - & - \\
\hline \multirow{3}{*}{$\begin{array}{l}\text { Lateral } \\
\text { strip }\end{array}$} & III & 0.71 & 5.68 & 22.37 & 43.25 & 8.72 & 0.56 & 0.37 & 0.00 & 81.66 & 23 \\
\hline & II & 2.28 & 5.87 & 14.43 & 31.54 & 4.97 & 0.70 & 0.00 & 0.00 & 59.79 & -10 \\
\hline & I & 0.48 & 5.49 & 16.83 & 26.72 & 4.77 & 2.78 & 0.32 & 0.00 & 57.39 & -13 \\
\hline \multicolumn{2}{|c|}{ Total (grams) } & 3.47 & 17.04 & 53.63 & 101.51 & 18.46 & 4.04 & 0.69 & 0.00 & 198.84 & 66.28 \\
\hline \multicolumn{2}{|c|}{ Percent of total amount } & 2 & 9 & 27 & 51 & 9 & 2 & 0 & 0 & \multicolumn{2}{|c|}{$\begin{array}{l}\text { Total Spread } \\
\text { (grams) }\end{array}$} \\
\hline \multicolumn{2}{|c|}{$\begin{array}{l}\text { Spread Thickness } \\
(\text { SDix) }(\mathrm{g} / \mathrm{m} 2)\end{array}$} & - & - & 8.94 & 16.92 & 3.08 & 0.67 & - & - & \multicolumn{2}{|c|}{473.45} \\
\hline \multicolumn{2}{|c|}{$\begin{array}{l}\text { Deviation of Spread } \\
\text { Thickness (AQix) (\%) }\end{array}$} & - & - & 115.77 & 308.41 & -25.73 & -83.75 & - & - & \multicolumn{2}{|c|}{$\%$ Recovered } \\
\hline \multicolumn{2}{|c|}{$\begin{array}{l}\text { Mean Spread Density } \\
(\mathrm{SDm})(\mathrm{g} / \mathrm{m} 2)\end{array}$} & \multicolumn{8}{|c|}{4.14} & \multicolumn{2}{|c|}{42.00} \\
\hline
\end{tabular}


Table C19 - Percentage of total salt recovered at 64 kilometers/hour (40 MPH) for Tyler Zero Velocity System

\begin{tabular}{|c|c|c|c|c|c|c|c|c|c|c|c|}
\hline & & \multicolumn{8}{|c|}{ Collected spread material amount (grams) } & \multirow{2}{*}{$\begin{array}{l}\text { Lateral } \\
\text { strip } \\
\text { (grams) }\end{array}$} & \multirow{2}{*}{$\begin{array}{l}\text { Deviation } \\
\text { from } \\
\text { average } \\
(\%)\end{array}$} \\
\hline & & $\mathrm{O}_{1}$ & $\mathrm{R}_{\mathrm{I}}$ & $\dot{\mathrm{i}}_{3}$ & $\mathrm{i}_{4}$ & $\mathrm{i}_{5}$ & $\mathrm{i}_{6}$ & $\mathrm{R}_{\mathrm{r}}$ & $\mathrm{O}_{\mathrm{r}}$ & & \\
\hline \multicolumn{2}{|c|}{ Column } & 1 & 2 & 3 & 4 & 5 & 6 & 7 & 8 & - & - \\
\hline \multicolumn{2}{|c|}{ Strip width (meters) } & 1 & 1 & 1 & 1 & 1 & 1 & 1 & 1 & - & - \\
\hline \multirow{3}{*}{$\begin{array}{l}\text { Lateral } \\
\text { strip }\end{array}$} & III & 19.72 & 16.22 & 15.23 & 13.88 & 10.09 & 7.15 & 0.00 & 0.00 & 82.29 & -33 \\
\hline & II & 22.26 & 41.91 & 47.23 & 19.12 & 9.89 & 4.61 & 2.90 & 5.69 & 153.61 & 24 \\
\hline & I & 23.37 & 31.14 & 27.28 & 27.13 & 12.77 & 5.50 & 1.93 & 5.67 & 134.79 & 9 \\
\hline \multicolumn{2}{|c|}{ Total (grams) } & 65.35 & 89.27 & 89.74 & 60.13 & 32.75 & 17.26 & 4.83 & 11.36 & 370.69 & 123.56 \\
\hline \multicolumn{2}{|c|}{ Percent of total amount } & 18 & 24 & 24 & 16 & 9 & 5 & 1 & 3 & \multicolumn{2}{|c|}{$\begin{array}{l}\text { Total Spread } \\
\text { (grams) }\end{array}$} \\
\hline \multicolumn{2}{|c|}{$\begin{array}{l}\text { Spread Thickness } \\
\text { (SDix) }(\mathrm{g} / \mathrm{m} 2)\end{array}$} & - & - & 14.96 & 10.02 & 5.46 & 2.88 & - & - & \multicolumn{2}{|c|}{739.76} \\
\hline \multicolumn{2}{|c|}{$\begin{array}{l}\text { Deviation of Spread } \\
\text { Thickness (AQix) (\%) }\end{array}$} & - & - & 93.67 & 29.77 & -29.32 & -62.75 & - & - & \multicolumn{2}{|c|}{$\%$ Recovered } \\
\hline \multicolumn{2}{|c|}{$\begin{array}{l}\text { Mean Spread Density } \\
(\mathrm{SDm})(\mathrm{g} / \mathrm{m} 2)\end{array}$} & \multicolumn{8}{|c|}{7.72} & \multicolumn{2}{|c|}{50.11} \\
\hline
\end{tabular}


Table C20 - Percentage of \#4 sieve salt recovered at 64 kilometers/hour (40 MPH) for Tyler Zero Velocity System

\begin{tabular}{|c|c|c|c|c|c|c|c|c|c|c|c|}
\hline & & \multicolumn{8}{|c|}{ Collected spread material amount (grams) } & \multirow{2}{*}{$\begin{array}{c}\text { Lateral } \\
\text { strip } \\
\text { (grams) }\end{array}$} & \multirow{2}{*}{$\begin{array}{l}\text { Deviatior } \\
\text { from } \\
\text { average } \\
(\%)\end{array}$} \\
\hline & & $\mathrm{O}_{1}$ & $\mathrm{R}_{\mathrm{l}}$ & $\mathrm{i}_{3}$ & $\mathrm{i}_{4}$ & $\mathrm{i}_{5}$ & $\mathrm{i}_{6}$ & $\mathrm{R}_{\mathrm{r}}$ & $\mathrm{O}_{\mathrm{r}}$ & & \\
\hline \multicolumn{2}{|l|}{ Column } & 1 & 2 & 3 & 4 & 5 & 6 & 7 & 8 & - & - \\
\hline \multicolumn{2}{|c|}{ Strip width (meters) } & 1 & 1 & 1 & 1 & 1 & 1 & 1 & 1 & - & - \\
\hline \multirow{3}{*}{$\begin{array}{l}\text { Lateral } \\
\text { strip }\end{array}$} & III & 3.01 & 2.36 & 1.12 & 1.77 & 0.58 & 0.29 & 0.00 & 0.00 & 9.13 & -71 \\
\hline & II & 10.59 & 13.97 & 11.88 & 3.70 & 1.56 & 0.14 & 0.28 & 0.26 & 42.38 & 34 \\
\hline & I & 7.31 & 10.69 & 10.60 & 10.45 & 3.00 & 0.88 & 0.00 & 0.34 & 43.27 & 37 \\
\hline \multicolumn{2}{|c|}{ Total (grams) } & 20.91 & 27.02 & 23.60 & 15.92 & 5.14 & 1.31 & 0.28 & 0.60 & 94.78 & 31.59 \\
\hline \multicolumn{2}{|c|}{ Percent of total amount } & 22 & 29 & 25 & 17 & 5 & 1 & 0 & 1 & \multicolumn{2}{|c|}{$\begin{array}{l}\text { Total Spread } \\
\text { (grams) }\end{array}$} \\
\hline \multicolumn{2}{|c|}{$\begin{array}{l}\text { Spread Thickness } \\
(\text { SDix) }(\mathrm{g} / \mathrm{m} 2)\end{array}$} & - & - & 3.93 & 2.65 & 0.86 & 0.22 & - & - & \multicolumn{2}{|c|}{473.45} \\
\hline \multicolumn{2}{|c|}{$\begin{array}{l}\text { Deviation of Spread } \\
\text { Thickness (AQix) (\%) }\end{array}$} & - & - & 99.20 & 34.37 & -56.62 & -88.94 & - & - & \multicolumn{2}{|c|}{$\%$ Recovered } \\
\hline \multicolumn{2}{|c|}{$\begin{array}{l}\text { Mean Spread Density } \\
(\mathrm{SDm})(\mathrm{g} / \mathrm{m} 2)\end{array}$} & \multicolumn{8}{|c|}{1.97} & \multicolumn{2}{|c|}{20.02} \\
\hline
\end{tabular}


Table C21 - Percentage of total salt recovered at 32 kilometers/hour (20 MPH) for Y-System

\begin{tabular}{|c|c|c|c|c|c|c|c|c|c|c|}
\hline & \multicolumn{8}{|c|}{ Collected spread material amount (grams) } & \multirow{2}{*}{$\begin{array}{l}\text { Lateral } \\
\text { strip } \\
\text { (grams) }\end{array}$} & \multirow{2}{*}{$\begin{array}{l}\text { Deviation } \\
\text { from } \\
\text { average } \\
(\%)\end{array}$} \\
\hline & $\mathrm{O}_{1}$ & $\mathrm{R}_{\mathrm{l}}$ & $\mathrm{i}_{3}$ & $\mathrm{i}_{4}$ & $\mathrm{i}_{5}$ & $\mathrm{i}_{6}$ & $\mathrm{R}_{\mathrm{r}}$ & $\mathrm{O}_{\mathrm{r}}$ & & \\
\hline Column & 1 & 2 & 3 & 4 & 5 & 6 & 7 & 8 & - & - \\
\hline Strip width (meters) & 1 & 1 & 1 & 1 & 1 & 1 & 1 & 1 & - & - \\
\hline \multirow{3}{*}{ 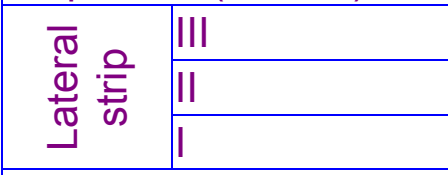 } & 27.95 & 19.37 & 26.25 & 28.21 & 26.41 & 19.92 & 9.36 & 27.94 & 185.41 & -13 \\
\hline & 58.91 & 39.93 & 45.82 & 30.88 & 19.85 & 8.86 & 10.06 & 38.02 & 252.33 & 19 \\
\hline & 40.11 & 31.38 & 34.35 & 24.81 & 16.85 & 9.80 & 8.24 & 33.69 & 199.23 & -6 \\
\hline Total (grams) & 126.97 & 90.68 & 106.42 & 83.90 & 63.11 & 38.58 & 27.66 & 99.65 & 636.97 & 212.32 \\
\hline Percent of total amount & 20 & 14 & 17 & 13 & 10 & 6 & 4 & 16 & \multicolumn{2}{|c|}{$\begin{array}{l}\text { Total Spread } \\
\text { (grams) }\end{array}$} \\
\hline $\begin{array}{l}\text { Spread Thickness } \\
\text { (SDix) (g/m2) }\end{array}$ & - & - & 17.74 & 13.98 & 10.52 & 6.43 & - & - & \multicolumn{2}{|c|}{924.71} \\
\hline \begin{tabular}{|l} 
Deviation of Spread \\
Thickness (AQix) (\%)
\end{tabular} & - & - & 33.66 & 5.37 & -20.74 & -51.55 & - & - & \multicolumn{2}{|c|}{$\%$ Recovered } \\
\hline $\begin{array}{l}\text { Mean Spread Density } \\
(\mathrm{SDm})(\mathrm{g} / \mathrm{m} 2)\end{array}$ & \multicolumn{8}{|c|}{13.27} & \multicolumn{2}{|c|}{68.88} \\
\hline
\end{tabular}


Table C22 - Percentage of \#4 sieve salt recovered at 32 kilometers/hour (20 MPH) for Y-System

\begin{tabular}{|c|c|c|c|c|c|c|c|c|c|c|}
\hline & \multicolumn{8}{|c|}{ Collected spread material amount (grams) } & \multirow{2}{*}{$\begin{array}{l}\text { Lateral } \\
\text { strip } \\
\text { (grams) }\end{array}$} & \multirow{2}{*}{$\begin{array}{l}\text { Deviation } \\
\text { from } \\
\text { average } \\
(\%)\end{array}$} \\
\hline & $\mathrm{O}_{1}$ & $\mathrm{R}_{\mathrm{I}}$ & $\dot{\mathrm{I}}_{3}$ & $\mathrm{i}_{4}$ & $\mathrm{i}_{5}$ & $\mathrm{i}_{6}$ & $\mathrm{R}_{\mathrm{r}}$ & $\mathrm{O}_{\mathrm{r}}$ & & \\
\hline Column & 1 & 2 & 3 & 4 & 5 & 6 & 7 & 8 & - & - \\
\hline Strip width (meters) & 1 & 1 & 1 & 1 & 1 & 1 & 1 & 1 & - & - \\
\hline \multirow{3}{*}{ 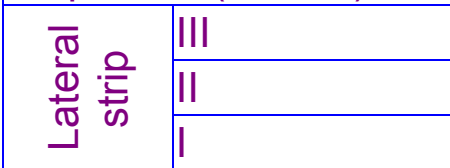 } & 24.28 & 12.91 & 19.50 & 23.64 & 24.88 & 19.50 & 9.36 & 27.94 & 162.01 & -9 \\
\hline & 53.03 & 27.80 & 32.35 & 25.01 & 18.09 & 8.24 & 9.38 & 37.80 & 211.7 & 19 \\
\hline & 34.00 & 20.73 & 27.60 & 19.97 & 13.14 & 8.44 & 2.54 & 33.69 & 160.11 & -10 \\
\hline Total (grams) & 111.31 & 61.44 & 79.45 & 68.62 & 56.11 & 36.18 & 21.28 & 99.43 & 533.82 & 177.94 \\
\hline Percent of total amount & 21 & 12 & 15 & 13 & 11 & 7 & 4 & 19 & \multicolumn{2}{|c|}{$\begin{array}{l}\text { Total Spread } \\
\text { (grams) }\end{array}$} \\
\hline $\begin{array}{l}\text { Spread Thickness } \\
\text { (SDix) }(\mathrm{g} / \mathrm{m} 2) \\
\end{array}$ & - & - & 13.24 & 11.44 & 9.35 & 6.03 & - & - & \multicolumn{2}{|c|}{591.81} \\
\hline $\begin{array}{l}\text { Deviation of Spread } \\
\text { Thickness (AQix) (\%) }\end{array}$ & - & - & 19.07 & 2.84 & -15.91 & -45.78 & - & - & \multirow{2}{*}{\multicolumn{2}{|c|}{$\begin{array}{c}\text { \% Recovered } \\
90.20\end{array}$}} \\
\hline $\begin{array}{l}\text { Mean Spread Density } \\
(\mathrm{SDm})(\mathrm{g} / \mathrm{m} 2)\end{array}$ & \multicolumn{8}{|c|}{11.12} & & \\
\hline
\end{tabular}


Table C23 - Percentage of total salt recovered at 64 kilometers/hour (40 MPH) for Y-System

\begin{tabular}{|c|c|c|c|c|c|c|c|c|c|c|c|}
\hline & & \multicolumn{8}{|c|}{ Collected spread material amount (grams) } & \multirow{2}{*}{$\begin{array}{l}\text { Lateral } \\
\text { strip } \\
\text { (grams) }\end{array}$} & \multirow{2}{*}{$\begin{array}{l}\text { Deviation } \\
\text { from } \\
\text { average } \\
(\%)\end{array}$} \\
\hline & & $\mathrm{O}_{1}$ & $\mathrm{R}_{\mathrm{l}}$ & $\dot{i}_{3}$ & $\mathrm{i}_{4}$ & $\mathrm{i}_{5}$ & $\mathrm{i}_{6}$ & $\mathrm{R}_{\mathrm{r}}$ & $\mathrm{O}_{\mathrm{r}}$ & & \\
\hline \multicolumn{2}{|l|}{ Column } & 1 & 2 & 3 & 4 & 5 & 6 & 7 & 8 & - & - \\
\hline \multicolumn{2}{|c|}{ Strip width (meters) } & 1 & 1 & 1 & 1 & 1 & 1 & 1 & 1 & - & - \\
\hline \multirow{3}{*}{ 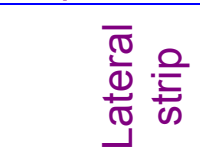 } & III & 30.00 & 13.48 & 13.01 & 14.65 & 10.85 & 14.75 & 10.58 & 21.56 & 128.88 & 18 \\
\hline & II & 35.18 & 14.08 & 16.53 & 11.75 & 6.95 & 4.42 & 3.91 & 11.10 & 103.92 & -5 \\
\hline & I & 38.73 & 16.31 & 13.14 & 6.14 & 5.71 & 3.47 & 3.67 & 7.15 & 94.32 & -13 \\
\hline \multicolumn{2}{|c|}{ Total (grams) } & 103.91 & 43.87 & 42.68 & 32.54 & 23.51 & 22.64 & 18.16 & 39.81 & 327.12 & 109.04 \\
\hline \multicolumn{2}{|c|}{ Percent of total amount } & 32 & 13 & 13 & 10 & 7 & 7 & 6 & 12 & \multicolumn{2}{|c|}{$\begin{array}{l}\text { Total Spread } \\
\text { (grams) }\end{array}$} \\
\hline \multicolumn{2}{|c|}{$\begin{array}{l}\text { Spread Thickness } \\
(\text { SDix) }(\mathrm{g} / \mathrm{m} 2)\end{array}$} & - & - & 7.11 & 5.42 & 3.92 & 3.77 & - & - & \multicolumn{2}{|c|}{924.71} \\
\hline \multicolumn{2}{|c|}{$\begin{array}{l}\text { Deviation of Spread } \\
\text { Thickness (AQix) (\%) }\end{array}$} & - & - & 4.38 & -20.42 & -42.50 & -44.63 & - & - & \multicolumn{2}{|c|}{$\%$ Recovered } \\
\hline \multicolumn{2}{|c|}{$\begin{array}{l}\text { Mean Spread Density } \\
(\mathrm{SDm})(\mathrm{g} / \mathrm{m} 2)\end{array}$} & \multicolumn{8}{|c|}{6.82} & \multicolumn{2}{|c|}{35.38} \\
\hline
\end{tabular}


Table C24 - Percentage of \#4 sieve salt recovered at 64 kilometers/hour (40 MPH) for Y-System

\begin{tabular}{|c|c|c|c|c|c|c|c|c|c|c|}
\hline & \multicolumn{8}{|c|}{ Collected spread material amount (grams) } & \multirow{2}{*}{$\begin{array}{l}\text { Lateral } \\
\text { strip } \\
\text { (grams) }\end{array}$} & \multirow{2}{*}{$\begin{array}{l}\text { Deviation } \\
\text { from } \\
\text { average } \\
(\%)\end{array}$} \\
\hline & $\mathrm{O}_{1}$ & $\mathrm{R}_{\mathrm{l}}$ & $\dot{\mathrm{i}}_{3}$ & $\mathrm{i}_{4}$ & $\mathrm{i}_{5}$ & $\mathrm{i}_{6}$ & $\mathrm{R}_{\mathrm{r}}$ & $\mathrm{O}_{\mathrm{r}}$ & & \\
\hline Column & 1 & 2 & 3 & 4 & 5 & 6 & 7 & 8 & - & - \\
\hline Strip width (meters) & 1 & 1 & 1 & 1 & 1 & 1 & 1 & 1 & - & - \\
\hline \multirow{3}{*}{ 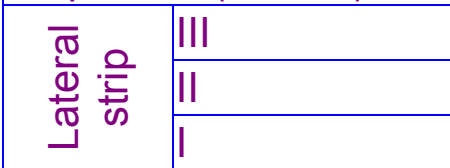 } & 26.34 & 11.33 & 12.29 & 14.53 & 10.52 & 13.54 & 10.41 & 21.33 & 120.29 & 18 \\
\hline & 32.98 & 12.43 & 15.19 & 10.09 & 6.95 & 4.17 & 3.91 & 10.45 & 96.17 & -5 \\
\hline & 37.33 & 15.56 & 11.77 & 4.54 & 5.36 & 3.25 & 3.57 & 7.15 & 88.53 & -13 \\
\hline Total (grams) & 96.65 & 39.32 & 39.25 & 29.16 & 22.83 & 20.96 & 17.89 & 38.93 & 304.99 & 101.66 \\
\hline Percent of total amount & 32 & 13 & 13 & 10 & 7 & 7 & 6 & 13 & \multicolumn{2}{|c|}{$\begin{array}{l}\text { Total Spread } \\
\text { (grams) }\end{array}$} \\
\hline $\begin{array}{l}\text { Spread Thickness } \\
\text { (SDix) }(\mathrm{g} / \mathrm{m} 2) \\
\end{array}$ & - & - & 6.54 & 4.86 & 3.81 & 3.49 & - & - & \multicolumn{2}{|c|}{591.81} \\
\hline $\begin{array}{l}\text { Deviation of Spread } \\
\text { Thickness (AQix) (\%) }\end{array}$ & - & - & 2.95 & -23.51 & -40.12 & -45.02 & - & - & \multirow{2}{*}{\multicolumn{2}{|c|}{$\begin{array}{c}\text { \% Recovered } \\
51.53\end{array}$}} \\
\hline $\begin{array}{l}\text { Mean Spread Density } \\
(\mathrm{SDm})(\mathrm{g} / \mathrm{m} 2)\end{array}$ & \multicolumn{8}{|c|}{6.35} & & \\
\hline
\end{tabular}

